\title{
Dynamics of Tokamak Plasma Experiments and Reactors
}

\author{
S. E. Attenberger \\ F. B. Marcus \\ D. G. McAlees
}

\section{OAK RIDGE NATIONAL LABORATORY}




\section{DISCLAIMER}

This report was prepared as an account of work sponsored by an agency of the United States Government. Neither the United States Government nor any agency Thereof, nor any of their employees, makes any warranty, express or implied, or assumes any legal liability or responsibility for the accuracy, completeness, or usefulness of any information, apparatus, product, or process disclosed, or represents that its use would not infringe privately owned rights. Reference herein to any specific commercial product, process, or service by trade name, trademark, manufacturer, or otherwise does not necessarily constitute or imply its endorsement, recommendation, or favoring by the United States Government or any agency thereof. The views and opinions of authors expressed herein do not necessarily state or reflect those of the United States Government or any agency thereof. 


\section{DISCLAIMER}

Portions of this document may be illegible in electronic image products. Images are produced from the best available original document. 
Printed in the United States of America. Available from National Technical Information Service

U.S. Department of Commerce

5285 Port Royal Road, Springfield, Virginia 22161

Price: Printed Copy \$5.00; Microfiche $\$ 2.25$

This report was prepared as an account of work sponsored by the United States Government. Neither the United States nor the Energy Research and Development Administration/United States Nuclear Regulatory Commission, nor any of their employees, nor any of their contractors, subcontractors, or their employees, makes any warranty, express or implied, or assumes any legal liability or responsibility for the accuracy, completeness or usefulness of any information, apparatus, product or process disclosed, or represents that its use would not infringe privately owned rights. 
ORNL/TM-5509

Dist. Category UC-20

Contract No. W-7405-eng-26

FUSION ENERGY DIVISION

DYNAMICS OF TOKAMAK PLASMA EXPERIMENTS
AND REACTORS

S. E. Attenberger

F. B. Marcus

D. G. McAlees

Date Published: November 1976

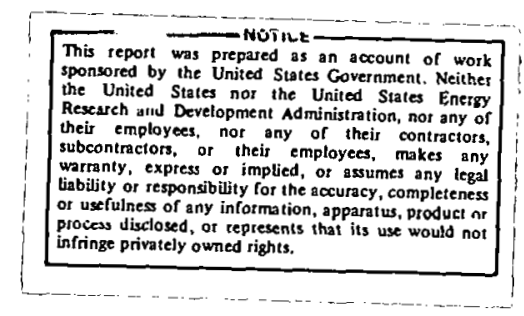

Prepared by the

OAK RIDGE NATIONAL LABORATORY

Oak Ridge, Tennessee 37830

operated by

UNION CARBIDE CORPORATION

For the

ENERGY RESEARCH AND DEVELOPMENT ADMINISTRATION

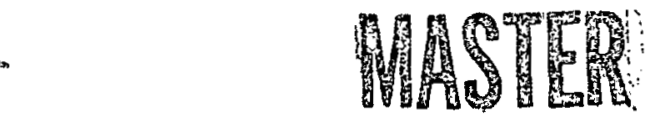


THIS PAGE

\section{WAS INTENTIONALLY LEFT BLANK}


CONTENTS

ABSTRACT . . . . . . . . . . . . . . . . . . . 1

1. INTRODUCTION . . . . . . . . . . . . . . . . . 2

2. PHYSICS MODELS IN THE SYSTEMS CODE . . . . . . . . . . 3

2.1 Rate Equations . . . . . . . . . . . . . 3

2.2 Fusion Rate . . . . . . . . . . . . . . . . . 7

2.3 Alpha Energy Deposition . . . . . . . . . . . . 7

2.4 Beam-Plasma Fusion Power . . . . . . . . . . . . . . 7

2.5 Neutral Beam Injection Heating . . . . . . . . . . 8

2.6 Electron-Ion Energy Transfer . . . . . . . . . . 8

2.7 Ohmic Heating . . . . . . . . . . . . . . . . 9

2.8 Bremsstrahlung and Synchrotron Radiation . . . . . . 9

2.9 Containment Times . . . . . . . . . . . . . 10

2.10 Plasma Inductance . . . . . . . . . . . . . . 13

2.11 Impurity Radiation Effects . . . . . . . . . . . . 14

2.12 Impurity Production-Sputtering . . . . . . . . . . . 17

2.13 Modifications for Noncircular Plasma Cross Sections . . . 19

3. MODELING OF EXPERIMENTS . . . . . . . . . . . . . . 23

3.1 Tokamak Fontenay-aux-Roses (TFR) . . . . . . . . . 23

3.2 Oak Ridge Tokamak (ORMAK) . . . . . . . . . . . . 27

3.3 The Princeton Large Torus (PLT) . . . . . . . . . . 28

4. POINT MODELING - STATIC CODE . . . . . . . . . . . 32

5. REACTOR MODELING . . . . . . . . . . . . . . . . 42

5.1 Experimental Power Reactor (EPR) . . . . . . . . 42

5.2 Demonstration and Commercial Reactors . . . . . . . 52

5.3 Impurity Effects on System Dynamics . . . . . . . . 61

6. CONCLUSIONS . . . . . . . . . . . . . . . . 69

ACKNOWLEDGMENTS . . . . . . . . . . . . . . . . . 71

REFERENCES ........................ 73 


\section{DYNAMICS OF TOKAMAK PLASMA EXPERIMENTS \\ AND REACTORS*}

S. E. Attenberger, F. B. Marcus, D. G. McAleest

Oak Ridge National Laboratory, Oak Ridge, Tennessee 37830

\section{ABSTRACT}

At the present state of knowledge, the design of fusion reactors is based on scaling which has not been fully verfied experimentally. Various choices of scaling laws can be made, leading to different results. Design studies demonstrate sensitivity to the scaling laws assumed. Models are described suitable for simulating the energy and particle balances of a tokamak plasma, for surveying the range of parameters possible during operation, and for surveying the sensitivities of the parameters to system changes. Physical models for transport losses, beam-plasma interactions, noncircular plasma behavior, sputtering, impurity effects, and reactor control are included. The calculations based on these models are tested against present experimental results and are used to predict the behavior of future devices.

Power balance results and their sensitivities are focused primarily on the ORNL Experimental Power Reactor (EPR), Demonstration Power Reactor (Demo), and Commercial Power Reactor (CPR) Designs. The sizes of these plants and the ranges of their possible power outputs are discussed. The limitations on the operation of these devices due to constraints such as beta limits, sputtering, and impurity buildup are described.

Conclusions which result from applying the model to the systems noted above, but which are applicable to tokamak design in general, are presented.

\footnotetext{
${ }^{*}$ Research sponsored by the Energy Research and Development Administration under contract with Union Carbide Corporation.

${ }^{\dagger}$ Exxon Nuclear Co., Inc., Bellevue, Washington.
} 


\section{INTRODUCTION}

In order to proceed with the design of a fusion reactor a somewhat arbitrary choice of scaling laws must be made, based on the best available knowledge. From these laws a detailed energy balance leads to the specification of device parameters. A computer code that simulates the energy and particle balances of a tokamak plasma is described here. The model has been developed to simulate current experimental data and theoretically predicted behavior. It is used to analyze existing machines, such as Oak Ridge Tokamak (ORMAK) and Tokamak Fontenay-aux-Roses (TFR), and newly operating machines, such as Princeton Large Torus (PLT), and to predict operating parameters for future reactor devices, such as experimental, demonstration, and commercial power reactors. Extensions of the code to include noncircular cross sections are discussed, with considerations of poloidal flux and transport.

The code is designed to be modular so that various physical models for transport, impurities, etc. can be easily tested and altered. The cases discussed here use seven coupled differential equations which represent deuterium, tritium, and alpha density; electron and ion temperature; and time-dependent impurity behavior for high and low charge states.

Following a description of the physics included in the code, the model is applied to ORMAK, TFR, and FLT and the results are discussed. Next, steady state solutions are used to characterize the basic parameters, including size, for advanced systems such as the $\bar{E} \bar{P} \bar{R}$, Demo, and commercial plants. The implications of circular and noncircular cross sections and the effects of impurity production_and transport on the power balance are given. Finally, conclusions drawn from the results obtained are discussed. 


\section{PHYSICS MODELS IN THE SYSTEMS CODE}

\subsection{RATE EQUATIONS}

The particle and energy balance equations used in the code include calculations of deuterium, tritium, alpha, carbon (to represent low-Z impurities), and iron density, and of electron and ion temperature. The equations are:

$$
\begin{aligned}
& \frac{d}{d t}\left(N_{D}\right)=S_{D c}-\dot{N}_{D} N_{T}<\sigma v{ }_{D T}-\frac{N_{D}}{\tau_{D}}+S_{D}-\frac{S_{D} E_{b}}{17600} \frac{N_{T}}{N_{e}} F\left(E_{b}, T_{e}\right) \\
& \frac{d}{d t}\left(N_{T}\right)=S_{T c}-N_{D} N_{T}\langle\sigma\rangle_{D T}-\frac{N_{T}}{\tau_{T}}-\frac{S_{D} E_{b}}{17600} \frac{N_{T}}{N_{e}} F\left(E_{b}, T_{e}\right) \\
& \frac{d}{d t}\left(N_{\alpha}\right)=N_{D} N_{T}\left\langle\sigma v{ }_{D T}-\frac{N_{\alpha}}{\tau_{\alpha}}+\frac{S_{D} E_{b}}{17600} \frac{N_{T}}{N_{e}} F\left(E_{b}, T_{e}\right)\right. \\
& \frac{d}{d t}\left(N_{c}\right)=-\frac{N}{\tau_{c}}+f(T) A_{c} d_{c}\left[\frac{\gamma_{c D} D_{D}}{\tau_{D}}+\frac{\gamma_{c} I^{N} N_{T}}{\tau_{T}}\right. \\
& \left.+\frac{\gamma_{c \alpha}{ }^{N} \alpha}{\tau_{\alpha}}+\frac{\gamma_{c c}{ }^{N} c}{\tau_{c}}+\frac{\gamma_{c F e} N_{F e}}{\tau_{F e}}\right] \\
& +d_{c n} A_{c} \gamma_{c n}\left(N_{D} N_{T}\langle\sigma v\rangle_{D T}+\frac{S_{D} E_{b}}{17600} \frac{N_{T}}{N_{e}} F\left(E_{b}, T_{e}\right)\right) \\
& +d_{c n} A_{c} \frac{\left(2.19 \times 10^{5}\right)}{a^{2}} \frac{N_{e}(0)}{N_{e}} \bar{\sigma}_{c x} \\
& x \int_{0}^{a} f(T(r)) \frac{N_{e}(r)}{N_{e}(0)} N_{0}(r) \sqrt{T(r)} \cdot r d r \\
& x\left[\frac{\gamma_{c D} \bar{N}_{D}}{\sqrt{2}}+\frac{\gamma_{c T^{N} T}}{\sqrt{3}}\right]+d_{c} \gamma_{c h}\left[\frac{N_{D}}{\tau_{D}}+\frac{N_{T}}{\tau_{T}}\right]
\end{aligned}
$$




$$
\begin{aligned}
& \frac{d}{d t}\left(N_{F e}\right)=\frac{N_{F e}}{\tau_{F e}}+f(T) A_{F e} d_{F e}\left[\frac{\gamma_{F e D} N_{D}}{\tau_{D}}+\frac{\gamma_{F e T} N_{T}}{\tau_{T}}+\frac{\gamma_{F e \alpha}{ }^{N} \alpha}{\tau_{\alpha}}+\frac{\gamma_{F e c}{ }^{N}}{\tau_{C}}\right. \\
& \left.+\frac{\gamma_{F e F e} N_{F e}}{\tau_{F e}}\right]+d_{F e n} A_{F e} \gamma_{n}\left(N_{D} N_{T}\left\langle\sigma v{ }_{D T}+\frac{S_{D} E_{b}}{17600} \frac{N_{T}}{N_{e}} F\left(E_{b}, T_{e}\right)\right)\right. \\
& +d_{F e n} A_{F e} \frac{\left(2.19 \times 10^{5}\right)}{a^{2}} \frac{N_{e}(0)}{N_{e}} \bar{\sigma}_{c x}\left[\frac{\gamma_{D} N_{D}}{\sqrt{2}}+\frac{\gamma_{T} N_{T}}{\sqrt{3}}\right] \\
& x \int_{0}^{a} f(T(r)) \frac{N_{e}(r)}{N_{e}(0)} N_{0}(r) \sqrt{T(r)} r d r \\
& \frac{d}{d t}\left(\frac{3}{2} N_{e} T_{e}\right)=N_{D} N_{T}\langle\sigma V\rangle{ }_{D T} U_{\alpha e}-\frac{\left(\frac{3}{2} N_{e} T_{e}\right)}{\tau e, E}-0.30 \times 10^{-20} Z_{e f f} N^{N^{2}} \sqrt{T_{e}} \\
& -\frac{1.5 \times 10^{5}}{\sqrt{\mathrm{a}}} \sqrt{\mathrm{N}} \mathrm{e}_{\mathrm{T}}^{5 / 2}(1-\beta)^{5 / 4} \mathrm{~T}_{\mathrm{e}}^{11 / 4}\left(1-\mathrm{R}_{\mathrm{e}}\right)\left(1+\frac{\mathrm{T}_{\mathrm{e}}}{204}\right) \\
& +1.5 \times 10^{-19} \frac{\mathrm{N}_{e}}{\mathrm{~T}_{e}^{3 / 2}} \ln \Lambda \Sigma\left(\frac{\mathrm{Z}_{j} \mathrm{~N}_{j}}{\mathrm{~A}_{j}}\right)\left(\mathrm{T}_{j}-\mathrm{T}_{e}\right)+\eta \mathrm{J}^{2} \\
& +S_{D} G_{e D}+S_{T} G_{e T}+\frac{S_{D} E_{b}}{17600} \frac{N_{T}}{N_{e}} F\left(E_{b}, T_{e}\right) U_{\alpha e}-P_{L I N E} \\
& \frac{d}{d t}\left(\frac{3}{2} N_{I} T_{I}\right)=N_{D} N_{T}<\sigma v{ }_{D T} U_{\alpha I}+S_{D} G_{I D}+S_{T} G_{I T} \\
& \frac{-\left(\frac{3}{2} N_{T} T_{T}\right)}{{ }_{T} T_{2} E} \quad 1.5 \times 10^{-19} \frac{N_{e}}{T_{c}^{3 / 2}} \ln \Lambda \Sigma\left(\frac{Z_{j}^{2} N_{j}}{A_{j}}\right)\left(T_{j}-T_{e}\right) \\
& +S_{D C} E_{D C}+S_{I^{\prime} c} F_{I^{\prime} I^{\prime} c}+\frac{S_{D} E_{b}}{17600} \frac{N_{T}}{N_{e}} F\left(E_{b} \cdot T_{e}\right) U_{w I}
\end{aligned}
$$

The parameters used in the equations are defined in Table 1. 
Table 1. Symbol table for rate equations

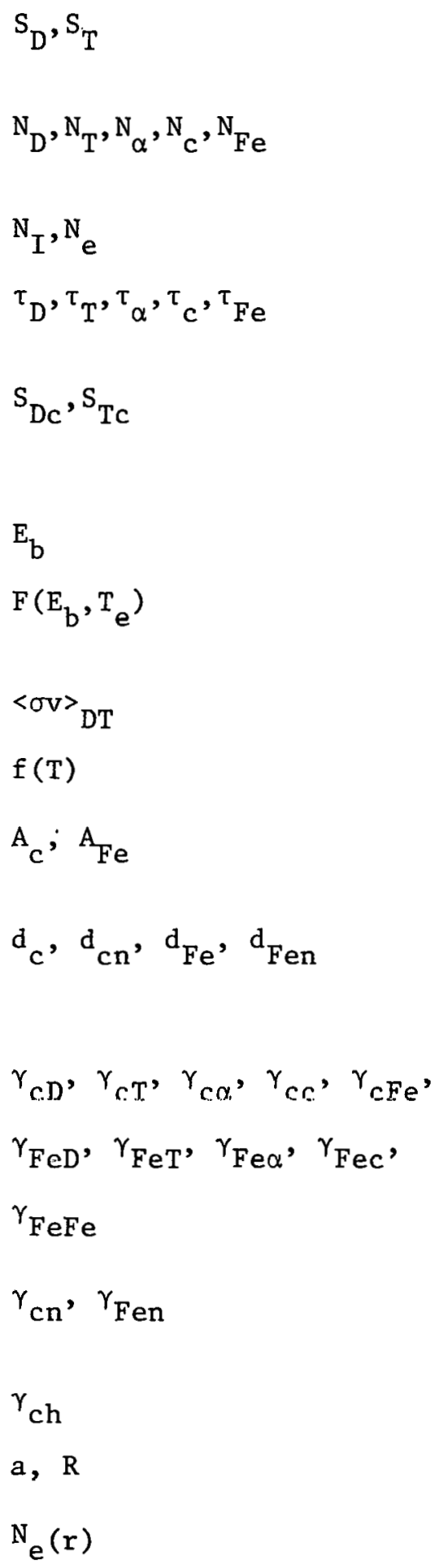

Deuterium and tritium source rate from fast ions, e.g., due to neutral injection.

Average deuterium, tritium, alpha, carbon, and iron densities.

Average ion and electron densities.

Particle confinement times of deuterium, tritium, alpha, carbon, and iron ions.

Deuterium and tritium source rate from fueling, e.g., due to injected recycling, injected pellets, or gas blanket.

Neutral beam injection energy.

Ratio of beam-plasma fusion power to injected beam power for $D$ into pure $T$.

D-T reaction rate parameter.

Sputtering yield as a function of $T$.

Fractional abundance of carbon and iron in wall.

Impurity control inefficiency for sputtering of carbon and iron by charged and neutral particles.

Peak sputtering yield of carbon and iron by incident deuterium, tritium, alpha, carbon and iron.

Sputtering yield of carbon and iron by incident ncutrons.

Chemical sputtering coefficient of carbon.

Plasma minor, major radius.

Radially dependent electron density. Peak value is $\mathrm{N}_{e}(0)$. 


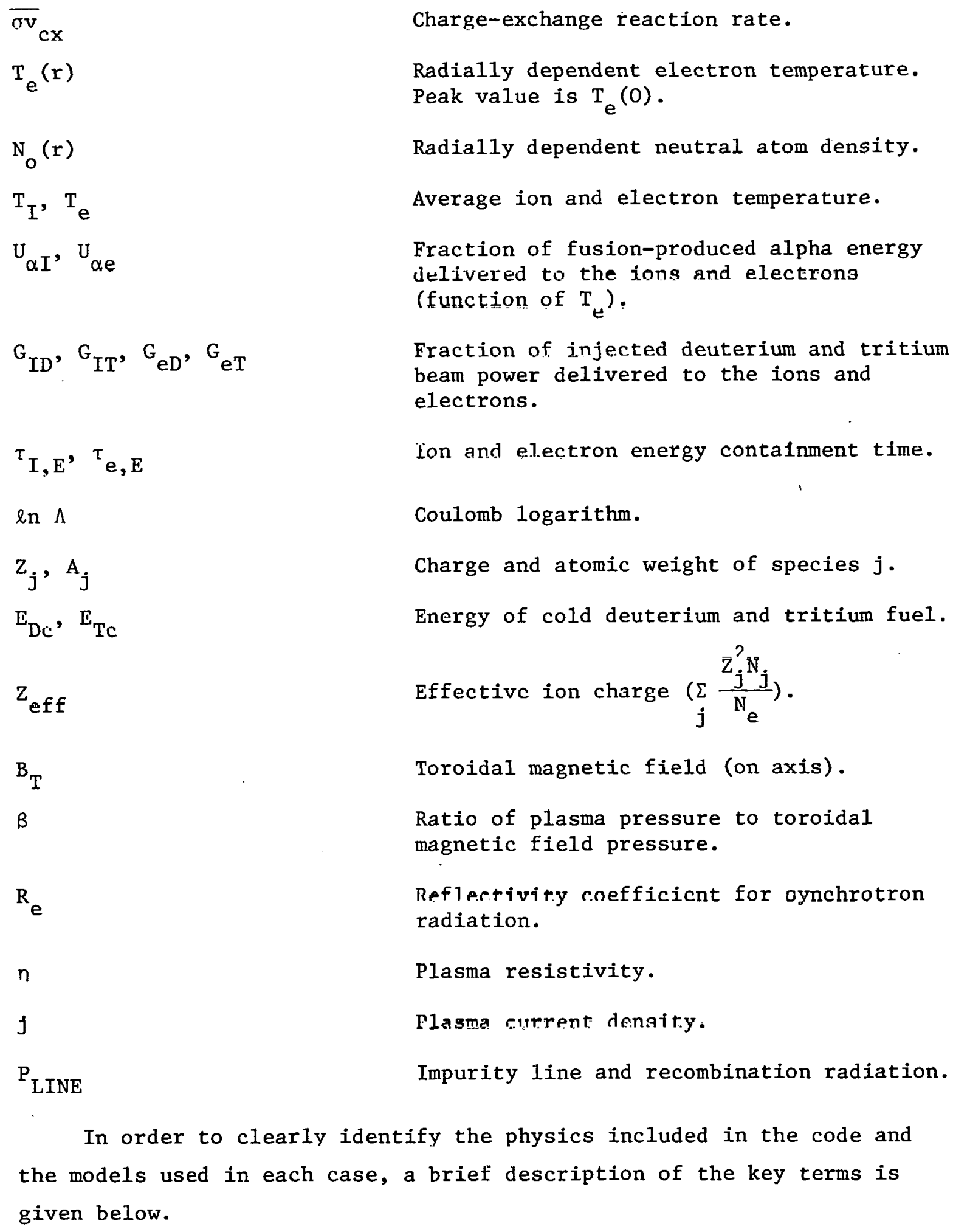

In order to clearly identify the physics included in the code and the models used in each case, a brief description of the key terms is given below. 


\subsection{FUSION RATE}

The deuterium-tritium fusion rate is given by $\mathrm{N}_{\mathrm{D}} \mathrm{N}_{\mathrm{T}}\langle\sigma v\rangle{ }_{\mathrm{DT}}$ where the reaction rate parameter is taken from Greene. ${ }^{l}$ The charged particle fusion energy produced by background reactions is $\mathrm{N}_{\mathrm{D}} \mathrm{N}_{\mathrm{T}}\left\langle\sigma \mathrm{\sigma V}{ }_{\mathrm{DT}} Q_{\alpha}\right.$ where $Q_{\alpha}=3.52 \mathrm{MeV}$. The fraction of the alpha energy delivered to the plasma depends on the containment of the fast ions. ${ }^{2}$

\subsection{ALPHA ENERGY DEPOSITION}

The fraction of the alpha energy produced which is delivered to the ions, $\mathrm{U}_{\alpha \mathrm{I}} / \mathrm{U}_{\mathrm{o}}$, is taken to be $\mathrm{T}_{\mathrm{e}}(\mathrm{keV}) / 50(\mathrm{keV})$. The fraction delivered to the electrons is $\left(1-\mathrm{U}_{\alpha \mathrm{I}} / \mathrm{U}_{\mathrm{O}}\right)$. These expressions were derived from curves developed by Sigmar and Joyce ${ }^{3}$ and are accurate for $\mathrm{T}_{e} \leqslant 20 \mathrm{keV}$.

\subsection{BEAM-PLASMA FUSION POWER}

The fusion power produced by beam-plasma interactions is expressed as a multiple, $\mathrm{F}$, of the injected beam power as discussed by Dawson et al. 4 For the case of deuterium injection,

$$
F=F\left(E_{b}, T_{e}\right) N_{T} / N_{e}
$$

where

$$
\begin{aligned}
F\left(E_{b}=150 \mathrm{keV}, \mathrm{T}_{\mathrm{e}}\right)=-0.1 .2759 & +0.27353 \mathrm{~T}_{\mathrm{e}} \\
& -0.00879 \mathrm{~T}_{\mathrm{e}}^{2}
\end{aligned}
$$

$F$ is taken to be zero for $F<0$ and $F=2$ for $T_{e} \geq 15 \mathrm{keV}$. For $200 \mathrm{keV}$, the coefficients change only slightly, to $-0.12893,0.2747$, and -.00752 , with $\mathrm{F}=2.3$ for $\mathrm{T}_{\mathrm{e}}>18 \mathrm{keV}$. The fusion energy is $17.6 \mathrm{MeV}$ and the 3.52-MeV alpha particles deliver their energy to the plasma as described above. The densily change lue to beam-plasma fusion is given by

$$
-\frac{S_{D} E_{b}}{17600} \frac{N_{T}}{N_{e}} F\left(E_{b}, T_{e}\right) .
$$




\subsection{NEUTRAL BEAM INJECTION HEATING}

The energy delivered to the background plasma electrons and ions by

fast injected deuterium and tritium beams is given by the functions $G_{e}$ and $G_{I} \cdot 5$ The critical energy $E_{c}$, i.e., the energy at which the fast-ion slowing-down rate on background electrons and ions is equal, is given by

$$
E_{c}=14.8 \mathrm{~T}_{e}\left(\frac{M_{f}}{M_{H}}\right)^{1 / 3}\left(\frac{M_{f}(z)}{M_{i}}\right)^{2 / 3}
$$

where

$$
\langle Z\rangle=\frac{\sum N_{j} Z_{j}^{2}\left(M_{i} / M_{j}\right)}{\sum N_{j} Z_{j}} .
$$

This quantity and the approximate fit to the $G_{e}$ and $G_{I}$ curves, ignoring charge exchange,

$$
\begin{aligned}
G_{I} & =0.5 \exp \left(-0.0916 \mathrm{E}_{\mathrm{b}} / \mathrm{E}_{c}\right) \\
& +0.5 \exp \left(-0.635 \mathrm{E}_{\mathrm{b}} / \mathrm{E}_{\mathrm{c}}\right), \\
G_{e} & =1-G_{L^{\prime}},
\end{aligned}
$$

permits the necessary fractions to be computed.

\subsection{ELECTRON-ION ENERGY TRANSFER}

This term is given by ${ }^{6-0}$

$$
1.5 \times 10^{-19} \frac{N_{e}}{T_{e}^{3 / 2}} \sum_{j}\left(\frac{Z_{j} N_{j}}{A_{j}}\right)\left(T_{j} \ln \Lambda_{j e}-T_{e} \ln \Lambda_{e j}\right) .
$$

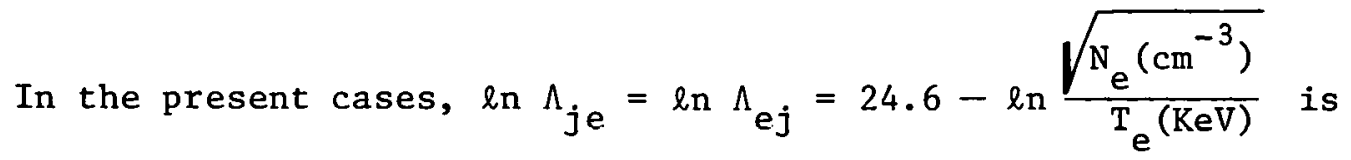

assumed. For further detailed discussion on $\ln \Lambda$, see Ref. 9 . 


\subsection{OHMIC HEATING}

The specific power delivered to the plasma due to ohmic heating is $n J^{2}$ where $J$ is the current density and $n$ is the plasma resistivity.10-11 From Ref. 11,

$$
\eta=\left(\frac{\ln \Lambda \text { ei }}{17}\right) \frac{2.8 \times 10^{-8}}{\mathrm{~T}_{\mathrm{e}}^{3 / 2}} \quad\left(z_{\text {eff }} \cdot \frac{\alpha}{0.51}\right)
$$

where $\alpha=0.51$ for hydrogen. The resistivity may be enhanced by neoclassical effects. ${ }^{12}$ The effect of radial profiles on this term can be neglected with little error. For plasma profiles of the form $\mathrm{T}_{\mathrm{e}}=\mathrm{T}_{\mathrm{e}}(0)\left[1-(\mathrm{r} / \mathrm{a})^{2}\right]^{\alpha}$ and $\mathrm{J} \propto \mathrm{T}_{\mathrm{e}}^{3 / 2}$, the ohmic heating power varies as

$$
n J^{2} \alpha\left(\frac{3 \alpha}{2}+1\right) /(\alpha+1)^{3 / 2}
$$

For a typical distribution taken to be parabolic, $\alpha=1$, the $\alpha$ dependent factor is 0.88 and the heating power is approximately given by using average values of $\mathrm{J}$ and $\mathrm{T}_{e}$.

\subsection{BREMSSTRAHLUNG AND SYNCHROTRON RADIATION}

These radiation loss terms are ${ }^{13}, 14,15$

$$
P_{\text {brem }}=0.30 \times 10^{-20} \mathrm{Z}_{\text {eff }} \mathrm{N}_{\mathrm{e}}^{2} \mathrm{~T}_{\mathrm{e}}
$$

and

$$
\mathrm{P}_{\text {synch }}=\frac{1.5 \times 10^{5}}{\sqrt{\mathrm{a}}} \sqrt{\mathrm{N}_{\mathrm{e}}} \mathrm{B}_{\mathrm{T}}^{5 / 2}(1-\beta)^{5 / 4} \mathrm{~T}_{\mathrm{e}}^{1 / / 4}\left(1-\mathrm{R}_{\mathrm{e}}\right)\left(1+\frac{\mathrm{T} \mathrm{e}}{204}\right),
$$

respectively. Here $\beta$ is the ratio of plasma pressure to toroidal magnetic field pressure and $R_{e}$ is the reflectivity from the chamber. The synchrotron term was modified to include finite $\beta$ as discussed by McNa11y. ${ }^{8}$ The basic term was taken from Rose, ${ }^{15}$ but the numerical coefficient was doubled for consistency with the results of Rosenbluth. 16 


\subsection{CONTAINMENT TIMES}

The particle and energy containment times used are critical in determining the detailed energy balance for a system. Theoretical estimates must be used in this regard since at present, scaling laws appropriate to large, hot plasmas are not known. Here scaling laws are taken from Ref. 11 and include both conduction and convection losses. The containment times are derived from the appropriate transport coefficients

$$
\tilde{\tau}_{\mathrm{d}}=\mathrm{a}^{2} / 4 \mathrm{D}
$$

and

$$
\tau_{\chi}=a^{2} / 4 \chi
$$

where the density scale length $r_{N}$ and the temperature scale length $r_{T}$. have been set equal to the minor radius a. Quasi-neutrality requires that the convection times for ions and electrons be equal. Thus, $\tau_{d}=$ $\tau_{d, e}=\tau_{d, i}$. The electron and ion thermal conductivity times, ${ }^{r}{ }_{\chi}, e$ and $\tau_{\chi, i}$, may be different. Table 2 indicates the transport modes included in the analysis and the symbols used to represent them.

Table 2

Symbol table of conduction and convection times

Pseudoclassical

Neoclatrleal

First trapped electron mode

Second trapped electron mode

Trapped ion mode

\begin{tabular}{|c|c|c|}
\hline- & $\tau_{x, c}^{F G}$ & $\tau_{\mathrm{d}}^{\mathrm{PS}}$ \\
\hline$L_{\chi, i}^{N E O}$ & - & $=$ \\
\hline - & $\tau_{\chi, e}^{\text {TEM } 1}$ & $\tau_{\mathrm{d}}^{\mathrm{TEM}} 1$ \\
\hline- & $\tau_{x, e}^{\text {TEM } 2}$ & $\tau_{\mathrm{d}}^{\text {TEM } 2}$ \\
\hline$\tau_{\widehat{\chi}, i}^{\text {TIM }}$ & $\tau_{x, e}^{T I M}$ & $\tau_{\mathrm{d}}^{\mathrm{TIM}}$ \\
\hline
\end{tabular}

Ion Conduction Electron Conduction Convection

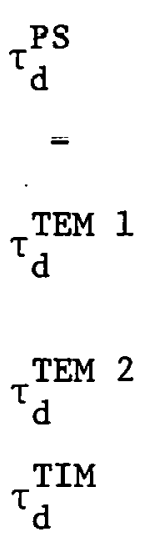


In the formulae which follow, a correction for noncircular plasma cross sections is given. The form of the correction is $\left[\left(1+E^{2}\right) / 2\right]^{k}$ where $\mathrm{k}$ is typically a multiple of $1 / 2$. $E$ is the elongation, i.e., the ratio of plasma height to width. Noncircularity is explained in detail in Section 2.13. The containment times are

$$
\tau_{\chi, e}^{P S}=\left(a^{2} / 4 C_{o} \nu_{e i} \rho_{\theta e}^{2}\right)
$$

and

$$
\tau_{d}^{P S}=\left(a^{2} / 4 C_{1} \nu_{e i} \rho_{\theta e}^{2}\right)
$$

where $\nu_{e i}$ is the electron-ion collision frequency and $\rho_{\theta e}$ is the electron gyroradius in the average poloidal field. $C_{0}$ is on the order of 3-10; $\mathrm{C}_{1}$ is on the order of $1-3$. For the first trapped electron mode, $\tau_{\chi, e}^{\text {TEM } 1=\varepsilon \tau_{D}^{T E M ~} 1 \text {, and }}$

$$
\frac{1}{\tau_{d}^{\text {TEM } 1}}=\frac{\left(2.2 \times 10^{5}\right) \mathrm{T}_{e}^{5.5} \varepsilon^{1.5} \mathrm{~N}_{\mathrm{e}}}{\left(\mathrm{I}^{2} \mathrm{~B}_{\mathrm{T}}{ }^{\beta} \theta \mathrm{e}^{2} \mathrm{Z}_{\mathrm{eff}}\right.}\left(\frac{1+\mathrm{E}^{2}}{2}\right)
$$

where $\varepsilon \equiv r / R_{0}$, the inverse aspect ratio. For the second trapped electron

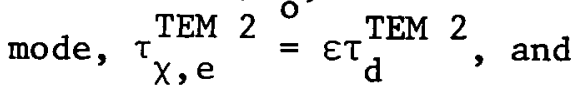

$$
\frac{1}{\tau_{\mathrm{d}}^{\text {TEM } 2}}=\frac{\left(1.57 \times 10^{-7}\right) \mathrm{Z}_{\text {eff }} \mathrm{N}_{\mathrm{e}} \varepsilon^{1 / 2}}{\mathrm{I}^{2} \mathrm{~T}_{\mathrm{e}}^{1 / 2}}\left(\frac{1+\mathrm{E}^{2}}{2}\right) \text {. }
$$

Collisionality determines which of the two trapped electron modes is applicable at a given time during the reactor pulse. For the trapped ion mode, $\tau_{\mathrm{d}}^{\mathrm{TIM}}=\tau_{\mathrm{X}, \mathrm{i}}^{\mathrm{T} I M}=\tau_{\chi, e}^{\mathrm{TIM}}$, and

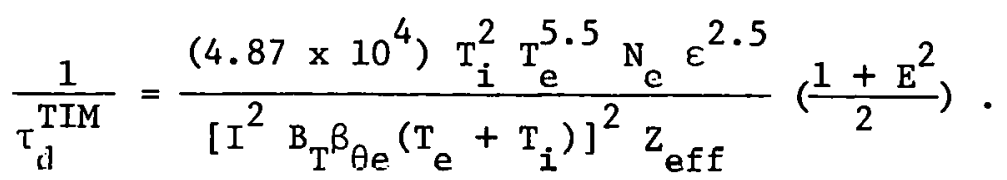

The neoclassical ion thermal conductivity time is given by ${ }^{17-19}$

$$
\frac{1}{\tau_{x, i}^{N E O}}=\left[1.18 \frac{\sqrt{ } 2 \varepsilon \rho_{i \theta}^{2}}{a^{2} \tau_{i}} f\left(\nu_{*_{i}}\right)\right]
$$


where $\rho_{i \theta}$ is the ion gyroradius in the poloidal field,

$$
\rho_{i \theta}=\left[\frac{2 \mathrm{~T}_{i}}{\mathrm{M}_{i} \Omega_{i \theta}^{2}}\right]^{1 / 2}
$$

and

$$
\Omega_{i \theta}=\frac{e \varepsilon B_{T}}{M_{i} q}\left[\frac{1+E^{2}}{2}\right]^{1 / 2} .
$$

The ion scattering time is $\tau_{i}$ and $f\left(\nu_{*_{i}}\right)$ is an empirical relation which characterizes the transitions from the Pfirsch-Schlïter to the plateau to the banana diffusion regimes. They are given by

$$
\tau_{i}=\left[\frac{2 \mathrm{~N}_{\mathrm{D}}+3 \mathrm{~N}_{\mathrm{T}}}{2.5\left(\mathrm{~N}_{\mathrm{D}}+\mathrm{N}_{\mathrm{T}}\right)}\right]^{1 / 2}\left(\frac{.17}{\ln \Lambda_{\mathrm{ei}}}\right) \frac{4.34 \times 10^{16} \mathrm{~T}_{i}^{3 / 2}}{z_{\text {eff }} \mathrm{N}_{\mathrm{e}}}
$$

and

$$
f\left(\nu_{*_{i}}\right)=\frac{1+0.43 \varepsilon^{3 / 2} \nu_{*_{i}}}{1+1.03 v_{*_{i}}^{1 / 2}+0.18 v_{*_{i}}}
$$

where

$$
v_{*_{i}}=\frac{\mathrm{R}_{\mathrm{o}} \mathrm{q}}{v_{t h, i} \tau_{i} \varepsilon^{3 / 2}}\left[\frac{1+E^{2}}{2}\right]^{1 / 2} .
$$

Profile effects are modeled by changing $q$ in these expressions. 'lhe transitions from one diffusion mode to another depend on collistonality and are modeled as follows. In addition, the value of the collisionality may have a strong radial dependence with a siguificant effect on the results.

$$
\frac{1}{\tau_{\operatorname{CONV}}}=\frac{1}{\tau_{d}^{\mathrm{PS}}}+\frac{1}{\tau_{\mathrm{d}}^{\mathrm{TEM}}}+\frac{1}{\tau_{\mathrm{d}}^{\mathrm{TTM}}}
$$




$$
\begin{gathered}
\frac{1}{\tau_{\text {COND,i }}}=\frac{1}{\tau_{X, i}^{\text {NEO }}}+\frac{1}{\tau_{d}^{\text {TIM }}} \\
\frac{1}{\tau_{\text {COND,e }}}=\frac{1}{\tau_{X, e}^{P S}}+\frac{1}{\varepsilon \tau_{d}^{\text {TEM }}}+\frac{1}{\tau_{d}^{\text {TIM }}} .
\end{gathered}
$$

The containment times used in the rate equations are:

$$
\begin{gathered}
\tau_{\mathrm{d}}=\tau_{\mathrm{D}}=\mathrm{C}_{\mathrm{T}} \tau_{\mathrm{T}}=\mathrm{C}_{\alpha} \tau_{\alpha}=\mathrm{C}_{\mathrm{C}} \tau_{\mathrm{C}}=\mathrm{C}_{\mathrm{Fe}} \tau_{\mathrm{Fe}}=\tau_{\mathrm{CONV}} \\
\frac{1}{\tau_{\mathrm{E}, \mathrm{i}}}=\frac{1}{\tau_{\mathrm{COND}, i}}+\frac{\mathrm{T}^{*}}{\tau_{\mathrm{CONV}}} \\
\frac{1}{\tau_{\mathrm{E}, \mathrm{e}}}=\frac{1}{\tau_{\mathrm{COND}, \mathrm{e}}}+\frac{\mathrm{T}^{*}}{\tau_{\mathrm{CONV}}} .
\end{gathered}
$$

The $\mathrm{C}$ factors permit consideration of different ion containment times for various ion species. The $T *$ factor is the fraction of the average ion energy assumed to be carried out of the system by particles which diffuse from the containment volume and are lost to a surface.

\subsection{PLASMA INDUCTANCE}

The flux swing of the tokamak transformer must supply the inductive energy stored in the plasma system as well as the resistive losses given by IVt.

The flux swing required to supply the stored magnetic energy is LI, where $\mathrm{L}$ is the sum of the internal and external inductance. Thus, the internal inductance per unit length is $\mu_{0} l_{i} / 4 \pi$ and

$$
L=\mu_{0} R\left(\ln \frac{b}{a}+\frac{l_{i}}{2}\right)
$$

where $\mathrm{b}$ is the primary winding radius. For uniform current, $\ell_{i}=0.5$; for more peaked current profiles, $\ell_{i}>0.5$. 


\subsection{IMPURITY RADIATION EFFECTS}

The simulation includes a treatment of line, radiative recombination, and dielectronic recombination radiation losses. ${ }^{20}$ The model used is based on theoretical calculations by Merts et al. ${ }^{21}$ The calculation is for iron and takes into account that the iron may be partially ionized in some regions of the plasma, depending on plasma parameters. The results are dependent on plasma electron temperature. The impurity radiation loss is found to be approximately constant below a temperature $\mathrm{T}_{e}^{\mathrm{L}}$, and again approximately constant (with reduced magnitude) above a temperature $T_{c}^{u}$. A linear interpolation is used to connect the two regions. This radially dependent loss process is included in the model.

The electron temperature and electron density profiles are assumed to be centrally peaked parabolic functions of $r$ (the minor radius). The widths of these profiles are fixed by the initial conditions, namely the initial values for the average temperature and density and their assumed values at the plasma edge. The profiles are then completely determined. The profiles are recomputed as a function of time as the code follows the evolution of all plasma parameter averages.

The high- $Z$ impurity density is treated similarly, but the peak of the profile is allowed to occur at arbitrarily chosen radii. In particular, the impurity density may be peaked at the wall. This model allows impurity buildup at the plasma edge or at the plasma center to permit assessment of the implications of various impurity diffusion thcorica.

With the above assumptions, the total radiation integ:al over the plasma volume is an eighth-order polynomial function of $r^{L}$ and $r^{u}$, the radii at which the temperature $\mathrm{T}_{e}^{\mathrm{L}}$ and $\mathrm{T}_{\mathrm{e}}^{\mathrm{u}}$ occur. At each time step, these radii and the corresponding total radiation are evaluated.

Figures 1 and 2 show typical profiles for electron density, electron temperature, impurity density, and atomic radiation. The two cases differ in that the impurity profile is centered at the plasma edge in Fig. 2 and at the plasma center in Fig. 1.

The high temperature region, the transition region, and the low temperature region can be distinguished between $r=0$ and $r=a$. The 


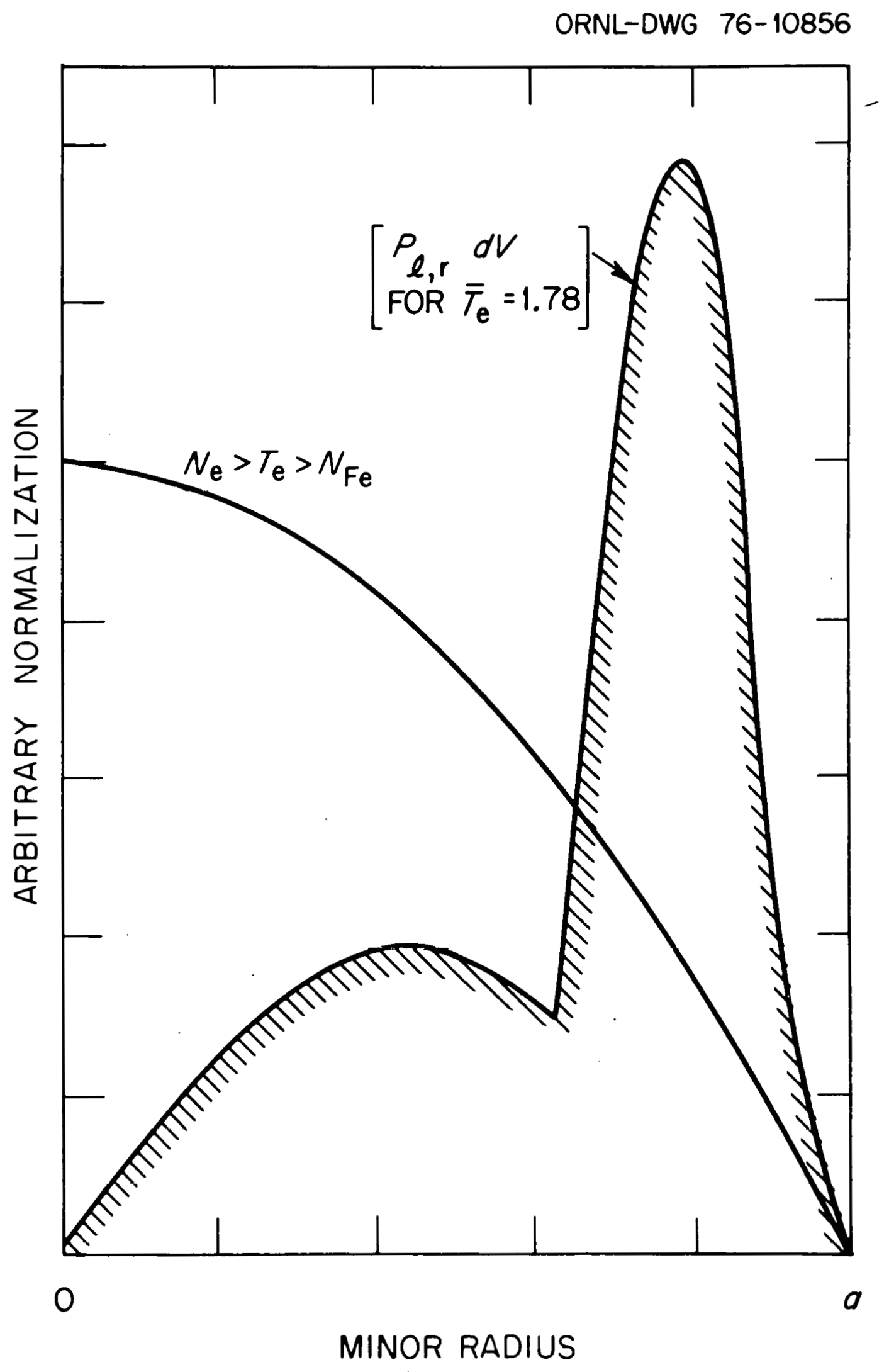

Fig. 1. Radiation losses (integrated over $\theta$ and $\phi$ ) vs minor radius $r$. The impurity center is at $r=0$. 


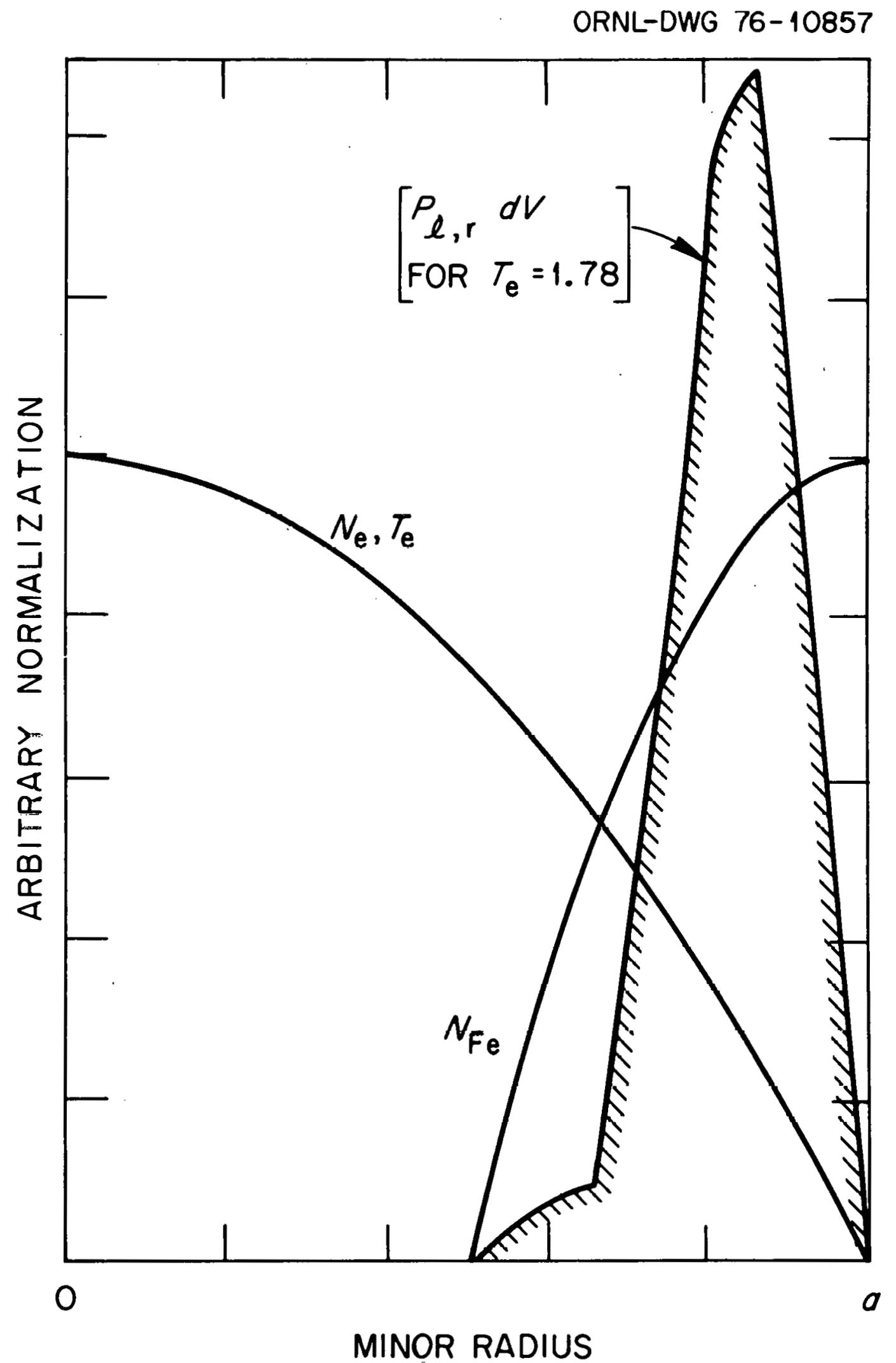

Fig. 2. Radiation losses (integrated over $\theta$ and $\phi$ ) vs minor radius $r$. The impurity center is at the edge. 
remainder of the shape is due to the volume element variation with $r$ and the density distributions used.

The equation used for the impurity radiation loss is

$$
\mathrm{P}_{\ell}\left(\mathrm{w} / \mathrm{m}^{3}\right)=C\left(\mathrm{~T}_{\mathrm{e}}\right) \times 10^{-32} \mathrm{~N}_{\mathrm{e}^{\left(\mathrm{m}^{-3}\right)} \mathrm{N}_{\mathrm{Fe}}}^{\left(\mathrm{m}^{-3}\right)}
$$

where

$$
\begin{array}{ccc}
C\left(\mathrm{~T}_{e}\right)=4.1 & \text { for } & \mathrm{T}_{\mathrm{e}} \leq \mathrm{T}_{\mathrm{e}}^{\mathrm{L}} \\
\mathrm{C}\left(\mathrm{T}_{\mathrm{e}}\right)=0.32 & \text { for } & \mathrm{T}_{\mathrm{e}} \geq \mathrm{T}_{\mathrm{e}}^{\mathrm{V}} \\
\mathrm{C}\left(\mathrm{T}_{\mathrm{e}}\right)=4.1-3.78 & \frac{\mathrm{T}_{\mathrm{e}}-\mathrm{T}_{\mathrm{e}}^{\mathrm{L}}}{\mathrm{T}_{\mathrm{e}}^{\mathrm{V}}-\mathrm{T}_{\mathrm{e}}^{\mathrm{L}}} \text { for } \mathrm{T}_{\dot{e}}^{\mathrm{L}} \leq \mathrm{T}_{\mathrm{e}} \leq \mathrm{T}_{\mathrm{e}}^{\mathrm{V}} .
\end{array}
$$

For iron, $\mathrm{T}_{\mathrm{e}}^{\mathrm{L}}=1.0 \mathrm{keV}$ and $\mathrm{T}_{\mathrm{e}}^{\mathrm{V}}=2.1 \mathrm{keV}$.

\subsection{IMPURITY PRODUCTION-SPUTTERTNG}

The buildup of the carbon and iron impurity densities due to sputtering from the walls is considered. The sputtering processes included in the $\mathrm{N}_{c}$ and $\mathrm{N}_{\mathrm{Fe}}$ equations are due to incident particles which result from diffusion, i.e., deuterons, tritons, alphas, carbon and iron ions; fusion neutrons and neutrons incident from the blanket; fast neutral atoms from charge exchange; and chemical sputtering of carbon.

The ions that diffuse from the plasma are assumed to be monoenergetic. The dependence of the sputtering yield on incident particle energy is given $\mathrm{by}^{22}$

$$
f(T)=\frac{4\left(T-E_{c}\right)^{3 / 2} E_{M}^{1 / 2}}{E_{M}^{2}+3 T^{2}}
$$

where

$$
E_{M}=6 \mathrm{keV} \quad \text { and } \quad E_{c}=0.07 \mathrm{keV} \text {. }
$$

The magnitudes of the sputtering coefficients depend on the incident species. 
The neutron sputtering rate is proportional to the neutron production rate in the plasma due to background and beam-plasma fusion events. The neutron sputtering coefficient is taken from Ref. 23. The result is actually for a $0.5-\mathrm{cm}$ niobium wall and a lithium-cooled blanket. It includes the $14.1-\mathrm{MeV}$ source neutrons and the random neutron flux at all energies which results from interactions in the blanket. The chargeexchange flux to the wall is computed from a spatial integration over the plasma. As in the radiation case described above, radially dependent ion and neutral profiles are used.

The oputtcring yicld per unit volume io

$$
\frac{1}{V} \int_{V} \gamma f[T(r)] \sigma_{C X} \frac{N_{O}}{4}\left(\gamma_{D} N_{D} v_{D}+\gamma_{T} N_{T} v_{T}\right) d V
$$

where $\gamma=\gamma_{c}$ or $\gamma_{\mathrm{Fe}}$ when appropriate. The neutral density is assumed to fall exponentially as given by

$$
N_{0}(r)=N_{0}(a) e^{-(a-r) / \lambda}
$$

where $\lambda$ is the characteristic length for neutral attenuation.

Chemical sputtering due to the interaction of deuterium and tritium with carbon on the wall is included in the model. The sputtering coefficient is taken from data ${ }^{24}$ for carbon temperatures assumed to be greater than $1000{ }^{\circ} \mathrm{C}$.

The sputtering coefficients, $\gamma$, are shown in Table 3 .

Tablc 3

Peak sputtering yields

Carbon and Iron

$\begin{array}{lc}\mathrm{d} & 0.04 \\ \mathrm{~T} & 0.06 \\ \alpha & 0.64 \\ \mathrm{C} & 13.0 \\ \mathrm{Fe} & 13.0\end{array}$


Table 3 (cont'd)

$$
\begin{array}{ll}
\mathrm{n} & 3.0 \times 10^{-5} \\
\text { chemical } & 0.03 \text { (carbon only) }
\end{array}
$$

\subsection{MODIFICATIONS FOR NONCIRCULAR PLASMA CROSS SECTIONS}

It has been suggested that a noncircular plasma may result in improved plasma.behavior. ${ }^{25,26}$ In this section, all elliptical cross section plasma is considered in order to include the features of noncircular plasmas in the model. For an elliptical cylinder of length $2 \pi R_{0}$, let the horizontal minor semi-axis in the $x$ direction be a and the vertical major semi-axis in the $y$ direction be $b$. The elongation ratio is defined as $E=b / a$. The poloidal flux function $\psi$ per unit length satisfies the equation

$$
-\nabla^{2} \psi=\mu_{\mathrm{o}} \mathrm{J}_{\mathrm{ZO}}
$$

where $J_{Z O}$ is the plasma current density (assumed to be uniforin). A solution to the equation in cylindrical geometry is ${ }^{27}$

$$
\psi=\psi_{0}-\frac{1}{2} \frac{a^{2} b^{2}}{a^{2}+b^{2}} \quad \mu_{0} J_{z 0}\left[\frac{x^{2}}{a^{2}}+\frac{y^{2}}{b^{2}}\right] .
$$

Thus the model results in flux surfaces which are nested ellipses,. all with elongation $E=b / a$.

The inductance $L$ is obtained by considering flux linkages and for a uniform current density is found to be

$$
L=\frac{\mu_{0} R_{0}}{4}\left(\frac{2 E}{1+E^{2}}\right) \text {. }
$$

Peaked current profiles correspond to an internal inductance (e.m.u.) per unit length $\ell_{i}>0.5$. The volt-second requirement to store the plasma internal magnetic energy associated with the current is

$$
\mathrm{V} \cdot \mathrm{s}=\left(\frac{2 \mathrm{E}}{1+\mathrm{E}^{2}}\right) \quad \mu_{0} \mathrm{R}_{\mathrm{o}}\left(\frac{l_{i}}{2}\right) \mathrm{I} \text {. }
$$


The external inductance requirements depend on the details of the plasma shaping coils. In the calculation of volt-second requirements, the turbulent losses during start-up and resistive losses must also be considered, although these are not specifically included in this model.

The noncircular effects on magnetic fields, current and magnetic fields, current, and safety factor $q$ are discussed following Ohkawa and Jensen. ${ }^{25}$ Let the circumference in the poloidal direction be $\emptyset \mathrm{ds} \perp$. The circumference ratio is

$$
\mathrm{C} \equiv \emptyset \mathrm{ds} L / 2 \pi \mathrm{R}_{\mathrm{o}}
$$

The inverse aspect ratio is $\frac{1}{A}=\frac{a}{R}$. In tokamaks with a circular plasma cross section, $E=1, C=2 \pi a / 2 \pi R_{0}^{O}=a / R_{0}$. For moderately elongated plasmas and moderate $q$ values, the poloidal field $B_{p}$ is less than the toroidal field $B_{t}$, so that the ratio of plasma pressure to magnetic pressure, $\beta$, is approximately equal to the toroidal $\beta_{t}$. These pressure ratios are obtained by summing the pressures of individual species:

$$
\begin{aligned}
& \beta \approx \beta_{t}=\operatorname{RNkT} /\left(B_{t}^{2} / 2 \mu_{o}\right), \\
& B_{\dot{p}}=\operatorname{RNkT} /\left(B_{\mathrm{p}}^{2} / 2 \mu_{\mathrm{o}}\right) .
\end{aligned}
$$

The relative strengths of the poloidal and toroidal fields determine the rotational transform

$$
i=2 \pi / q \text {, }
$$

where $q \equiv$ safety factor. Combining the above,

$$
B \lambda B_{p} c^{2}(1 / 2 \pi)^{2} \text {. }
$$

and

$$
q=\frac{\mathrm{CB}_{t}}{\mathrm{~B}_{0}} \text {. }
$$


This shows that noncircular cross sections have the possibility of achieving a higher plasma $B$. Although not considered in detail, the property of plasma flux conservation may also permit the attainment of high $\beta$.

The area of an ellipse is $\pi \mathrm{a}^{2} \mathrm{E}$, and the circumference $\sigma \mathrm{ds} \perp=4 \mathrm{a} \varepsilon$, where $\varepsilon$ is an elliptic integral. To a good approximation,

$$
\emptyset \mathrm{ds}_{\perp}=2 \pi \mathrm{a} \sqrt{\frac{1+\mathrm{E}^{2}}{2}} .
$$

Therefore, the average poloidal field $\bar{B}_{p}$ is

$$
\bar{B}_{p}=\frac{B_{t}}{q} \frac{a}{R} \sqrt{\frac{1+E^{2}}{2}}=B_{p}(E=1) \sqrt{\frac{1+E^{2}}{2}} .
$$

The current required to produce this field is obtained from $0 \mathrm{ds} \perp$. $\left(\mathrm{B}_{\mathrm{p}} / \mu_{\mathrm{o}}\right)=$ IO $\frac{\mathrm{B}_{\mathrm{p}}}{\mu_{\mathrm{o}}}=\mathrm{I}$. The exact answer can be found by performing the integration using the spatially varying $B_{p}$ and elliptic coordinates. An appropriate answer is obtained by letting

$$
\emptyset \mathrm{ds} \perp \cdot \frac{\mathrm{B}_{\mathrm{p}}}{\mu_{\mathrm{o}}}=\frac{\overline{\mathrm{B}}_{\mathrm{p}}}{\mu_{\mathrm{o}}} \text { } \sigma \mathrm{ds} \perp \text {, }
$$

so that

$$
\begin{aligned}
I & =\frac{2 \pi a}{\mu_{n}} \bar{B}_{p} \sqrt{\frac{1+E^{2}}{2}} \\
& =I(E=1)\left(\frac{1+E^{2}}{2}\right) .
\end{aligned}
$$

Thus an elongation $E$ increases $B_{p}$ and $\bar{I}$ by $\sqrt{\left(1+E^{2}\right) / 2}$ and $\left[\left(1+E^{2}\right) / 2\right]$, respectively. The current density is

$$
J=\frac{I}{\pi a^{2} E}
$$


Particle and energy containment times are changed as a result of the parameter modifications described above. The scaling laws discussed in Ref. 11 were derived for circular plasma cross sections. The extension of these results to noncircular cases is therefore suspect, and in any case, transport is strongly dependent upon the details of shear, current profiles, etc. Noncircular corrections have been developed for use in this and similar models. 28,29

The general procedure is to express derivatives in terms of the flux function, $\psi$, instead of the radius, $r$. This results in corrections to the electron temperature gradient and diamagnetic drift frequencies. The modifications to $\beta_{p}, B_{p}$, and $I$ have been discussed above. 


\section{MODELING OF EXPERIMENTS}

The primary purpose of this code is to permit a survey of the large parameter space associated with the operation of $D-T$ power-producing devices. In addition, the model can be used to determine the sensitivity of system performance to changes in key parameters such as density, field strength, injected power, etc. In order to gain confidence in the predictive value of the code, it is necessary to compare its results to actual experimental data obtained from presently operating tokamaks. The code can predict only the global features of a discharge, but this comparison will indicate whether or not the code can provide a reasonably good description of system dynamics. In particular, the model is used to simulate the Tokamak Fontenay-aux-Roses (TFR), which has operated at high levels of plasma current over a reasonably long period (the Princeton Large Torus (PLT) and T-10 have started operating only recently and their performance is not well documented). A lower-current case, including neutral injection heating, is compared to the Oak Ridge Tokamak (ORMAK) results. Finally, the code is used to investigate the implications of these scaling laws for "next generation devices," using nominal parameters which might occur in PLT.

\subsection{TOKAMAK FONTENAY-AUX-RUSES (TFR)}

The Tokamak Fontenay-aux-Roses (TFR) has obtained high current operation and has been well diagnosed. ${ }^{30,31,32}$ The basic parameters of the machine and the values used as input for a typical deuterium discharge are shown in Table 4. The results are values which are reached in a quasi-equilibrium state. The experimental data include a range of plasma current levels from 100 to $400 \mathrm{kA}$, with increasing values of toroidal field, electron density, and impurity level concentrations.

The main inputs in the computer model which should be noted are the use of multiplicative constants for the scaling laws, assumed average highand low-Z impurity concentrations, and the resultant level of radiative power. In the TFR discharges, the values assumed resulted in a domination of the power balance by transport rather than by radiation losses. 
In the following analysis, we first examine the scaling of macroscopic observable parameters, i.e., the average electron temperature $\bar{T}_{e}$ and the energy containment time $\tau_{E}$, to evaluate the trends which result from particular scaling laws. The $300 \mathrm{kA}$ case is then examined in some detail.

Figure 3 shows $\bar{T}_{e}$ and $\tau_{e}$ at equilibrium for the four different current levels described in Table 4. The experimental results show a saturation of energy containment time with increasing plasma current, with the main energy balance occurring between the ohmic heating input, and wi,th transport losses rather than impurity line radiation. The maximum energy containment time achieved experimentally in deuterium was approximately $16 \mathrm{msec}$. The model that gave the best fit to the data was one which includes the dissipative trapped electron loss rate but reduces it by a factor of two relative to the theoretical prediction. ${ }^{11}$ The average electron temperature also agreed with the data and increased to $1.2 \mathrm{keV}$ at $400 \mathrm{kA}$. On the other hand, models based on pseudoclassical scaling, with the electron thermal conductivity $\chi_{e}=5 \rho_{\theta e}^{2} \nu_{e i}$, indicated a marked increase in containment time when current was increased and did not fit the data. The results suggest that pseudoclassical scaling does not apply and that the trapped electron modes should be considered in predicting the behavior of future systems.

Other causes of the observed losses such as MHD-induced fluctuations have been proposed, but the results are not conclusive. The scaling is consistent with the trapped electron modes.

A detailed study of the energy and particle balance for a $300 \mathrm{kA}$ discharge in TFR is shown in Table 5. The experimental results are shown for ' $t E, e, \bar{T}_{e}$, the peak electron temperature $T_{e}$ (max), the ion energy containment time $\tau_{E, i}$, and the maximum ion temperature $T_{i}$ (max). The computer results in columns I. II. III, and IV prefict $\tau_{E}, \bar{T}_{e}, \tau_{E, i}$, the averagc ion temperature $\bar{T}_{i}$, and the individual scaling times. Column I shows the purely pseudoclassical results, which give a somewhat high $\tau_{E}$ and $\bar{T}_{e}$, but a low $\bar{T}_{i}$ and $\tau_{E, i}$. Column II gives the trapped particle scaling results, which give a better fit to $\tau_{E}$ and $\bar{T}_{e}$; however, the ion time and temperature are still too low. The dominant process here is neoclassical ion thermal conductivity. The discrepancies are probably due to profile effects, since the ion temperature is measured on axis, where $\mathrm{T}_{e}$ is higher and $\mathrm{q}$ is lower 


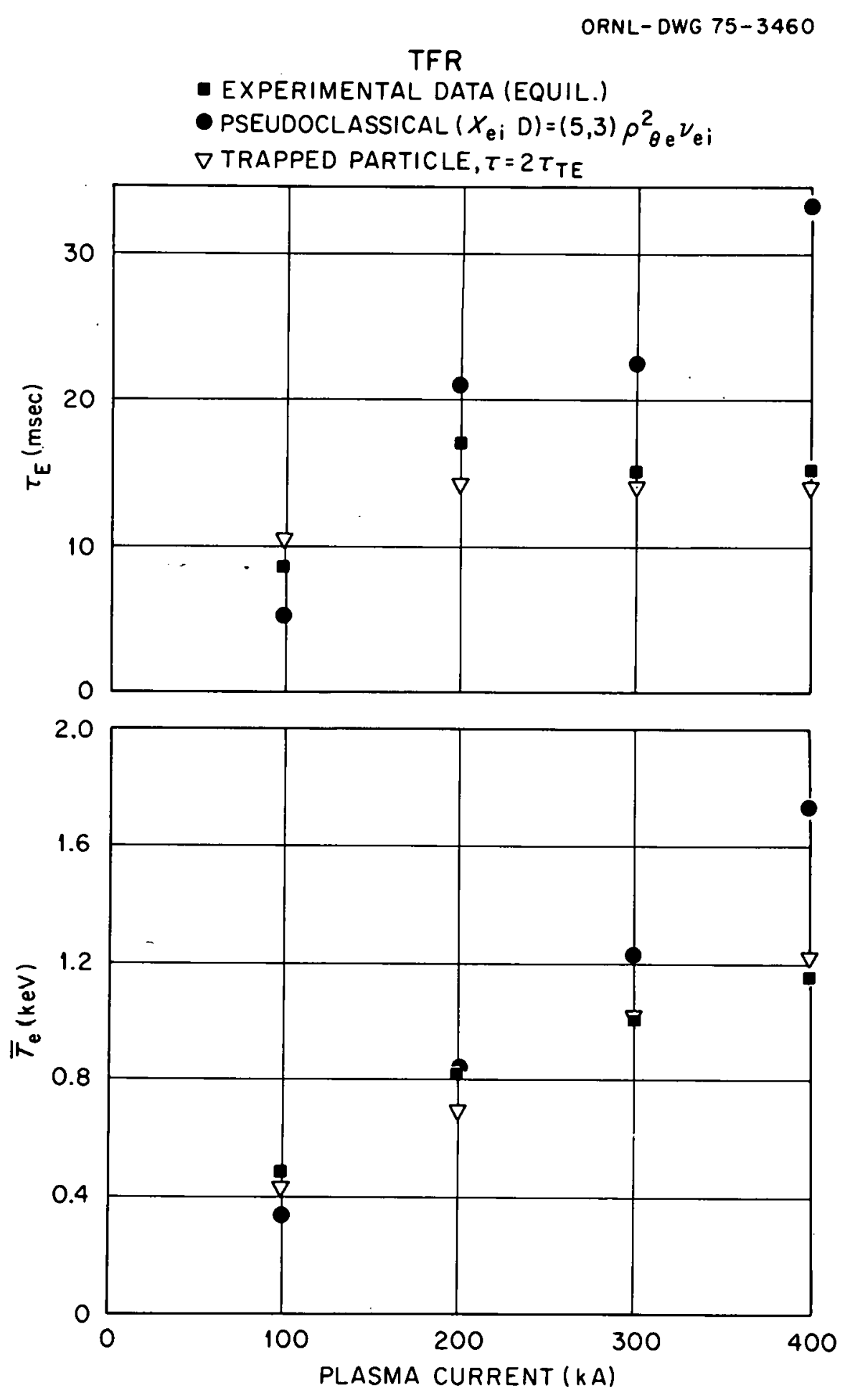

Fig. 3. TFR simulation. 
than the values used. This effect is taken into account in column III, where the neoclassical correction factor is set at 0.5 . This gives better agreement for the ion results. In column IV, the scaling is shown for a combination of pseudoclassical, trapped particle, and neoclassical transport. These results show that for the standard value of trapped particle loss and pseudoclassical loss, the trapped particle losses are dominant.

These results suggest the possible existence of the trapped electron modes. However, the system does not operate in the trapped ion regime, which may be dominant in large, hot reactor regimes. Whether or not this mode can exist in a tokamak and the magnitude of its effect are subjects of great interest.

Table 4

TFR parameters

$$
\begin{aligned}
& \text { Major radius }=0.98 \mathrm{~m} \\
& \text { Minor radius }=0.20 \mathrm{~m}
\end{aligned}
$$

\begin{tabular}{cccc}
$\begin{array}{c}\text { Plasma current } \\
(\mathrm{kA})\end{array}$ & $\begin{array}{c}\text { Toroidal field } \\
(\mathrm{T})\end{array}$ & $\begin{array}{c}\text { Electron density } \\
\left(\mathrm{m}^{-3}\right)\end{array}$ & $\begin{array}{c}\text { Effective } \\
\text { charge } \\
\text { eft }\end{array}$ \\
\cline { 1 - 2 } 100 & 2 & $0.18 \times 10^{20}$ & $\frac{3.7}{20}$ \\
200 & 4 & 0.27 & 3.5 \\
300 & 5 & 0.40 & 5.5 \\
400 & 6 & 0.47 & 6.0
\end{tabular}

Table 5

TFR experimental and simulation results

$I=300 \mathrm{kA}$

Experiment $\quad$ I $\underline{\text { II }}$ III $\quad \underline{\text { IV }}$

$\tau_{E}(s)$

0.015

0.023

0.014

0.016

0.011

$\overline{\mathrm{T}}_{\mathrm{e}}(\mathrm{keV})$

1.0

0.22

1.0

1.0

0.85 
Table 5 (cont'd)

\begin{tabular}{llllll} 
Experiment & $\underline{I}$ & $\underline{\text { II }}$ & $\underline{\text { III }}$ & $\underline{\text { IV }}$ \\
\cline { 1 - 4 } 2.3 & & & & \\
0.040 & 0.014 & 0.016 & 0.035 & 0.029 \\
0.85 & 0.48 & 0.47 & 0.66 & 0.57 \\
& & & & \\
& & & & \\
& 0.05 & $\infty$ & $\infty$ & 0.042 \\
& $\infty$ & 0.019 & 0.018 & 0.016 \\
& $\infty$ & 0.002 & 0.002 & 0.001 \\
& $\infty$ & 19.6 & 12.2 & 10.6 \\
& 0.02 & 0.02 & 0.06 & 0.061
\end{tabular}

$\tau$ - Convection (s)

Pseudoclassical

Trapped electron mode (1)

Trapped electron mode (2)

Trapped ion mode

$\begin{array}{cccl}0.08 & \infty & \infty & 0.21 \\ \infty & 0.092 & 0.087 & 0.077 \\ \infty & 0.012 & 0.012 & 0.005 \\ \infty & 19.6 & 12.2 & 10.6\end{array}$

Case I: Pseudoclassical and neoclassical scaling

Case II: Neoclassical and $1 / 2 \times$ trapped particle mode scaling

Case III: $1 / 2 \times$ neoclassical and $1 / 2 \times$ trapped particle mode scaling (best fit)

Case IV: Pseudoclassical and trapped particle mode scaling

\subsection{OAK RIDGE TOKAMAK (ORMAK)}

The Oak Ridge Tokamak (ORMAK) has explored the effects of plasma heating by neutral beam injection. The results are documented in Ref. 33 .

The parameters of the case used for study here ${ }^{34}$ include $\mathrm{N}_{e}=1.95 \times 10^{19}$ $\mathrm{m}^{-3}, \mathrm{R}_{\mathrm{o}}=0.795 \mathrm{~m}, \mathrm{a}=0.21 \mathrm{~m}, \mathrm{~B}_{\mathrm{t}}=1.8 \mathrm{~T}, \mathrm{I}_{\mathrm{p}}-107 \mathrm{kA}, \mathrm{z}_{\text {eff }}=6.8$, and $\mathrm{a}$ neutral injection beam of $8 \mathrm{~A}$ of deuterium at an energy of $25 \mathrm{keV}$. The results are summarized and compared with simulation results in Table 6 . Note that an adjustment by a factor of two of the neoclassical ion conductivity yields good agreement with the experimental results. The background plasma in the experimental case shown was primarily hydrogen, but 
the beam injection results in a buildup in the deuteron density. A comparison case where zero neutral injection power is used shows a lower electron temperature and a considerably lower ion temperature. The ion temperature is lower than that observed in the experiment.

Table 6

ORMAK experimental and simulation results

$$
I=107 \mathrm{kA}
$$

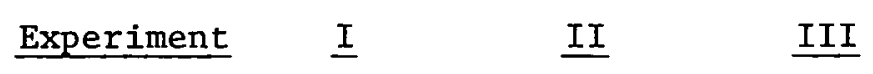

$\begin{array}{lcccc}\tau_{E}(\mathrm{~s}) & 0.005 & 0.003 & 0.004 & 0.004 \\ \overline{\mathrm{T}}_{\mathrm{e}}^{(\mathrm{keV})} & 0.503 & 0.400 & 0.410 & 0.350 \\ \mathrm{~T}_{i}(\mathrm{keV}) & 0.310 & - & - & - \\ \overline{\mathrm{T}}_{i}(\mathrm{keV}) & - & 0.131 & 0.300 & 0.140 \\ \beta_{p e}^{(-)} & 0.34 & 0.300 & 0.310 & 0.270\end{array}$

Case I: Neoclassical, pseudoclassical, and trapped particle mode scaling

Case II: $1 / 2 \times$ neoclassical, pseudoclassical, and trapped particle mode scaling

Caoc II.T, $1 / 2$ w neoclassical and trapped particle mode scaling; zero injection power

\subsection{THE PRINCETON LARGE TORUS (PLT)}

The next tokamak in the national program which will operate at high current is the Princeton Large Torus (PLT). The device has a major radius of $1.3 \mathrm{~m}$, a minor radius of $0.45 \mathrm{~m}$, a maximum toroldal fleld on the order of $5 \mathrm{l}$, and the capability of driving plasma currents in excess of a milion amperes. It is of interest to apply the code to this parameter range in order to study the implications of the scaling laws for "next generation" machines. The results should not be considered to be more than an indication of possible behavior, since there is a large range of operating parameters possible, i.e., current, density, impurity levels, auxiliary heating, etc. However, a few cases may well be indicative of future performance. 
Initial cases with an electron density of $10^{20} \mathrm{~m}^{-3}$, and effective charge from impurities $\mathrm{z}_{\text {eff }}=3$, varying amounts of neutral injection power, impurity line radiation, and plasma current are considered. Furthermore, since this is a high current regime, a case is considered without pseudoclassical diffusion, with neoclassical ion conductivity, and with trapped particle loss rates reduced by a factor of two relative to those theoretically predicted. This is consistent with the TFR simulations. The results are shown in Fig. 4 for the energy containment time and the average ion and electron. temperatures as a function of supplemental neutral injection power. At these high densities the electron and ion temperatures are nearly equal.

For a plasma current of $1.1 \mathrm{MA}$, a case with no line radiation is compared to one with line radiation losses of 0.24 watts $/ \mathrm{cm}^{3}$, which corresponds to a high-Z impurity density of $0.24 \% \times \mathrm{N}_{e}$. This is comparable to the impurity levels used in the TFR simulation, which did not affect the energy balance in that machine. In the case of zero-line radiation, the temperature obtained is $1 \mathrm{keV}$, and the energy containment time is $180 \mathrm{msec}$. Supplemental neutral beam heating of $4 \mathrm{MW}$ increases the temperature to $1.6 \mathrm{keV}$, and decreases the energy containment time to $80 \mathrm{msec}$. These effects are due to operation further into the collisionless regime where the trapped electron mode losses increase and ohmic heating input at higher temperatures decreases. Including 0.24 watt $/ \mathrm{cm}^{3}$ of line radiation only slightly modifies the results at the 4 MW beam heating level but in the case of zero supplemental heating, the energy balance is dominated by line radiation rather than transport losses, yielding a containment time of $90 \mathrm{msec}$ and a temperature of $0.8 \mathrm{keV}$. This illustrates the sensitivity of large tokamaks to radiation losses, since the heating power per unit volume is lower than that in smaller tokamaks. In the case with line radiation, an increase in plasma current to $1.6 \mathrm{MA}$ results in little change at high injection power levels due to the nature of the scaling laws. The conclusion is that the present scaling laws used for reactor design show a limit to the performance of intermediate-sized devices and that it is possible for small amounts of impurity to result in line radiation losses which will dominate the detailed energy balance. It may be acceptable to 

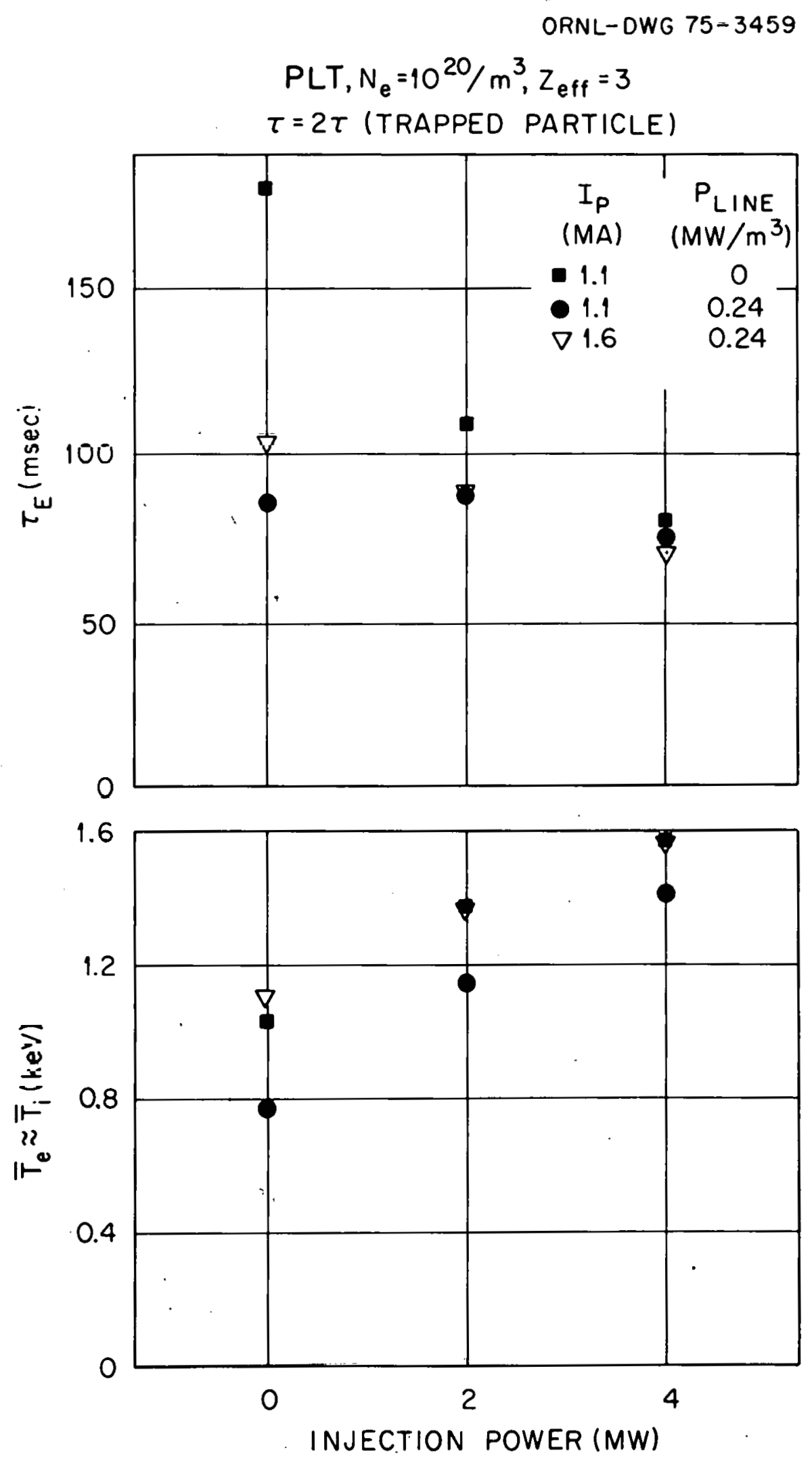

Fig. 4. PLT simulation. 
have a large radiation loss from the outer regions if the inner core is well insulated. 


\section{POINT MODELING - STATIC CODE}

A static code called POINT has been written to solve the detailed energy balance equations for a tokamak system at equilibrium. The physics included is the same as that described in Section 2. The POINT code is used interactively to obtain sensitivity plots for selected variables as a function of system parameters. The calculation is fast, which permits a large range of variables to be surveyed, and the results are good approximations to the time-dependent equilibria. The following simplifying assumptions are made: $\mathrm{T}_{e}=\mathrm{T}_{i}$; the equilibrium alpha density is zero; and ohmic heating is neglected.

The following input parameters must be specifled: aspect ratio, toroidal field, safety factor $q(a)$, effective charge $z_{\text {eff }}$, fraction of ion density composed of deuterium, charge of low- and high-Z impurities, ratio of low $Z$ density to electron density, thermal conversion and neutral beam efficiencies, and $N \tau$. If two of the following three parameters are given, then the third can be computed: electron density $\mathrm{N}_{\mathrm{e}}$, temperature $T$, and the ratio of electron pressure to poloidal field pressure $\beta_{p e} \cdot A$ graphical display program allows cross-plotting of virtually any two variables.

Given these parameters, the program computes the fusion reaction rate, stored energy, bremsstrahlung, line radiation losses, and the diffusion loss power. The deuterium-tritium ratio which optimizes the specific power produced, the infected power required, the beam-plasma fusion power, and the background fusion power produced are also found. The density and temperature are assumed to be uniform. A strong peaking of these quantities could lead to a significant change in background fusion power.

Using a different set of input variables, the code can compute the NT products required for ignition, a background fusion power production equal to the injected beam power, and energy "breakeven" including thermal and beam efficiencies. 
For a given $N \tau$ requirement, the associated plasma minor radius necessary to attain the $\mathrm{N} \tau$ assuming various transport scaling laws may be computed. The pseudoclassical, dissipative trapped electron, and trapped ion modes are inverted to obtain the radius. Since the collisionality parameter in the neoclassical ion thermal conductivity is a function of a, an iterative technique is used to find a radius which is self-consistent with the various operative scaling laws.

In addition, the ratio of the total plasma pressure to poloidal field pressure may be found by specifying the injected beam energy, the fast ion atomic weight and charge, and the impurity atomic weight and charge as well as the background plasma parameters.

It is interesting to compare the results of the static code to those of the time-dependent code. Two cases, in which $\mathrm{T}_{e}$ is approximately equal to $T_{i}$ are presented in Table 7. An important point is that the static code accepts the energy confinement time as an input, and computes the machine size necessary to achieve that confinement time. The time-dependent code accepts the machine parameters, including size, as input, and computes the confinement time.

The first case is a device typical of experimental power reactor sizes with $\mathrm{T}=4.5 \mathrm{keV}, \mathrm{N} \tau=0.94 \times 10^{20} \mathrm{sec} \mathrm{m}^{-3}, \mathrm{R}_{\mathrm{o}}=6.0 \mathrm{~m}$, and $\mathrm{a}=2.0 \mathrm{~m}$. The second case is a PLT simulation with $\mathrm{T}=1.36 \mathrm{keV}, \mathrm{N} \tau=0.11 \times 10^{20} \mathrm{sec}^{-\mathrm{m}^{-3}}$. Parameters not listed were fixed at typical values for the device in question.

Table 7

Comparison of static and time-dependent codes

$\begin{array}{ccc}\underline{\text { EPR }} & \begin{array}{c}\text { Stat1c } \\ \text { code }\end{array} & \begin{array}{c}\text { Time } \\ \text { dependent } \\ \text { code }\end{array} \\ \text { Minor radius }(\mathrm{m}) & 2.05 & 2.00 \\ \text { Beam power }\left(\mathrm{w}-\mathrm{cm}^{-3}\right) & 0.048 & 0.052 \\ \underline{\text { PLT }} & & \\ \text { Minor radius }(\mathrm{m}) & 0.415 & 0.450 \\ \text { Beam power }\left(\mathrm{w}-\mathrm{cm}^{-3}\right) & 0.516 & 0.370\end{array}$


The agreement is good in the EPR case. Agreement can be improved in the PLT case by adjusting the beam power to account for ohmic heating. One obtains $0.400 \mathrm{w}-\mathrm{cm}^{-3}$ as the adjusted static result. The minor radius is not affected.

The STATIC code has been used extensively to examine the sensitivity of assumed reference cases to the variation of critical parameters. The results are usually displayed graphically, as shown in Figs. 5-8.

Figure 5 displays information over the $N \tau$ region of interest. Since $\mathrm{N} \tau$ is used as the independent variable, this figure has no implicit scaling assumptions inherent in it and the information is valid for tokamaks of arbitrary size. Typical values have been chosen for the reference case parameters: $Z_{\text {eff }}=2$, aspect ratio $=3, q=2.5$, and $B_{t}=4 \mathrm{~T}$. This figure is for operation at a temperature of $T=8 \mathrm{keV} . \mathrm{P}_{b} / \mathrm{V}$ is the beam power per unit volume necessary to provide equilibrium operation. Note that $P_{b} / V$ is sensitive to the assumed value of $\beta_{\theta e^{\cdot}} \quad P_{\alpha}^{M} / P_{\alpha}$ is the ratio of the Maxwellian or background-produced fusion alpha power to the total alpha power produced (which also includes beam-plasma fusion events). This ratio is independent of $\beta_{\theta e} \cdot P_{\alpha}^{M} / P_{\alpha}=1$ indicates that no beaminjected energy is required to maintain equilibrium. This condition corresponds to ignition and occurs in the present case at about $N \tau=10^{15} \mathrm{~cm}^{-3}-\mathrm{sec}$ and $T=8 \mathrm{keV}$.

Figure 6 covers the same $N \tau$ interval as Fig. 5. Again $N \tau$ is taken to be the independent variable, but assumptions are made relative to confinement time scaling laws in order to compute the machine size necessary to maintain $\mathrm{T}=8 \mathrm{keV}$ for the assumed reference case parameters. The minor radius required to attain various $N \tau$ values is shown for the scaling assumptions given in Section 2 and also for cases where the trapped particle confinement times factored into the ovcrall cnergy balance are improved by factors of $\sqrt{ } 10$ and 10 . The latter may be considered as an effort to reflect optimism, an indication that trapped particle modes are profile-dependent and are predicted using a "worst case" analysis, or simply as a sensitivity calculation. This choice is left to the reader.

Note that a factor of ten uncertainty in the trapped particle confinement time at $\mathrm{NT}=10^{15} \mathrm{~cm}^{-3}-\mathrm{sec}$ results in an uncertainty of a factor of 


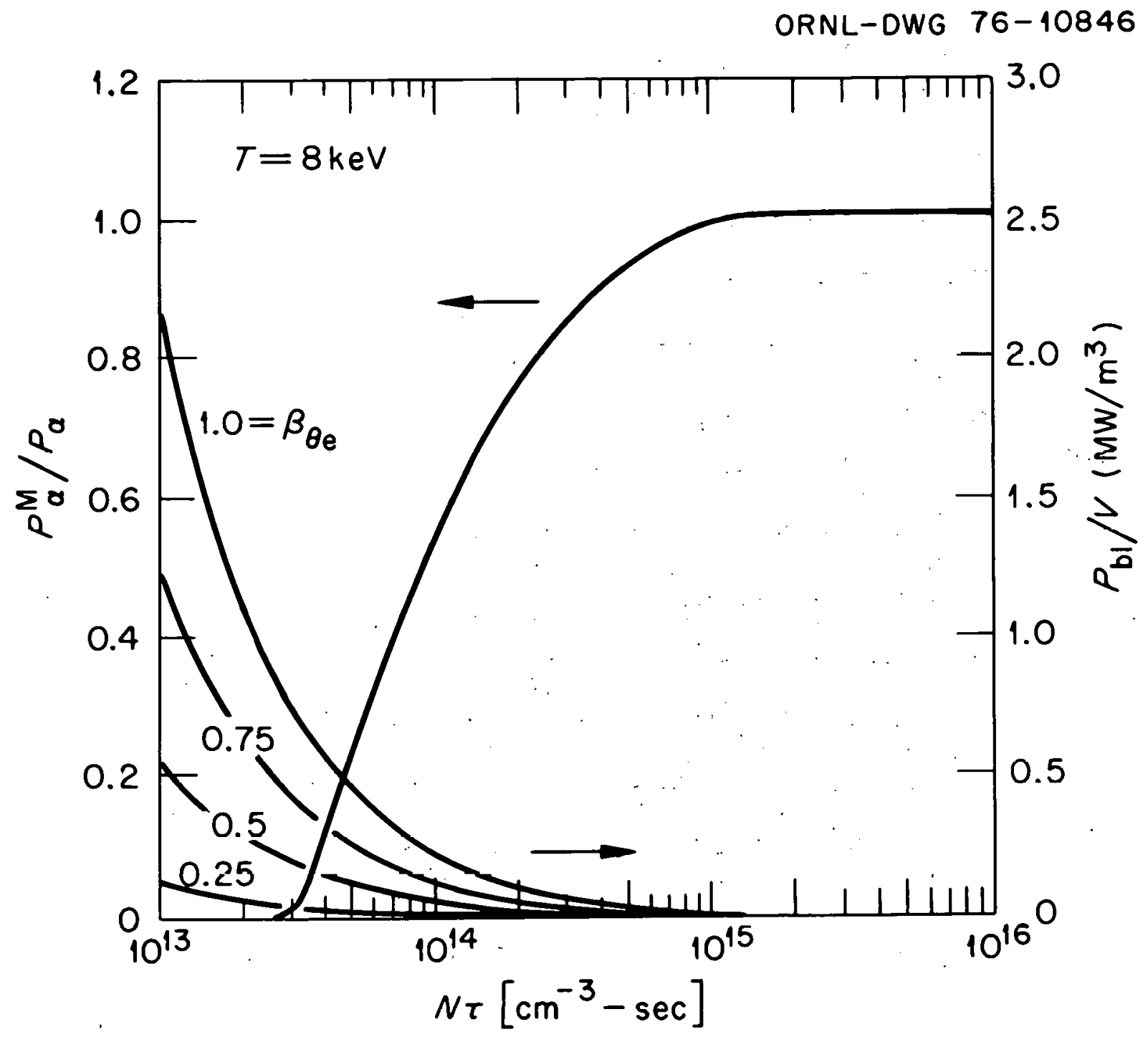

Fig. 5. Beam power per unit volume and the ratio of Maxwellian alpha power to total alpha power for several $\beta_{\theta e}$ at $T=8 \mathrm{keV}$. 
ORNL-OWG $75-11170$

TRAPPED PARTICLE LOSS VARIATION

$T=8 \mathrm{KeV}$

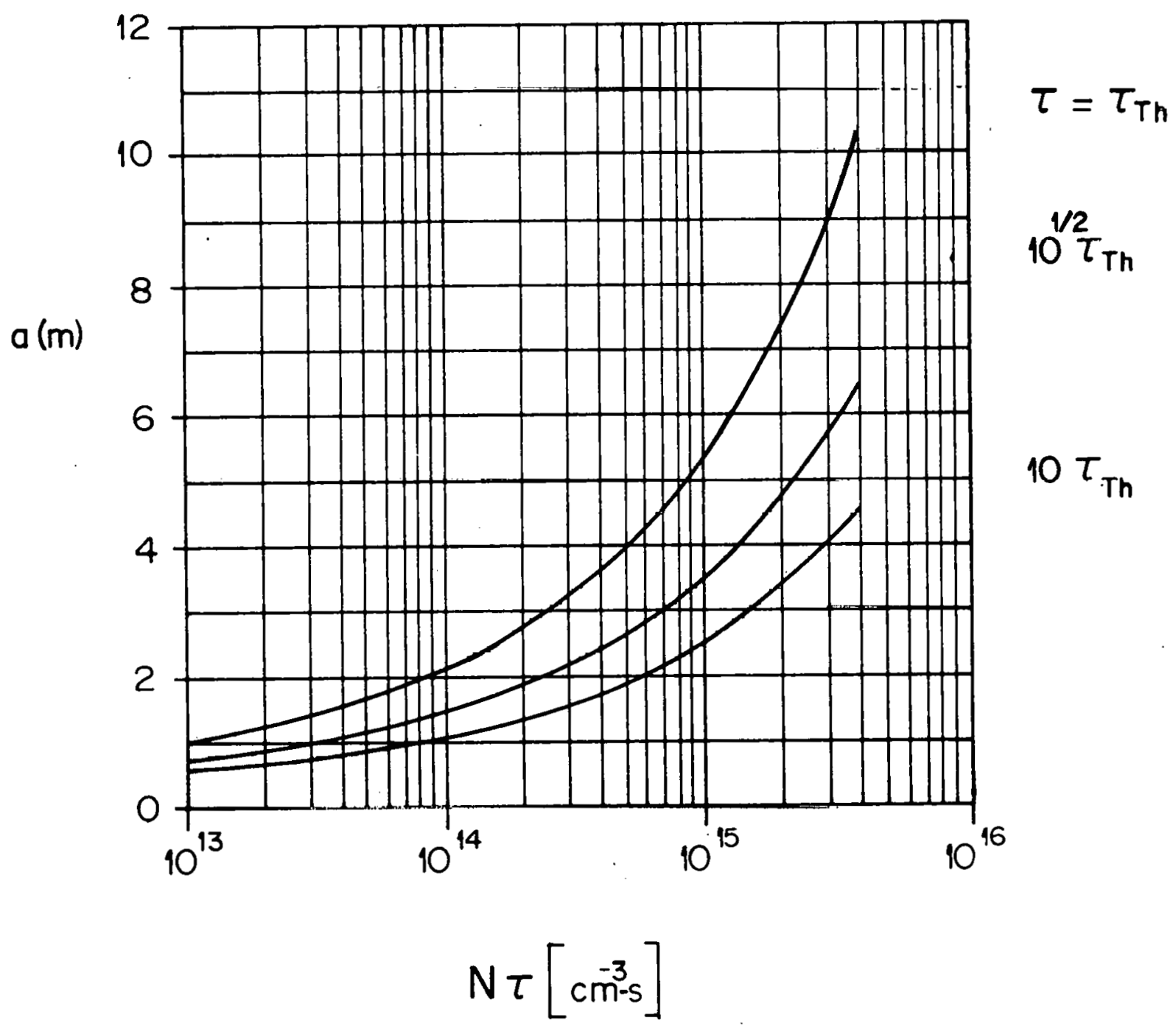

Fig. 6. P1 asma radius required to attain temperature of $8 \mathrm{keV}$ for different trapped particle loss coefficients. 


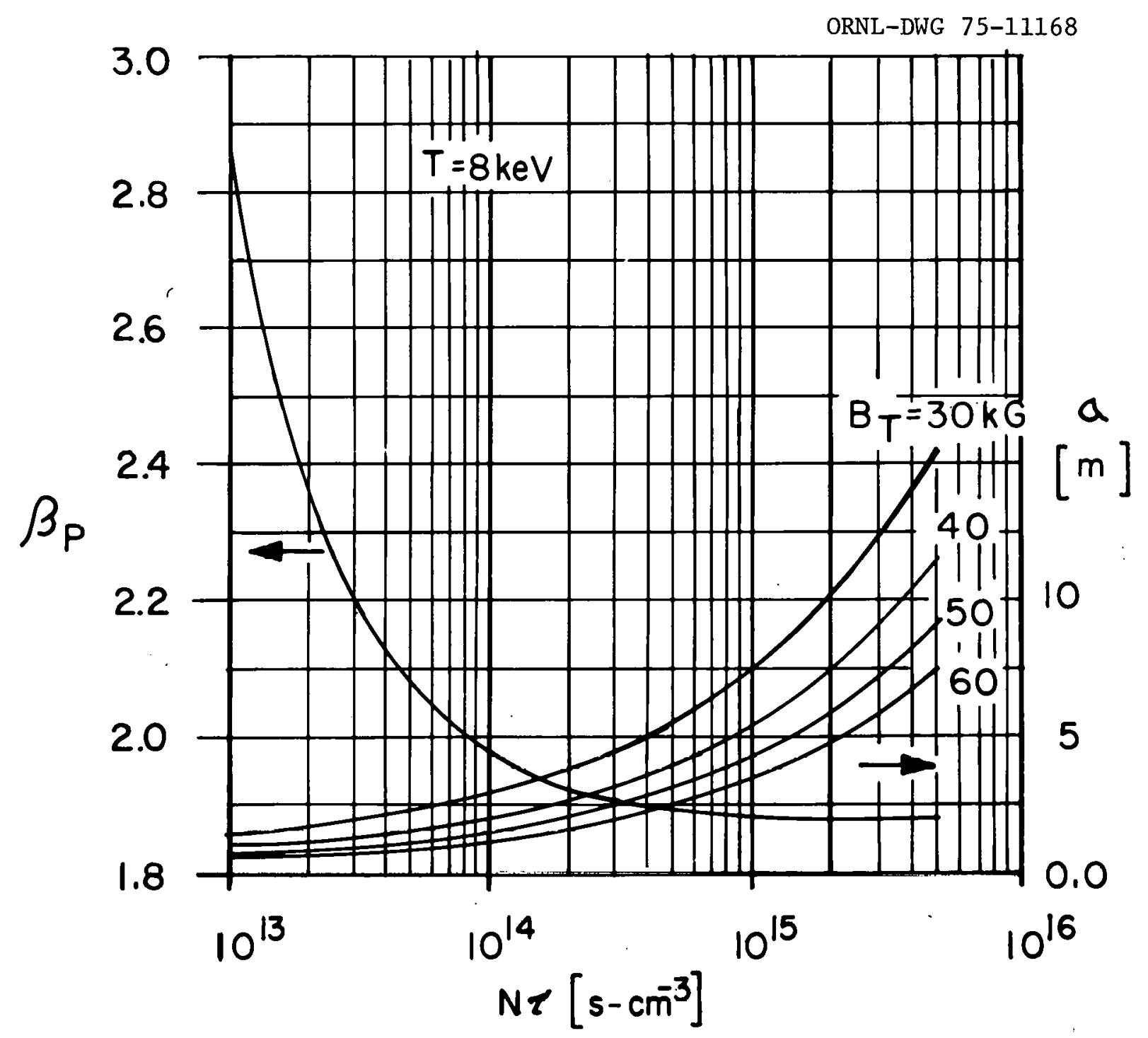

Fig. 7. Poloidal beta and plasma radius as a function of $N \tau$ for different toroidal magnet field strengths. 


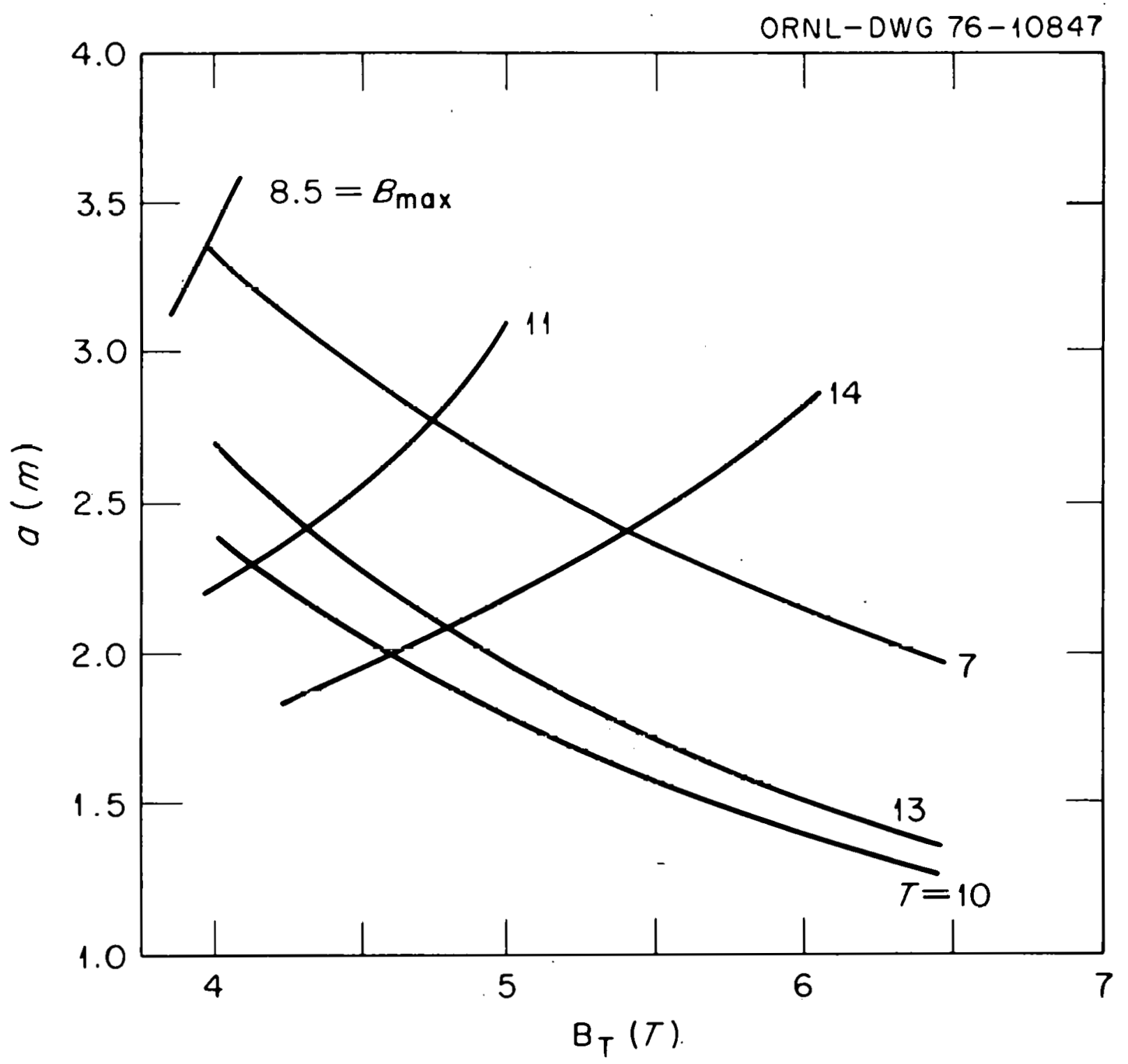

Fig. 8. Minimum minor radius required for ignition at given $B_{T}$ and $\mathrm{T}\left(\frac{1}{10} \times \mathrm{T} . \mathrm{P}\right.$. losses $)$. 
2 in the plasma size required to attain that $\mathrm{N} \tau$. Similarly, for $a=2 \mathrm{~m}$, the range shown for $\tau_{\mathrm{TP}}$ results in a range of achievable $N \tau$ which includes $8 \times 10^{13}-6 \times 10^{14} \mathrm{~cm}^{-3}-\mathrm{sec}$.

Figure 7 is similar to Fig. 6 except that the total poloidal beta is displayed, including the contribution from the fast-injected beam and alpha particles. This computation involves an integration over the energy range of the particles as they slow down. In the case shown, the sensitivity of size to changes in magnetic field strength on axis is displayed. Note that $B_{p}$ is not sensitive to $B_{T}$, but that the size required to attain a particular $\mathrm{N} \tau$ is strongly dependent on field strength when $\mathrm{N} \tau \gtrsim 10^{14} \mathrm{~cm}^{-3}$ $-\sec$.

Figure 8 is an example of a useful technique used to determine the size of a tokamak fusion reactor. The minor radius, $a(m)$, is plotted vs toroidal magnetic field on axis, $B_{t}$, for various values of $B_{\max }$, the peak toroidal field at the toroidal windings. Values of $A=3$ and $t_{b s}=2 \mathrm{~m}$ have been assumed for the aspect ratio and blanket thickness respectively. In addition, ignition curves are shown for various ignition and operating temperatures.

For each value of $T$ and $B_{t}$ the $N \tau$ value required for ignition is computed. The selected scaling law is then inverted to find the smallest minor radius which is consistent with operation at that NT. For clarity, only three different temperatures are displayed on F1g. 8, but any point on the plot above the 10-keV curve is a solution for two different temperatures. This is a result of the fact that $N \tau$ increases with temperature in the second trapped electron regime, but decreases with temperature once the trapped ion regime dominates transport behavior. Therefore, there are two temperatures at which plasma heating due to fusion alpha particle energy input exactly balances plasma energy losses. This is illustrated graphically in Fig. 9. A machine of radius $a_{1}$ will not ignite at any temperature. At point 1 , the $N \tau$ achieved in a device of radius $a_{2}$ is just sufficient for ignition. A machine of radius $a_{4}$ is ignited for temperatures between points 2 and 3 , and reaches a stable equilibrium at point 3 . Thus, the system with plasma radius $a_{3}$ will ignite at point 2 , undergo a thermal excursion to point 3 since $P_{\alpha}>P_{\text {logs }}$ following ignition, and operate. stably at point 3 . 


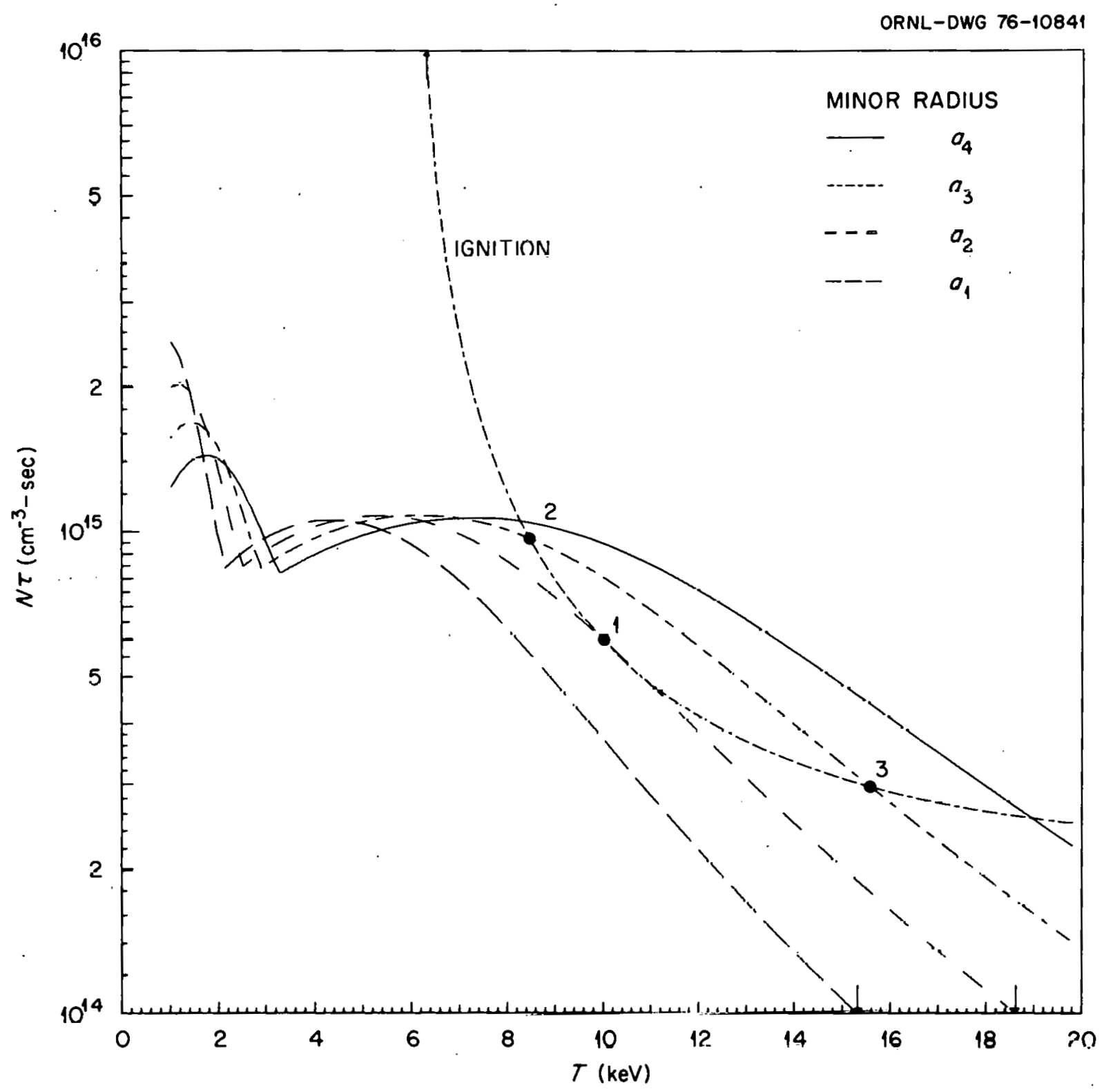

Fig. 9. The density-confinement time product as a function of temperature for several plasma radii, and the ignition condition. 
For example, from Fig. 8 with $\mathrm{B}_{\max }=11 \mathrm{~T}$, the minimum plasma radius for ignition is $2.3 \mathrm{~m}$. Ignition would occur at $\mathrm{T} \approx 10 \mathrm{keV}$, corresponding to operation at point 1 on Fig. 9. 


\section{REACTOR MODELING}

The functional dependences of the transport laws which will govern reactor plasma dynamics are not known at present. The detailed energy balance which will dictate the parameters attained in the plasma is better understood than before, but many uncertainties remain. These uncertainties will be clarified as the experimental and theoretical research programs progress. In parallel with these programs, it is necessary to assess the implications of various possible outcomes of this research. The models previously described are used to predict the size and operating characteristics of several reactor-scale devices in this section.

\subsection{EXPERIMENTAL POWER REACTOR (EPR)}

It is assumed here that the EPR is a low B ignition device that will produce net power during a single operating cycle. The ignition requirement immediately imposes constraints on the $N \tau$ which must be achieved by the system. Figure 10 shows the beam power per unit volume which is required in the model to maintain the energy balance as a function of $N \tau$. The temperature assumed is $8 \mathrm{keV}$; other values are $B_{T}=4 \mathrm{~T}, \beta_{\theta e}=1.0$, and $A=3$. When the beam power required is zero, ignition has been achieved and the thermonuclear alpha particles produced maintain the energy balance. The ignition point for various $z_{\text {eff }}$ values is more clearly shown on the ordinate labeled $\mathrm{P}_{F}^{\mathrm{M}} / \mathrm{P}_{F}$. The total fusion power produced is the sum of the power due to beam-plasma fusion events and of that due to background or Maxwellian events. When the Maxwellian fusion power, $\mathrm{P}_{\mathrm{F}}^{\mathrm{M}}$, is equal to the total fusion power, $\mathrm{P}_{\mathrm{F}}$, ignition has been achieved. Thus, in the present example, $\mathrm{N} \tau=5 \times 10^{14^{\mathrm{s}}} \mathrm{s} / \mathrm{cm}^{3}$ for ignition at $\mathrm{T}=8 \mathrm{keV}$ and $\mathrm{z}_{\text {eff }}=1$. For $\mathrm{z}_{\text {eff }}=2, \mathrm{N \tau}=10^{15} \mathrm{~s} / \mathrm{cm}^{3}$, and for $z_{\text {eff }}=3$, ignition cannot be achieved. For the EPR, a low-Z impurity (carbon) and $\mathrm{Z}_{\text {eff }}=2$ are assumed.

Figure 11 shows curves similar to those on Fig. 10 except various operating temperatures are assumed. Operation at increased temperature reduces the $\mathrm{N} \tau$ required for ignition but does not necessarily reduce the size of the device required to achieve $\mathrm{N} \tau$ itself. This again depends 


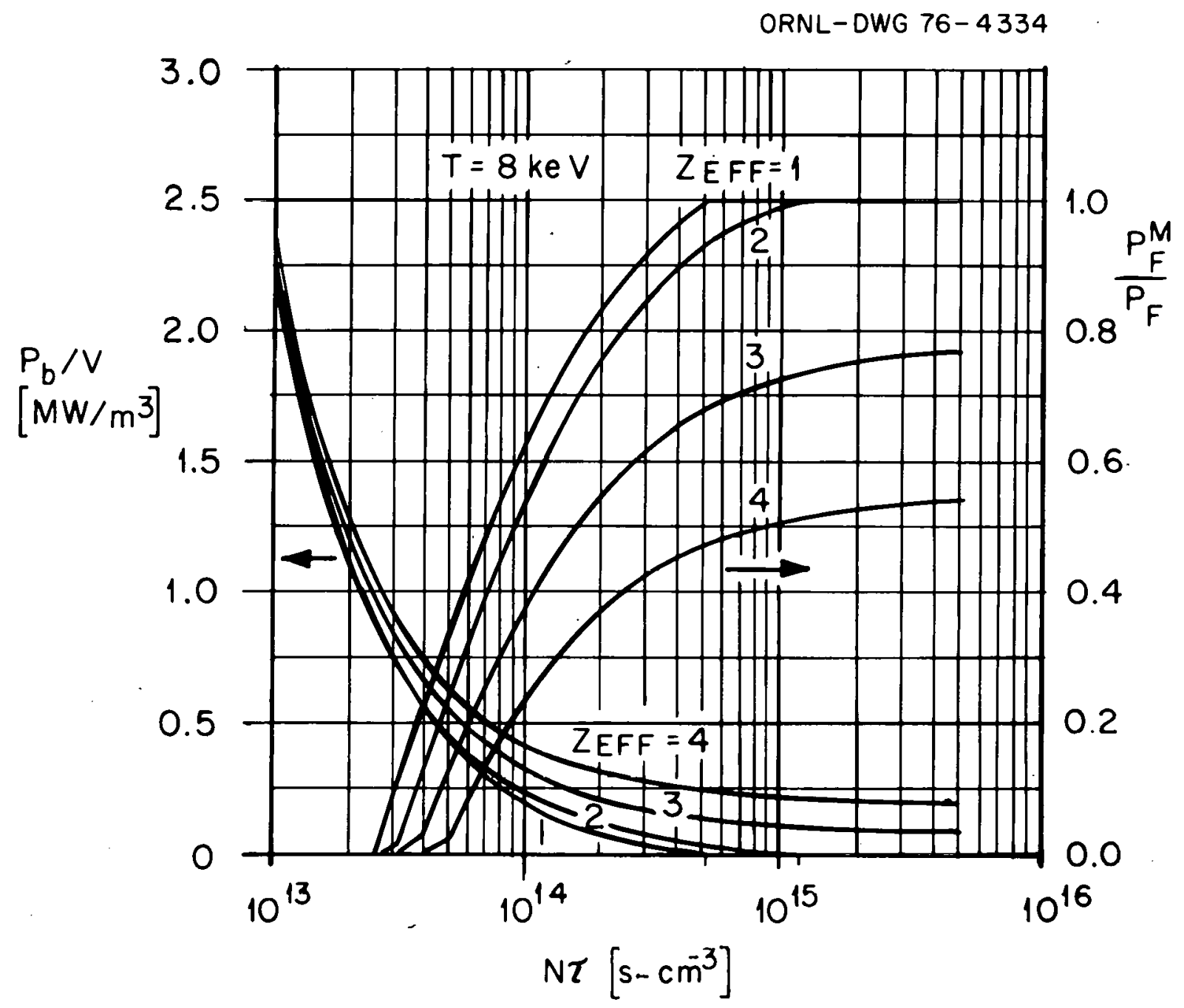

Fig. 10. Beam power per unit volume and the ratio of Maxwellian fusion power to total fusion power as a function of $N \tau$ for $Z_{\text {eff }}$ at $T=$ $8 \mathrm{keV}$. 


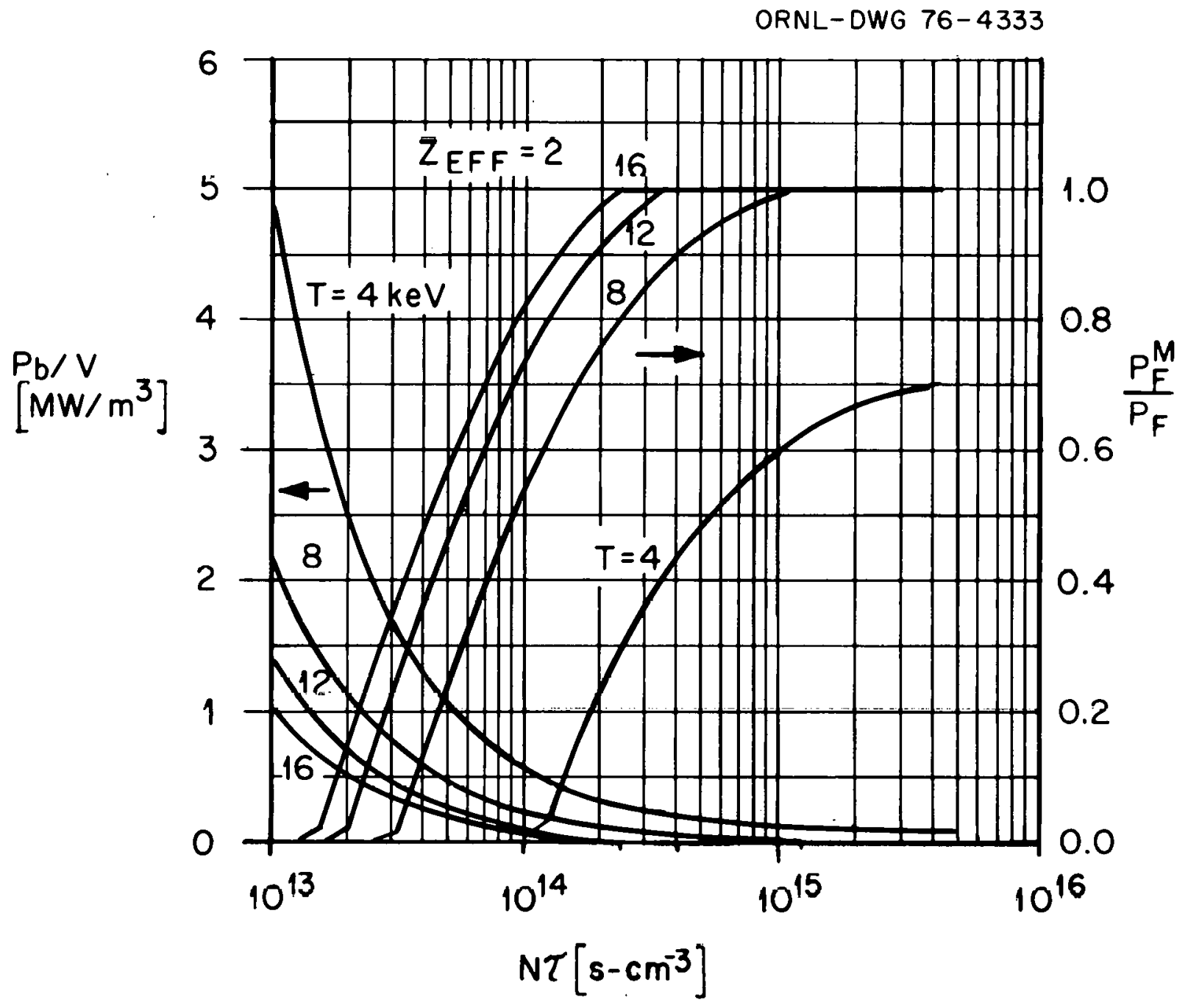

Fig. 11. Beam power per unit volume and the ratio of Maxwellian fusion power to total fusion power as a function of $N \tau$ for $Z_{\text {eff }}=2$ and several temperatures. 
directly on the scaling laws and their functional dependences. Here the model is that described in Section 2 with the trapped particle mode coefficients (convection and conduction) assumed to be one-tenth those estimated by linear instability analyses. ${ }^{12}$ Figure 6 shows the impact of varying the trapped particle mode coefficients and Fig. 7 shows the effect of varying the magnetic field on axis.

The basic EPR machine parameters are given in Table 8, determined by the scaling indicated above. It should be emphasized that this device assumes the scaling described in Section 2, stable plasma operation at $q=2.5$, low- $\beta$ equilibria, a maximum magnetic field strength at the toroidal field coil superconducting winding of $11 \mathrm{~T}$, and that radial profiles do not significantly alter the global power balance.

Table 8

EPR machine parameters

$\begin{array}{lc}\text { Major radius, } \mathrm{R}_{\mathrm{o}}(\mathrm{m}) & 6.75 \\ \text { Plasma radius, } \mathrm{a}(\mathrm{m}) & 2.25 \\ \text { Field strength on axis, } \mathrm{B}_{\mathrm{T}}(\mathrm{T}) & 4.8 \\ \text { Field strength at winding, } \mathrm{B}_{\text {max }}(\mathrm{T}) & 11.0 \\ \text { Wall area, } \mathrm{S}\left(\mathrm{m}^{2}\right) & 600 \\ \text { Plasma volume, } \mathrm{V}\left(\mathrm{m}^{3}\right) & 675 \\ \text { Safety factor, } \mathrm{q}(-) & 2.5 \\ \text { Plasma surrent, } \mathrm{T}(\mathrm{MA}) & 7.2 \\ \text { Beam power, } \mathrm{P}_{\mathrm{b}}(\mathrm{MW}) & 50 \\ \text { Beam energy, } \mathrm{E}_{\mathrm{b}}(\mathrm{keV}) & 200\end{array}$

The above considerations established a size for the EPR. In an assessment of EPR's performance, there are, again, many parameters involved, and the results are very sensitive to the assumptions. Based on the value in Table 8 on an initial temperature of $100 \mathrm{eV}\left(\mathrm{T}_{e}=\mathrm{T}_{i}\right)$, and on an initially clean plasma, the achievable steady-state operating points for the EPR were determined using the dynamic code described in Section 2. The key parameter difference in each case is initial density. Figure 12 shows 


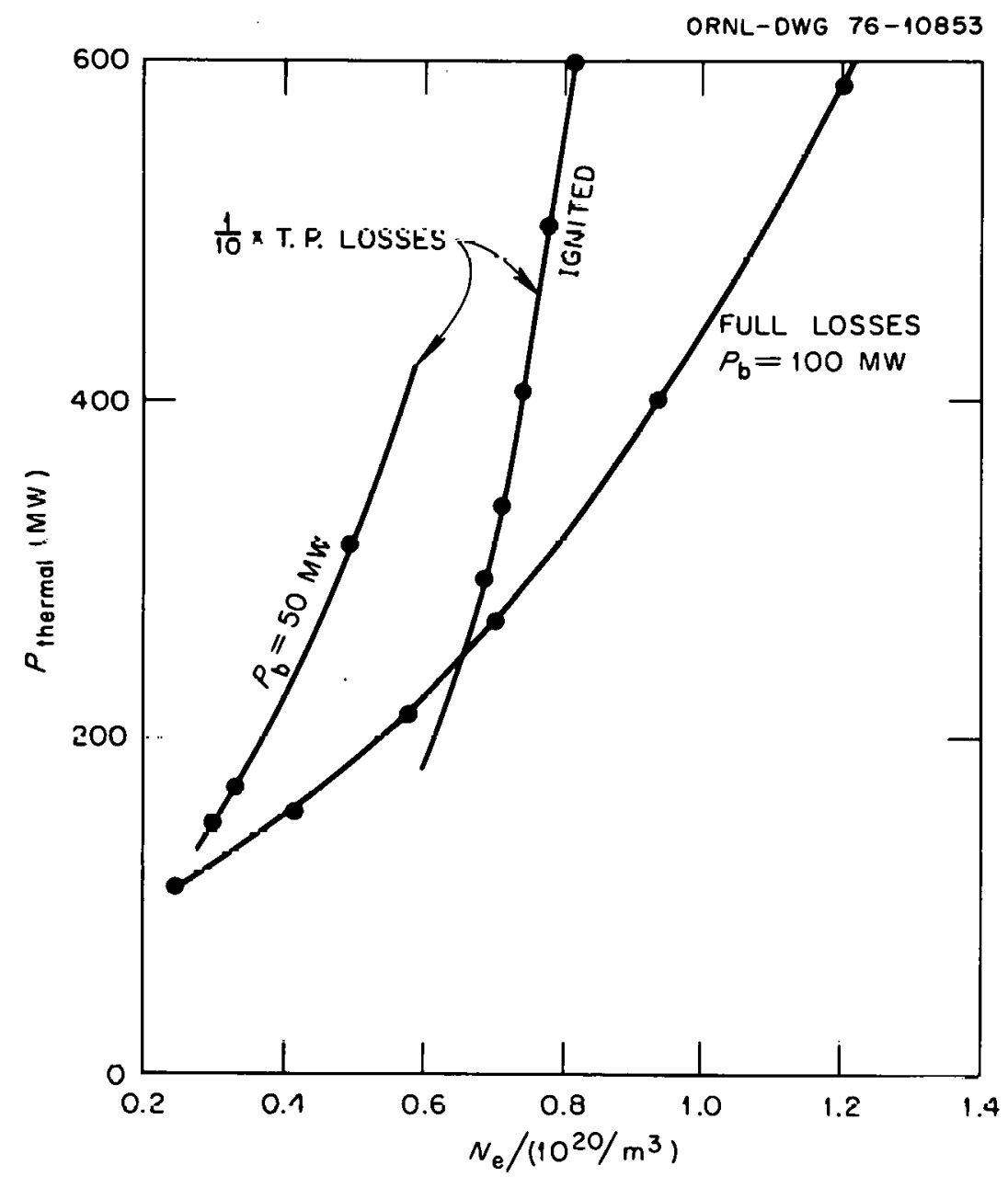

Fig. 12. EPR steady state operating points, $P_{\text {themmal }}$ vs $\mathrm{N}_{\mathrm{e}}$. 
the results for thermal power as a function of the operating density. For example, consider the curve labeled full losses, $P_{b}=100 \mathrm{MW}$. These cases correspond to driven operation where the beams (100 MW) plus the alpha power produced balance the plasma losses. Ignition is not achieved, since full trapped particle losses are assumed and the device was not designed for ignition under those circumstances.

Thus, power outputs between 100 and $420 \mathrm{MW}$ are possible when the operating density is varied between $2 \times 10^{19} \mathrm{~m}^{-3}$ and $1 \times 10^{20} \mathrm{~m}^{-3}$, respectively. The corresponding $\beta_{\theta e}$ and $T$ for the various operating points are shown in Figs. 13 and 14. Note from Fig. 14 that in the driven cases, $T \sim 9 \mathrm{keV}$ over a wide range of operating densities. This is due to the fact that the dissipative trapped ion mode losses are proportional to $\beta_{\theta e}^{2} / T^{11 / 2}$. The strong temperature dependence dominates the scaling so that the driven machine with $\mathrm{P}_{\mathrm{b}}=100 \mathrm{MW}$ can only achieve $\mathrm{T} \sim 9 \mathrm{keV}$. Since $\beta_{\theta e} \propto \mathrm{N}_{e} \mathrm{~T}_{e}$ and $\mathrm{T}_{e}$ is approximately constant, $\beta_{\theta e}$ varies linearly with density as shown in Fig. 13. The output power in the driven cases varies approximately as the square of the density as shown in Fig. 12 . I'his also follows from $P(t h) \propto \beta^{2} \propto N^{2}$. The driven cases are uninteresting if net power or commercial power is desired.

Figure 12 also shows operating points for cases in which the trapped particle mode losses are reduced by a factor of 10 relative to those typically assumed. In the lower density cases, the beams remain on and thermal powers between $100 \mathrm{MW}$ and $400 \mathrm{MW}$ are possible. As reasoned above, the operating temperature again is about constant ( $\mathrm{T} \sim 14.5 \mathrm{keV}$ ). See, for example, Fig. 14. The ignition curve is of interest here. At densities above about $6 \times 10^{13} \mathrm{~cm}^{-3}$, ignition is achieved by injecting $50 \mathrm{MW}$ of neutral deuterium atoms into the plasma for $\sim 5$ seconds. After ignition, the beam power is terminated and the plasma system attains the steady-state parameters shown on Figs. 12-14, again depending on the density of operation. Thermal power outputs between $\sim 200 \mathrm{MW}$ and $\sim 800$ $\mathrm{MW}$, temperatures between $\sim 10 \mathrm{keV}$ and $\sim 18 \mathrm{keV}$, and $\beta_{\mathrm{p}}$ between $\sim 1$ and $\sim 3$ are typical parameter ranges for ignited systems.

The parameters for the nominal operating point for the EPR are shown in Table 9. In this case it has been assumed that initially the 


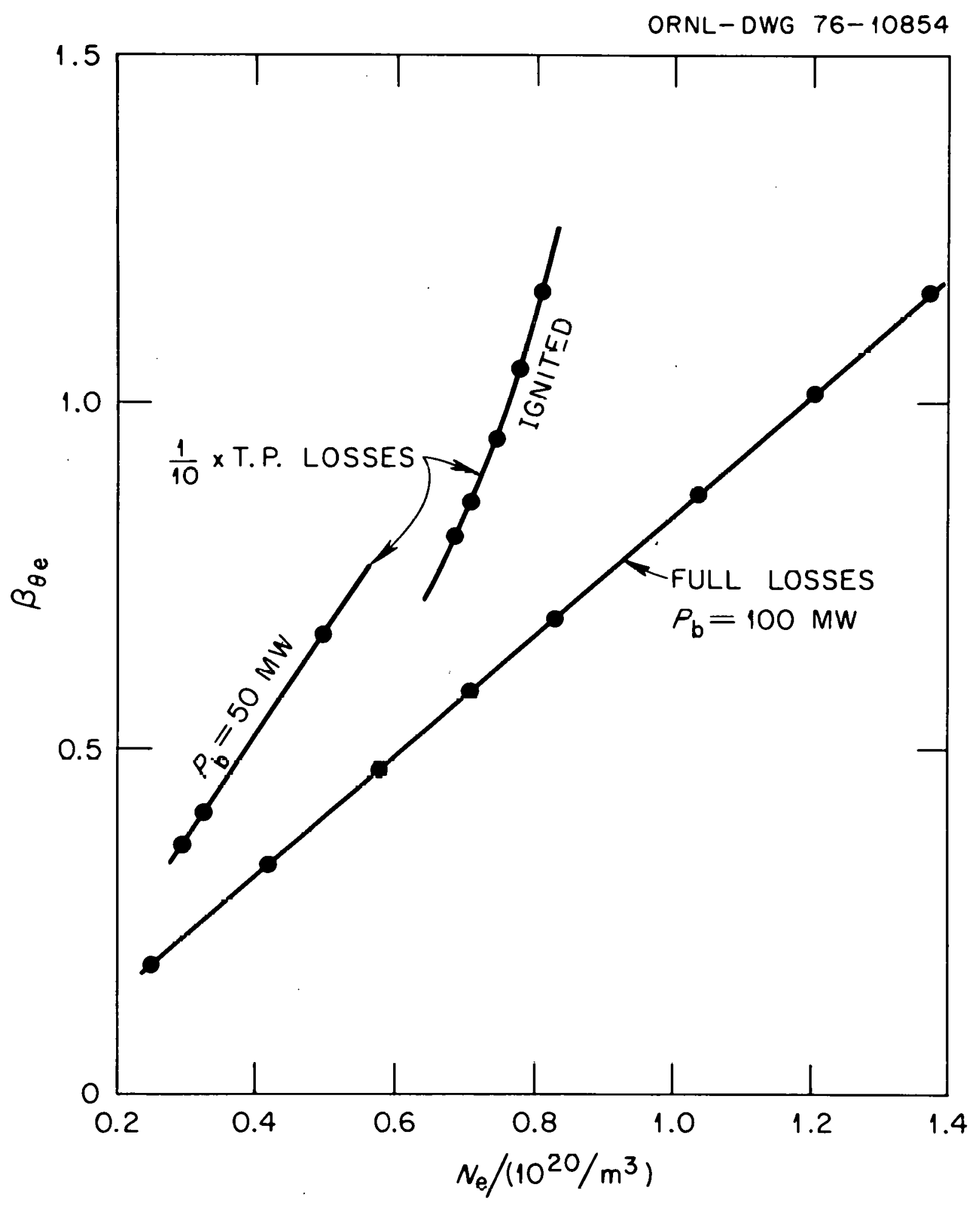

Fig. 13. EPR steady state operating points, $\beta_{\theta e}$ vs $\mathrm{N}_{e}$. 


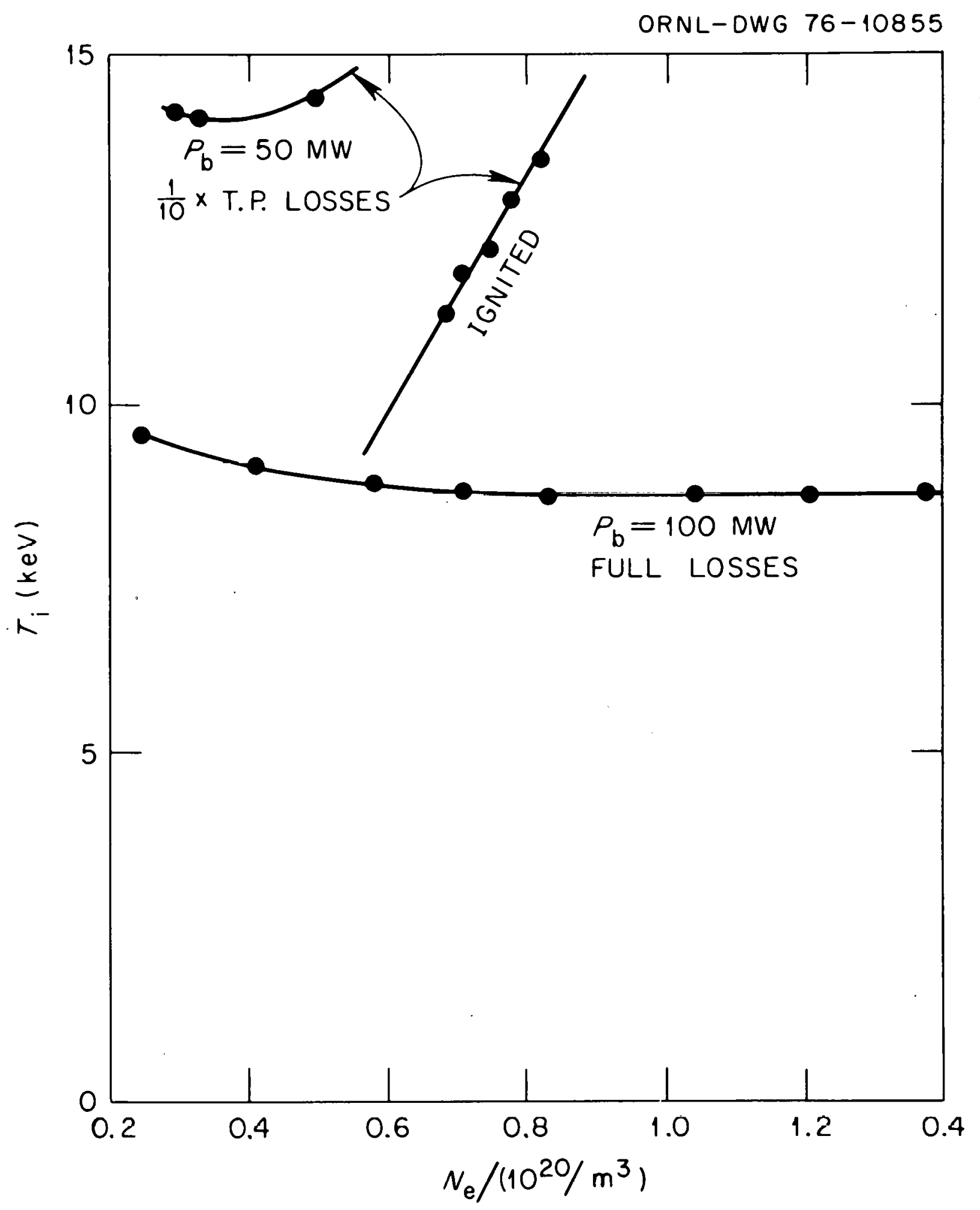

Fig. 14. EPR steady state operating points, $T_{i}$ vs $N_{e}$. 
plasma is free of impurities. Sputtering occurs according to the model described in Section 2. It is also assumed that the neutral density at the plasma boundary is $10^{15} / \mathrm{m}^{3}$ and that the density decreases exponentially with a characteristic length of $5 \mathrm{~cm}$. This permits charge exchange sputtering to be included in the modeling. An impurity control scheme is assumed to be $99 \%$ effective with respect to charged particles and $90 \%$ effective with respect to neutral charge exchange sputtering, i.e., the return impurity flux is assumed to be attenuated by $90 \%$. These models and assumptions result in an increase in $Z_{\text {eff }}$ to 1.34 after 50 sec of plasma burning. This $z_{\text {eff }}$ is tolerable and suggests the degree of impurity control required in the case of a stainless steel wall if the impurities entering the plasma mix throughout the reacting volume on a time scale short compared to a burn time. The effect of low $Z$ walls and a more general description of burn cycle limitations due to sputtering are given below.

\section{Table 9}

\section{Sceady stace plasma parameters}

and power balance

$\begin{array}{lc}\text { Electron density, } \mathrm{N}_{\mathrm{e}}\left(\mathrm{m}^{-3}\right) \times 10^{-19} & 7.4 \\ \text { Electron temperature, } \mathrm{T}_{\mathrm{e}}(\mathrm{keV}) & 13 \\ \text { Ion temperature, } \mathrm{T}_{i}(\mathrm{keV}) & 12.2 \\ \text { Energy confinement time, } \tau_{\mathrm{E}}(\mathrm{s}) & 3.7 \\ \text { Particle confinement time, } \tau_{\mathrm{p}}(\mathrm{s}) & 9.6 \\ \text { Poloidal beta, } \beta_{\mathrm{p}}(-) & 1.9 \\ \text { Thcrmal power, } \mathrm{P}_{\text {th }}(\mathrm{MW}) & 410 \\ \text { Neutron wall Loading, } \mathrm{F}_{\mathrm{M}} / \mathrm{H}\left(\mathrm{MW} / \mathrm{m}^{2}\right) & 0.55 \\ \text { Impurity level, } \mathrm{Z}_{\mathrm{eff}}(-) & 1.34(\mathrm{t}=50 \mathrm{~s}) \\ \text { Neutral density }(\mathrm{r}=\mathrm{a}), \mathrm{N}_{\mathrm{o}}\left(\mathrm{m}^{-3}\right) & 10^{15} \\ \text { Characteristic length, } \lambda(\mathrm{cm}) & 5 \\ \text { Alpha power, } \mathrm{P}_{\alpha}(\mathrm{MW}) & +82 \\ \text { Transport power, } \mathrm{P}_{\mathrm{tr}}(\mathrm{MW}) & -66 \\ \text { Bremsstrahlung power, } \mathrm{P}_{\mathrm{br}}(\mathrm{MW}) & -9\end{array}$




$$
\begin{aligned}
& \text { Table } 9 \text { (cont'd) } \\
& \text { Line radiation power, } \mathrm{P}_{\ell}(\mathrm{MW}) \\
& \text { Synchrotron power, } \mathrm{P}_{\text {synch }}(\mathrm{MW}) \\
& \sum \mathrm{P}_{\mathrm{k}}=0 \text { (ignition) } \\
& \mathrm{k} \quad-1
\end{aligned}
$$

One final tabulation is of interest in comparing circular to noncircular plasma operation. Steady state ignited operating points are shown in Table 10. In the first column, the reference parameters are defined for the comparison; they are similar to those in Table 9 except that the density is $9 \times 10^{13} \mathrm{~cm}^{-3}$ in this table compared to $7.4 \times 10^{13} \mathrm{~cm}^{-3}$ in the previous case. Operation parameters when $q=3.3$ (and, therefore, $I_{p}=5.4$ ) are shown in the second column. Columns 3, 4, and 5 are equivalent cases (as explained below) except that the EPR plasma is assumed to be elongated by a factor of 1.6. This results in a higher total current, a higher average poloidal field and a larger plasma volume when two cases with the same $\mathrm{q}$ are compared. The wall loading and total power output are correspondingly higher also. By operating the elongated plasma at higher $q$ values, i.e., $q=3.3$ and 4.4 , the same poloidal beta can be obtained as in the lower $q$ cases $(q=2.5$ and 3.3). The noncircular devices still achieve a greater power output and wall loading. The incentive for noncircular plasma shapes is clear although the physics in this area also is uncertain. Recent MHD equilibrium and stability studies at $\mathrm{ORNL}^{26}$ suggest that $E=1.6$ is a reasonable elongation ratio within the limitations imposed by local stability and acceptable pressure and current profiles. Work is in progress to determine the effect of flux conservation on this result.

Table 10

\section{Circular and noncircular EPR operating parameter comparison}

(In all cases: $\mathrm{R}_{\mathrm{o}}=6.75 \mathrm{~m}, \mathrm{a}=2.25 \mathrm{~m}, \mathrm{~B}_{\mathrm{T}}=4.8 \mathrm{~T}, \mathrm{P}_{\mathrm{b}}=50 \mathrm{MW}$ until

$$
\text { injection, } \tau=\tau \text { T.P. } \times 10 \text { ) }
$$


Table 10 (cont'd)

Elongation ratio, $E=b / a(-)$

\begin{tabular}{ccccc}
1 & 2 & 3 & 4 & 5 \\
\hline 1 & 1 & 1.6 & 1.6 & 1.6
\end{tabular}

Safety factor, q (-)

$\begin{array}{lllll}2.5 & 3.3 & 2.5 & 3.3 & 4.4\end{array}$

Average poloidal field, ${ }_{p}(T)$

0.64

0.48

0.85

0.64

0.48

Plasma current, $I_{p}$ (MA)

7.2

5.4

12.8

9.6

7.2

Electron density, $\mathrm{N}_{\mathrm{e}} \times 10^{-20}\left(\mathrm{~m}^{-3}\right)$

0.9

0.52

0.9

0.8

0.5

Energy confinement time, $\tau_{E}$ (s)

3.32 .5

2.8

3.7

2.7

Electron temperature, $\mathrm{T}_{\mathbf{e}}(\mathrm{keV})$

$15.2 \quad 14.8$

19.5

17.1

17.1

Ion lemperalure, $T_{i}$ (kev)

$14.7 \quad 17.0$

19.5

16.7

19.6

Impurity level, $Z_{\text {eff }}(-)$

1.9

2.5

1.9

2.0

2.6

Average poloidal beta, $\beta_{p}(-)$

2.7

2.7

1.9

2.6

2.9

Average total beta, $\beta_{T}(-)$

0.05

0.03

0.06

0.05

0.03

Thermal power, $P_{\text {th }}$ (MW)

604

207

1450

850

305

Average neutron wall loading, $\mathrm{P}_{\mathrm{M}} / \mathrm{S}\left(\mathrm{MW} / \mathrm{m}^{2}\right)$

0.81

0.28

1.21

0.71

0.25

\subsection{DEMONSTRATION AND COMMERCIAL REACTORS}

Information similar to that described above was developed for the parameter ranges applicable to low beta demonstration reactors (Demo) and commercial power reactors (CPR). Circular plasmas only are discussed here. Economic considerations are also reflected in the commercial case. Figure 15 shows neutron wall loading as a function of plasma radius for three values of $B_{\theta e}$. The conditions are $A=3, q=2.5$, blanket/ shield thickness $\Delta=2 \mathrm{~m}$, and $\mathrm{z}_{\text {eff }}=2$, with an operating temperature of $13 \mathrm{keV}$ (to maximize $\langle\sigma v\rangle / \mathrm{T}^{3}$ ). The wall loading $\overline{\mathrm{L}}_{\mathrm{n}}$ exceeds $1 \mathrm{MW} / \mathrm{m}^{2}$ for $a \leq 5 \mathrm{~m}$ only when $B_{\theta}>2.4$. In all cases shown on Fig. 15, $B_{\max }=8.5 \mathrm{~T}$ at the superconducting winding. Figures 16 and 17 show simllar results for $B_{\max }=11 \mathrm{~T}$ and $14 \mathrm{~T}$, respectively. Finally, a criterion is established for the volt-second capability of the device. That is, the number of voltseconds needed to establish the plasma current I depends on the internal inductance $L$, the maximum magnetic field which can be produced in the air core $\mathrm{B}_{\mathrm{A}}$, and the plasma size. It is assumed that $\Delta \phi_{\max }=2 \times \mathrm{B}_{\mathrm{A}} \times \mathrm{A}_{\text {core }}=$ 2.5 LI is required to account for losses during start-up and the burn 


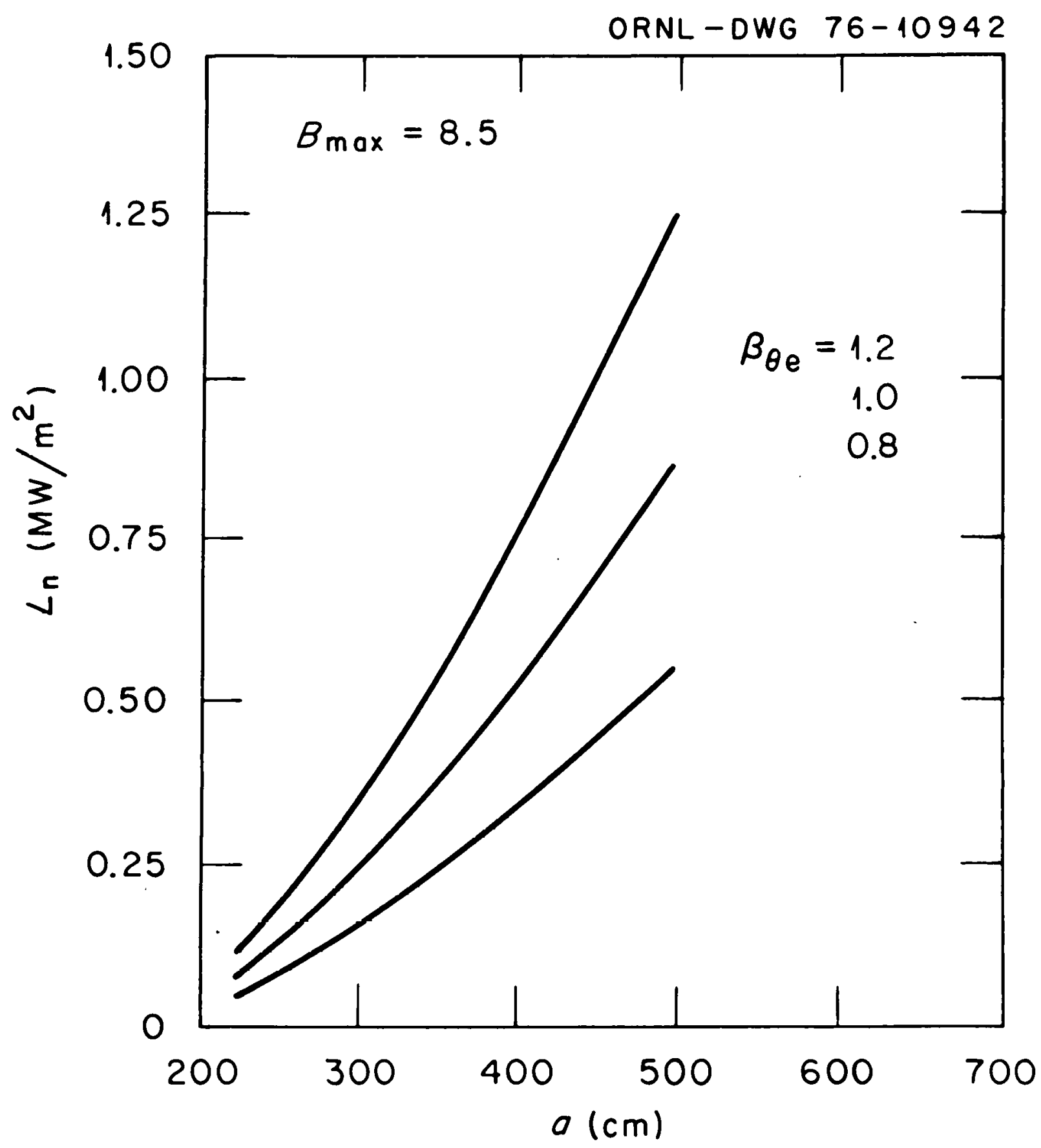

Fig. 15. Neutron wall loading as a function of plasma minor radius at $B_{\max }=8.5 \mathrm{~T}$ for various $\beta_{\theta e}$. 


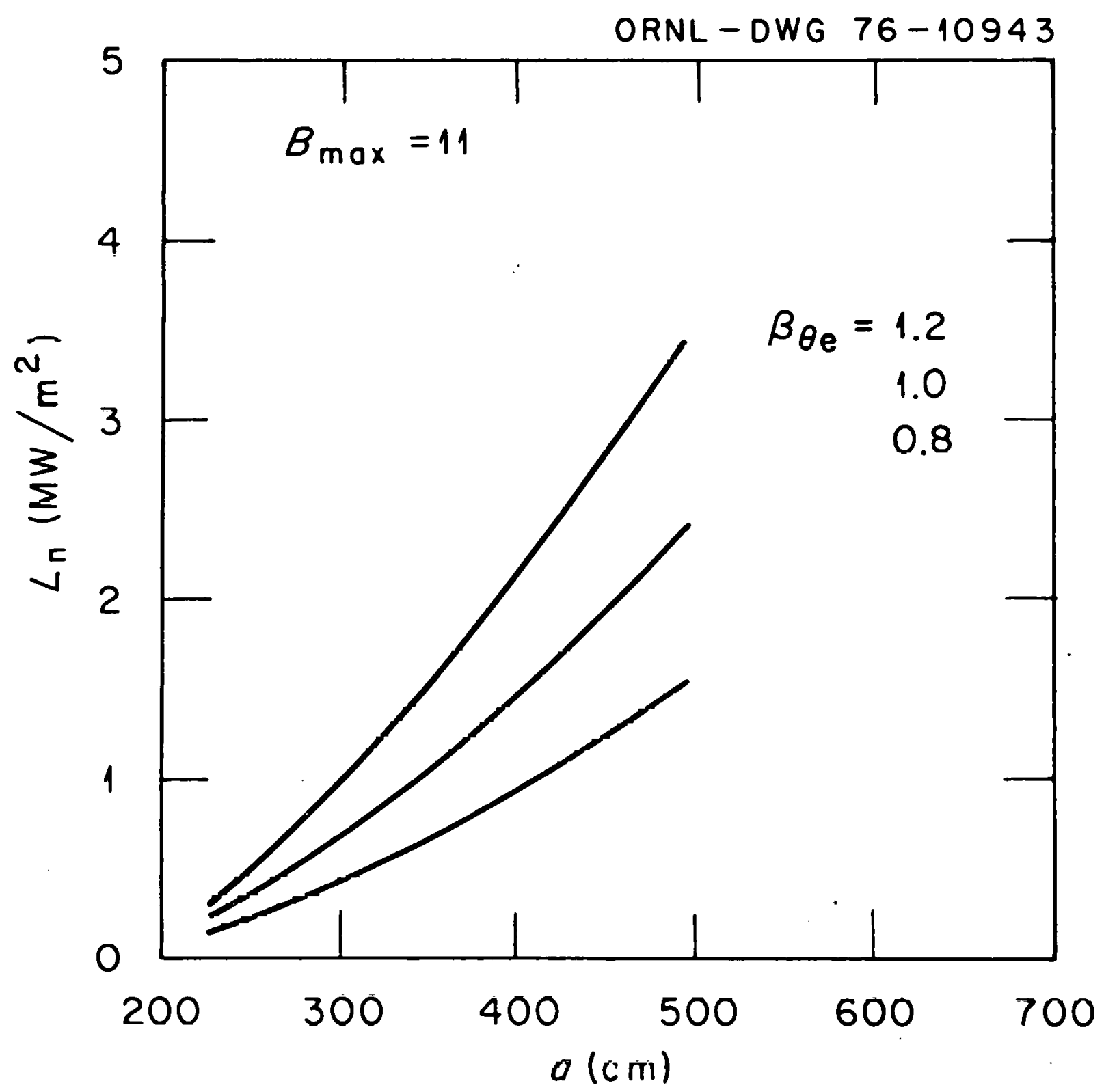

Fig. 16. Neutron wall loading as a function of plasma minor radius at $\mathrm{B}_{\max }=11 \mathrm{~T}$ for various $\beta_{\theta \mathrm{e}}$. 


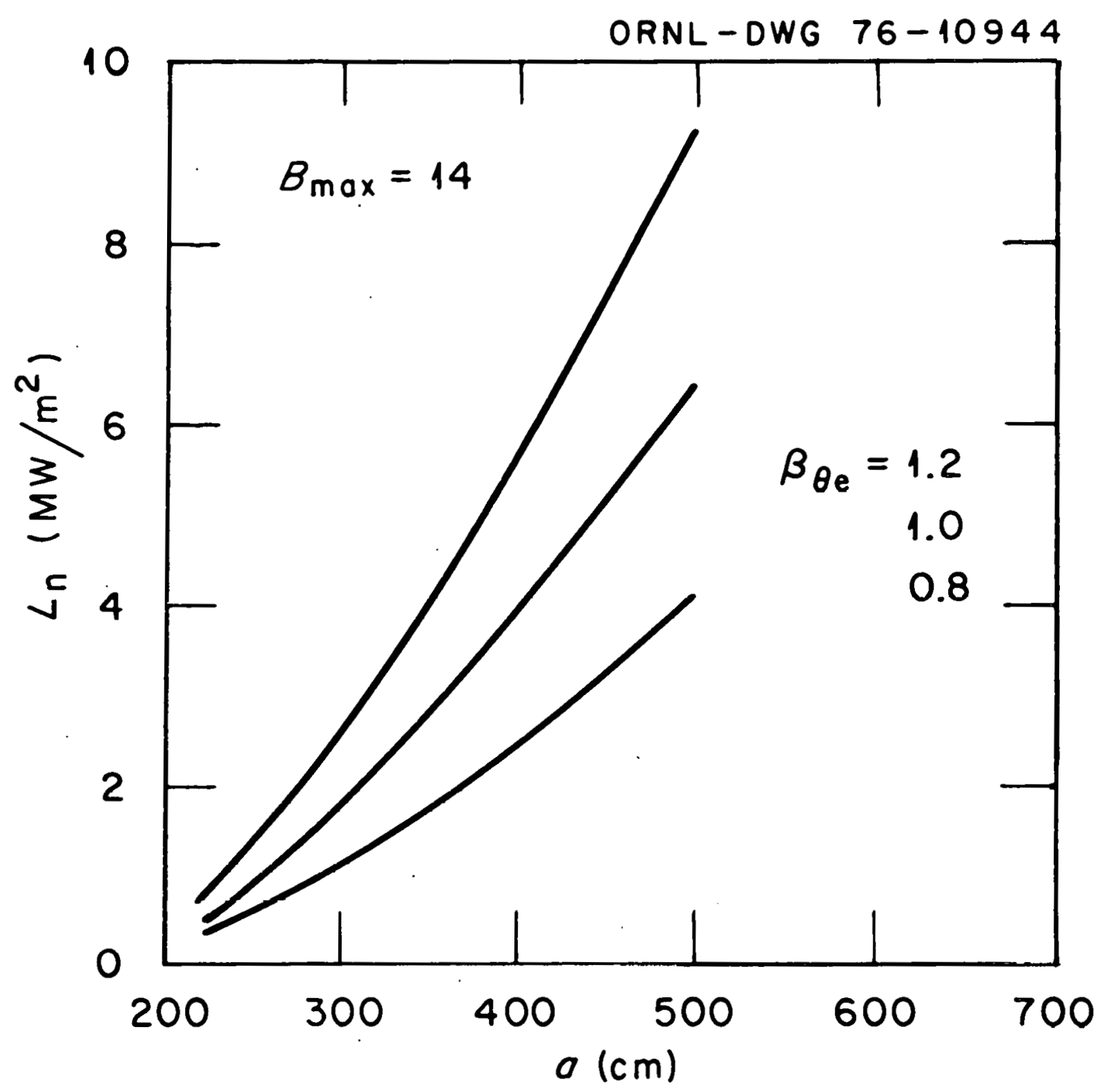

Fig. 17. Neutron wall loading as a function of plasma minor radius at $B_{\max }=14 \mathrm{~T}$ for various $\beta_{\theta e^{\circ}}$ 
cycle. Figure 18 shows that for $\mathrm{B}_{\mathrm{A}}=6 \mathrm{~T}, \mathrm{a}>4.5 \mathrm{~m}$ is required. Similarly, Fig. 19 shows that when $\mathrm{B}_{\max }=11 \mathrm{~T}, \mathrm{a} \sim 3 \mathrm{~m}$ is acceptable. If $L I / \Delta \phi_{\max }$ is larger, the size is reduced.

Table 11 shows the machine and plasma parameters considered reasonable for a low beta Demo and:CPR. The precise thermal output in each case is a sensitive function of the operating density. Figure 20 shows $P_{\text {th }}$ vs $\mathrm{N}_{\mathrm{e}}$ for the Demo, assuming $1 / 10,1 / 2,2 \mathrm{x}$, and full-trapped particle losses. Note that a Demo size device subject to ful1-trapped particle losses can sti.1.1. achieve ignition. Finally, Fig. 21 shows similar information for two CPR'E; in one case $R_{0}=13.5 \mathrm{~m}$ and $a=4.5 \mathrm{~m}$ and in the other case $\mathrm{R}_{0}=12 \mathrm{~m}$ and $\mathrm{a}=4 \mathrm{~m}$. In the CPR full losses are assumed.

Table 11

Demo and CPR steady state parameters

\section{Machine parameters}

$\underline{\text { Demo }} \quad \underline{C P R}$

$\begin{array}{lrr}\text { Major radius, } \mathrm{R}_{\mathrm{o}}(\mathrm{m}) & 10.5 & 13.5 \\ \text { Plasma radius, } \mathrm{a}(\mathrm{m}) & 3.5 & 4.5 \\ \text { Field strength, } \mathrm{B}_{\mathrm{T}}(\mathrm{T}) \text { on axis } & 5.2 & 5.7 \\ \text { Field strength, B }{ }_{\max }(\mathrm{T}) \text { at winding } & 11.0 & 11.0 \\ \text { Wall area, S }\left(\mathrm{m}^{2}\right) & 1451 & 2400 \\ \text { Plasma volume, } \mathrm{V}\left(\mathrm{m}^{3}\right) & 2540 & 5400\end{array}$

Pl.Asme parametcro

$\begin{array}{lcc}\text { Safety factor, } q(-) & 2.5 & 2.5 \\ \text { Plasma current, } \mathrm{T}(\mathrm{MA}) & 12.2 & 17.1 \\ \text { Beam power, } \mathrm{P}_{\mathrm{b}}(\mathrm{MW}) & 100 & 150 \\ \text { Electron density, } \mathrm{N}_{\mathrm{e}}\left(\mathrm{m}^{-3}\right) \times 10^{-19} & 7.3 & 7.5 \\ \text { Electron temperature, } \mathrm{T}_{\mathrm{e}}(\mathrm{keV}) & 14.6 & 18.2 \\ \text { Ion remperature, } \mathrm{T}_{\mathrm{i}}(\mathrm{keV}) & 13.7 & 18.3 \\ \text { Energy confinement time, } \tau_{\mathrm{E}}(\mathrm{s}) & 3.3 & 3.71 \\ \text { Particle confinement time, } \tau_{\mathrm{p}}(\mathrm{s}) & 7.7 & 9.28 \\ \text { Poloidal beta, } \beta_{\mathrm{p}}(-)(\sim \sqrt{\mathrm{A}}) & 1.8 & 1.9\end{array}$




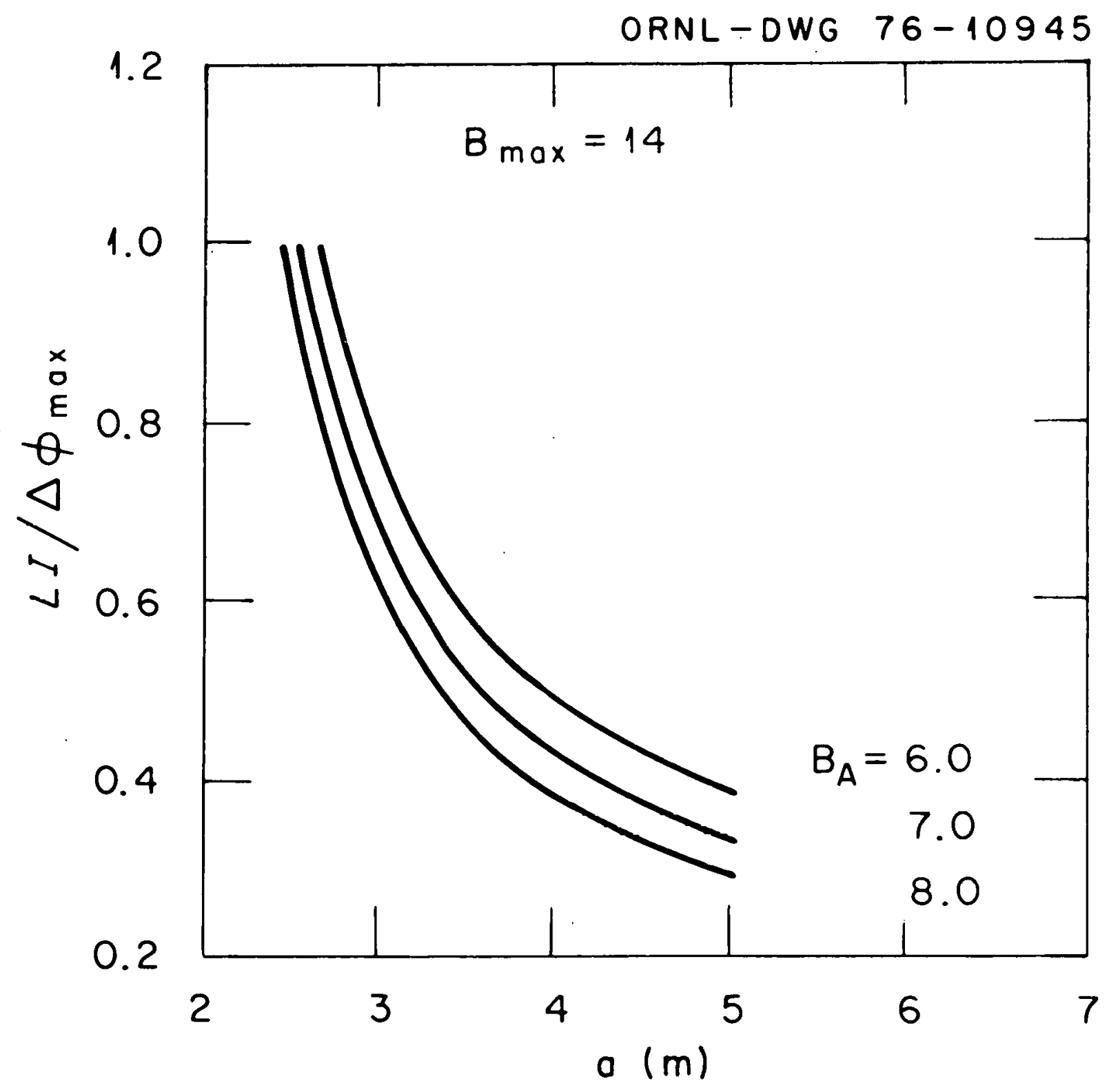

Fig. 18. Ratio of stored magnetic flux LI in the plasma to the flux swing available from the air core, $\Delta \phi_{\max }$, as a function of plasma minor radius at $\mathrm{B}_{\max }=14 \mathrm{~T}$, for various maximum air core fields. 


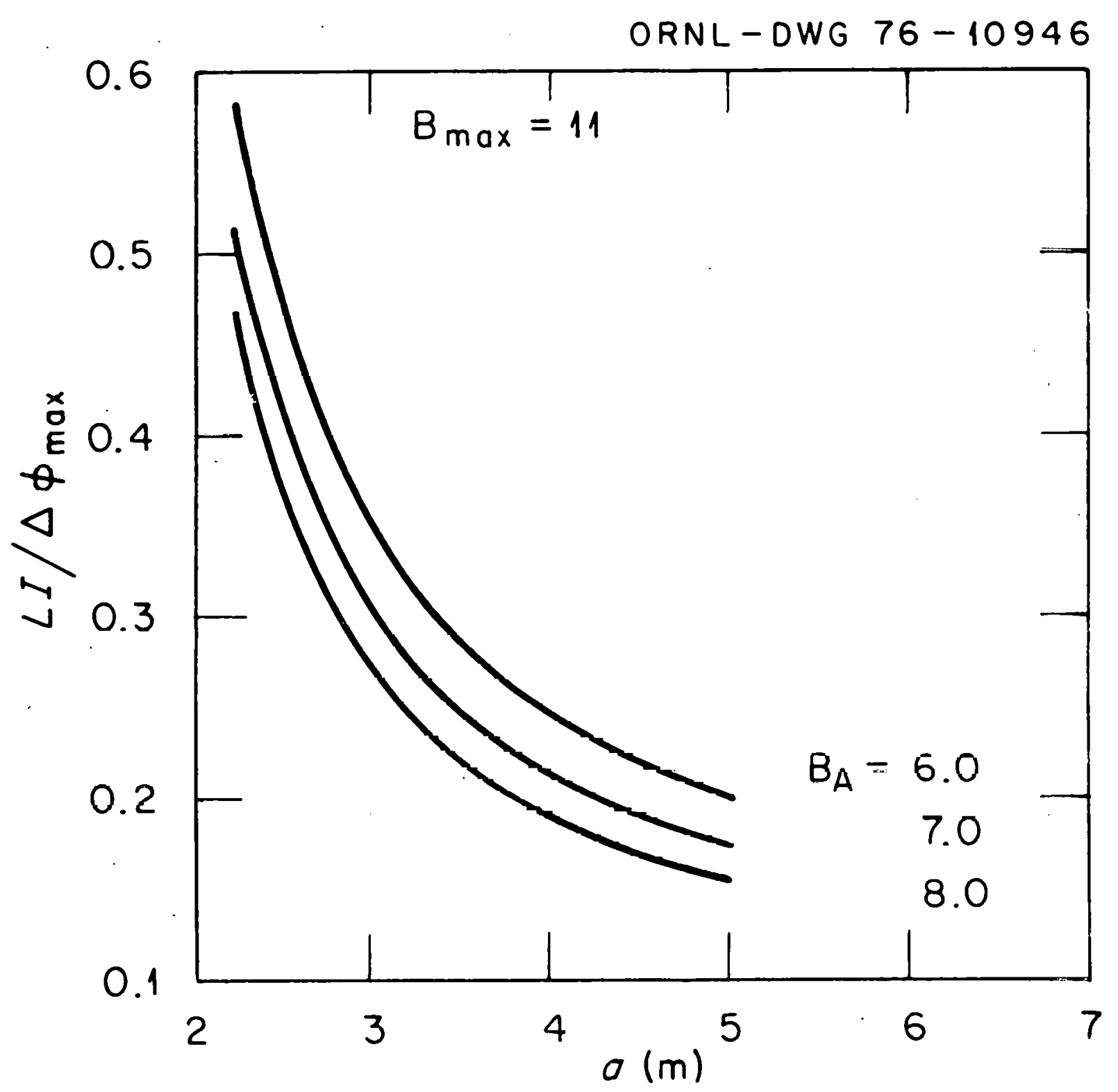

Fig. 19. Ratio of stored magnetic flux LI in the plasma to the flux swing available from the air core, $\Delta \phi_{\max }$, as a function of plasma minor radius at $\mathrm{b}_{\max }=11 \mathrm{~T}$, for various maximum air core fields. 


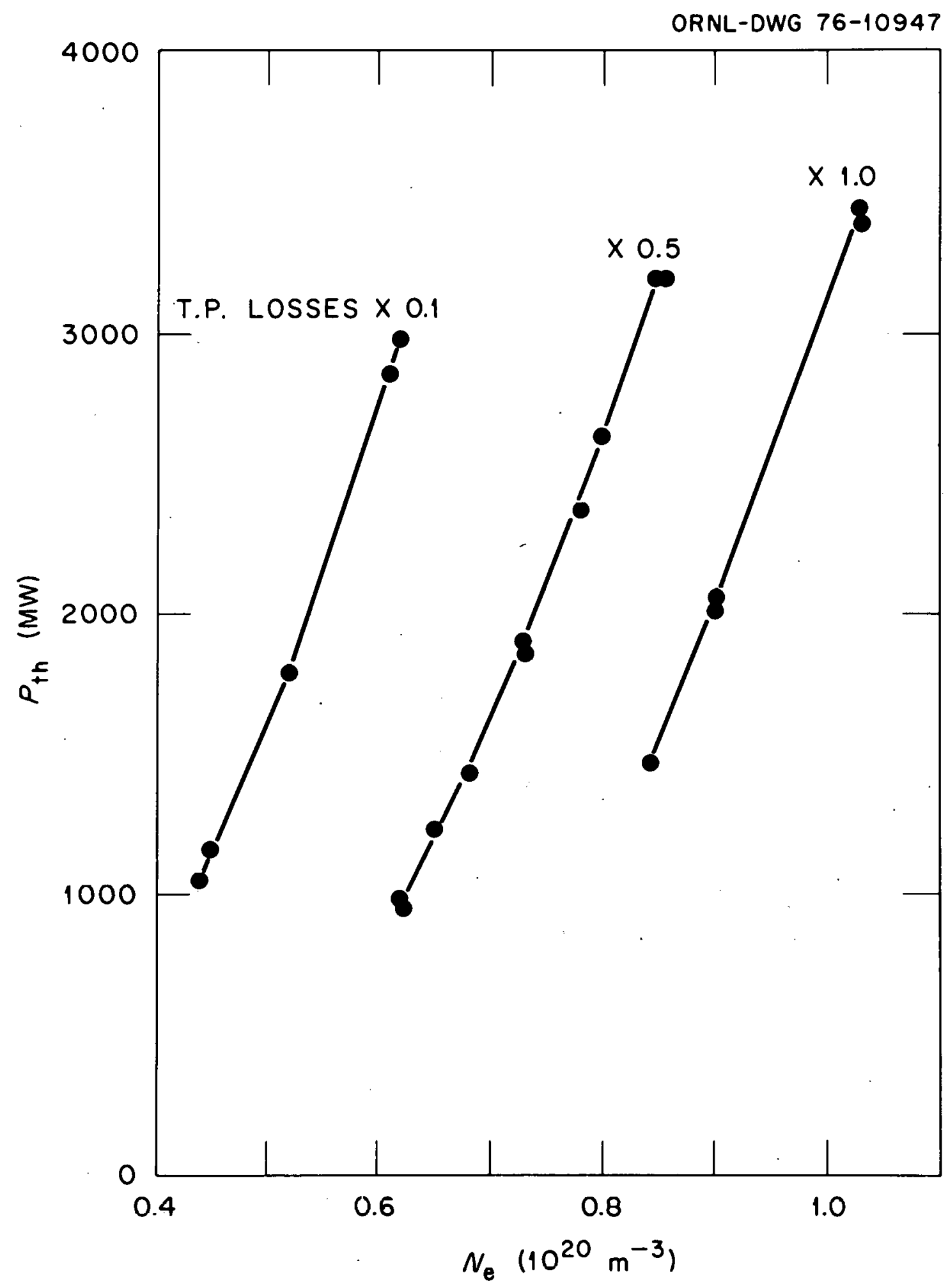

Fig. 20. Steady state operating parameters for Demo, $\mathrm{P}_{\text {th }}$ vs $\mathrm{N}_{e}$. 


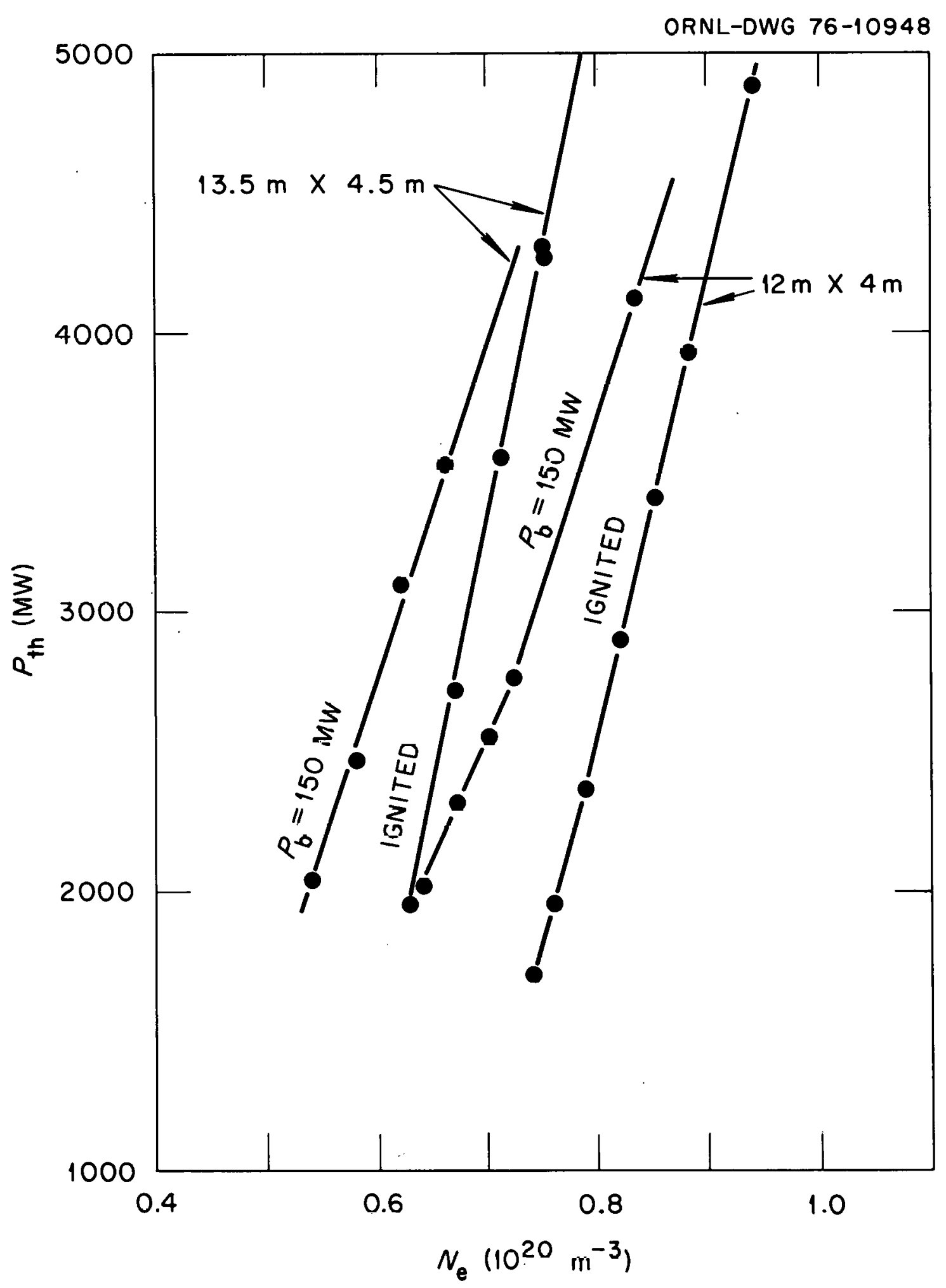

Fig. 21. Steady state operating parameters for CPRs, $\mathrm{P}_{\text {th }}$ vs $\mathrm{N}_{\mathrm{e}}$. 
Table 11 (cont'd)

Thermal power, $\mathrm{P}_{\text {th }}$ (MW)

Impurity level, $z_{\text {eff }}(-)$

Neutral density $(\mathrm{r}=\mathrm{a}), \mathrm{N}_{\mathrm{o}}\left(\mathrm{m}^{-3}\right)$

Attenuation length, $\lambda(\mathrm{cm})$
Neutron wall loading, $\mathrm{P}_{\mathrm{n}} / \mathrm{S}\left(\mathrm{MW} / \mathrm{m}^{2}\right)$

1910
1.05
$(t=3.00 \mathrm{~s})$
1.16
$10^{15}$
5

4280

1.4 $(t=300 s)$

2.1

$10^{15}$

5

Power balance

Alpha power, $\mathrm{P}_{\alpha}(\mathrm{MW})$

$+382$

$+856$

Transport power, $\mathrm{P}_{t r}$ (MW)

$-333$

$-716$

Bremsstrahlung power, $\mathrm{P}_{\mathrm{br}}(\mathrm{MW})$

$-29$

$-128$

Line radiation power, $\mathrm{P}_{\ell}$

$-17$

0

Synchrotron power, $P_{\text {synch }}(\mathrm{MW})$

12

\subsection{IMPURITY EFFECTS ON SYSTEM DYNAMICS}

The technique used to incorporate sputtering and impurity effects into the system dynamics analyses is described in Section 2. Figure 22 summarizes the important assumptions and the approach followed. Spatially averaged. time-dependent parameters are computed and advanced in time in the program. As part of the calculation, spatial profiles for the plasma parameters, impurity species, and neutrals in the system are assumed. The profiles are chosen to have average values consistent with those in the code. Using the spatially dependent information, charge state distributions and line and recombination radiation losses are calculated. The results are integrated over the plasma volume and the integral results are used in the spatially independent energy balance computation. Similarly, the spatially and energy dependent charge-exchange flux can be computed from the assumed profiles. This source of particle flux, together with the flux resulting from particle diffusion, is coupled to the wall by the sputtering model previously discussed. The diffusion flux is assumed to have a temperature of $100 \mathrm{eV}$. Sputtered impurities are assumed to reenter the plasma with some efficiency and on a profile which is selected a priori. It shoul.d 


\section{ASSUMED PROFILES ARE NORMALIZED}

TO AVERAGE VALUES

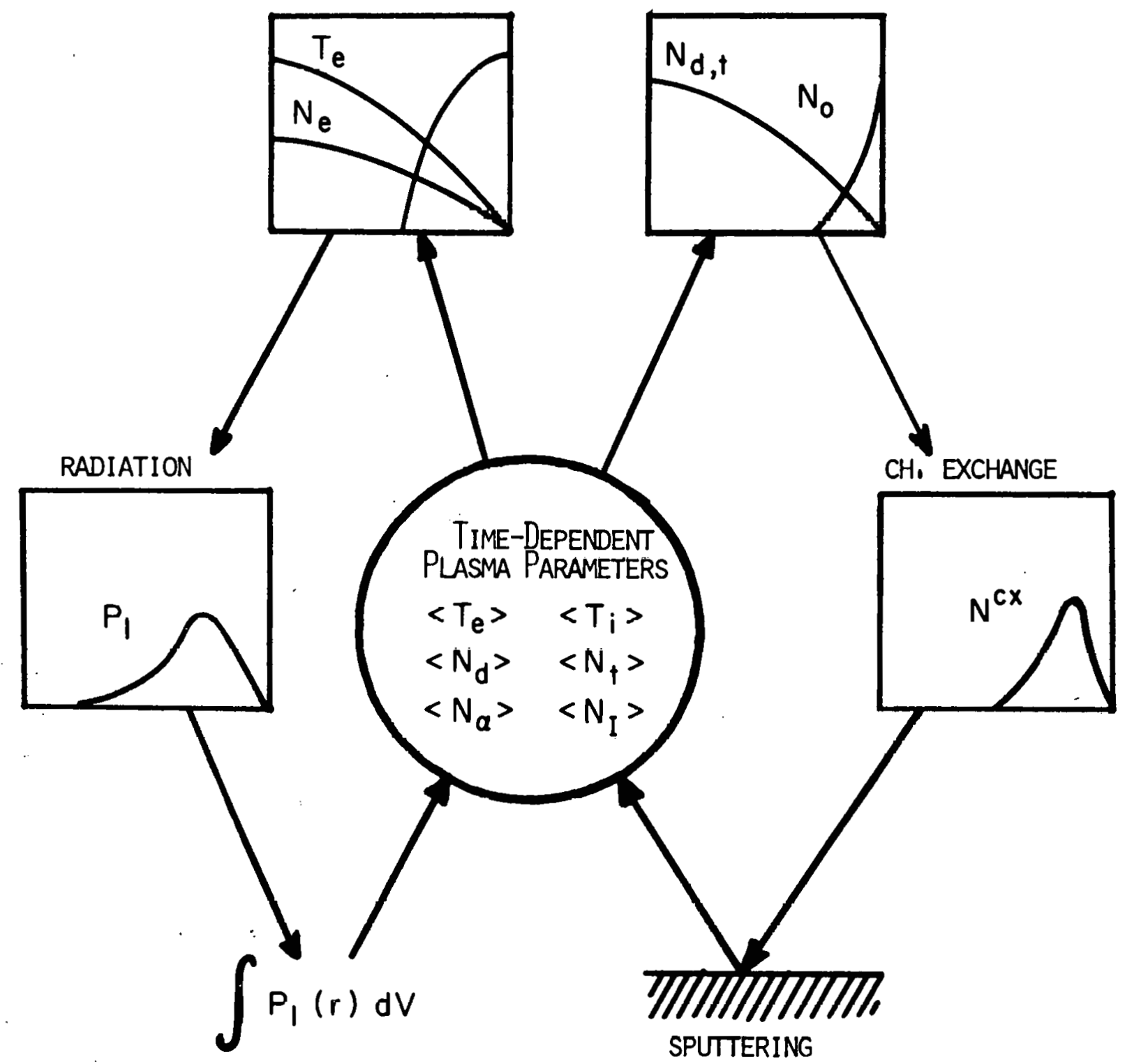

Fig. 22. Incorporation of sputtering and impurity effects in the plasma simulation model. 
be noted that major uncertainties exist in this area. For example, impurity transport and therefore the density profiles are not well understood; sputtering models (especially at low energies) remain to be verified; and detailed neutral behavior is an active area of concern. Within the context of the models outlined, impurity control criteria and system responses to certain possible outcomes are described.

A reference case is established using the EPR machine parameters given in Table 8 . The initial density is $7.5 \times 10^{20} \mathrm{~m}^{-3}$, the neutral density at $r=a$ is assumed to be $10^{15} \mathrm{~m}^{-3}$, and the neutral profile decreases exponentially into the plasma with a $5-\mathrm{cm}$ characteristic length. The impurity confinement time is assumed to be equal to that for the deuterons, and the wall is taken to be stainless steel (iron for calculational purposes). It should be noted that the reference case assumes a "divertor efficiency" of $90 \%$, even though there is no divertor in the EPR design. This efficiency means that $90 \%$ of the charged particle flux diffusing toward the wall does not result in sputtering. Also, $90 \%$ of the impurities sputtered do not reenter the plasma. If a divertor is ultimately chosen as the means of impurity control, then this model requires that it must remove $90 \%$ of a charged particle flux which crosses the scrape-off zone. In this case, some means must be provided to reinject a corresponding flux of fuel if the burn time is not to be limited. Alternatively, the efficiencies establish a target for other impurity control schemes. The reference case shown in Fig. 23 achieves a burn time of $100 \mathrm{sec}$.

Sensitivity calculations shown as curves 2-4 indicate results for no flux attenuation, $70 \%$ attenuation but impurity accumulation during the burn $\left(\tau_{\text {imp }}=\infty\right)$, and an increased neutral edge density which enhances sputtering due to charge exchange, respectively. In all cases, burn time is limited to less than $60 \mathrm{sec}$.

The reactor control model used here leads 10 the discontinuitico which appear in the curves. After about $5 \mathrm{sec}$, ignition occurs and the injected beam power is discontinued where $T_{i}=10 \mathrm{keV}$. The temperature continues to increase, and when $B_{\theta} \sim A$ the cold fueling rate which is used to maintain the plasma density is decreased. This is considered 

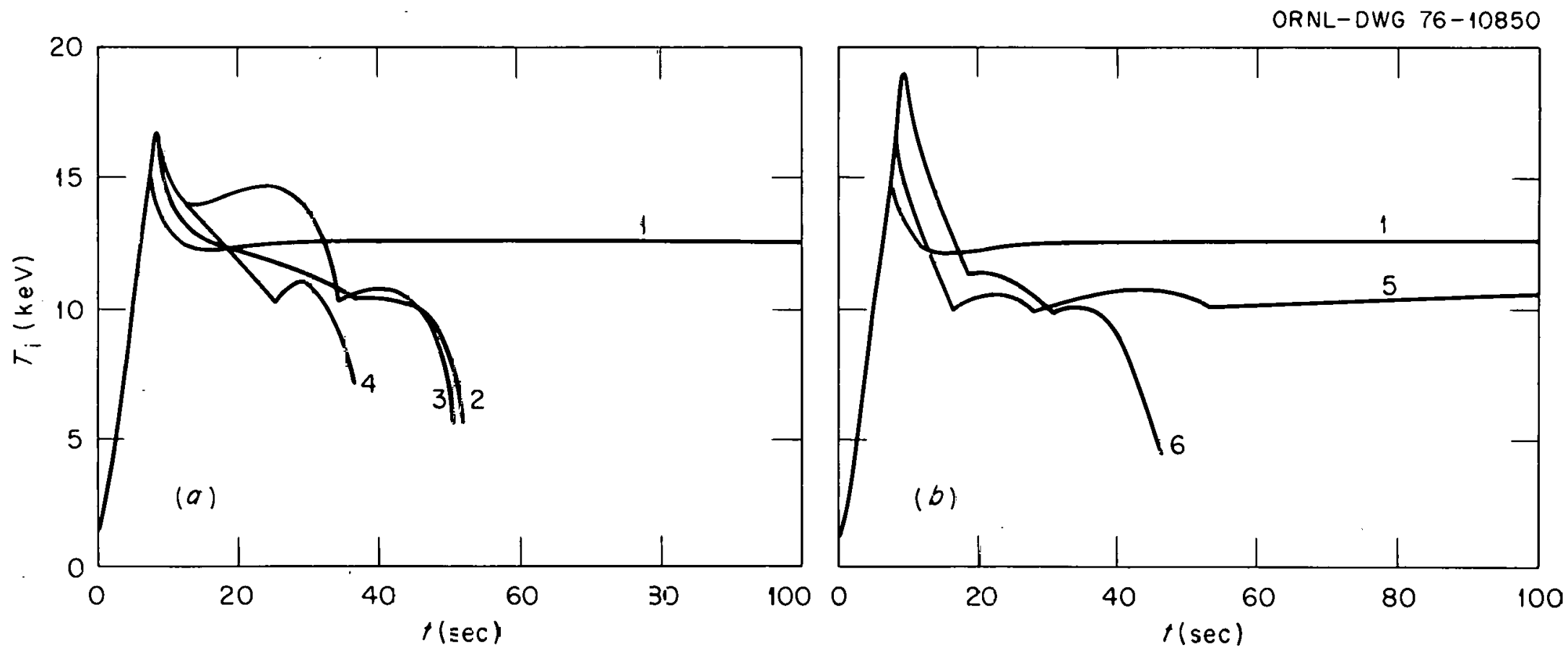

1. REFERENCE CASE: DIVERTOR EFF, $=90 \%, \tau_{\text {imp }}=\tau_{D}$. $N_{0}$ (edge) $=1 \times 10^{15} / \mathrm{m}^{3}$, STAINLESS STEEL WALL

2. NO DIVER-OR

3. DIVERTOR EFF, $=70 \%, \tau_{\text {imp }}=I N F I N I T Y$

4. $N_{0}$ (edge) $=5 \times 10^{15} / \mathrm{m}^{3}$

5. NO DIVERTOR, CARBON LINER

6. NO DIVERTOR, CARBON LINER, $\tau_{\text {imp }}=$ INFINITY

Fig. 23. Time dependence of temperature for various impurity cortrol conditions. 
to be a realistic reactivity control. This leads to the abrupt temperature change near $t=10 \mathrm{sec}$. When $\beta_{\theta}<A$, fueling continues to maintain the fuel ion density. If the temperature decreases to $10 \mathrm{keV}$, the beams are turned on in an attempt to maintain the temperature in the range of EPR practicability. For example, curve 3 shows the effect of impurity accumulation. The fuel ion density decreases due to the buildup of impurities. The reactivity therefore decreases and the temperature drops. When a level of $10 \mathrm{keV}$ is reached, the beams are used but continued fue1ion decrease prevents the burn from continuing beyond $\sim 50 \mathrm{sec}$.

Curves 5 and 6 show the results when a carbon or low $-Z$ wall is assumed. In curve $5, \tau_{\text {imp }}=\tau_{\text {ion }}$; after initial transients, ignition is reestablished at $t=50 \mathrm{sec}$ and a long burn is found to be possible. When $\tau_{\text {imp }}=\infty$, again the burn is limited to $\sim 50 \mathrm{sec}$ even in the low-Z case.

Figure 24 shows the model used for sputtering by deuterons. For cases in which carbon is assumed, the chemical sputtering yield ${ }^{24}$ is taken to be constant. For the curve labeled "O.R." the particle sputtering yields are energy dependent ${ }^{22}$ and in the same ratios as those given by Behrisch ${ }^{35}$ for $\mathrm{Nb}$. The absolute values are normalized to those for deuterons $(0.04)$. A numerical formulation or fit to the recent sputtering data from Behrisch et al. ${ }^{36}$ was obtained from Conn ${ }^{37}$ and is shown for comparison. Returning to the modified EPR reference case (as shown in the lower portion of Fig. 24), the sensitivity to the sputtering model assumed is apparent. The diffuston flux is assumed to impinge on the wall with an energy of $100 \mathrm{eV}$. Sputtering due to this source is tolerable as indicated by the burn curve labeled "Conn" which represents calculational results obtained using that model. The $0 . R$. model limits the burn to less than $40 \mathrm{sec}$, which indicates that the dominant sputtering source results from charge exchange at energies greater than $\sim 1.5 \mathrm{keV}$ where the sputtering coefficient in the O.R. model exceeds that of Conn for the iron model.

Finally, Fig. 25 shows similar results for the same reference EPR but for the case in which the alpha particles accumulate. The lower curves show the density behavior. Note that for $\tau_{\alpha}=\infty$ for burn times less than $\sim 1.20 \mathrm{sec}$, fueling malntains the fuel ion density approximately constant. 

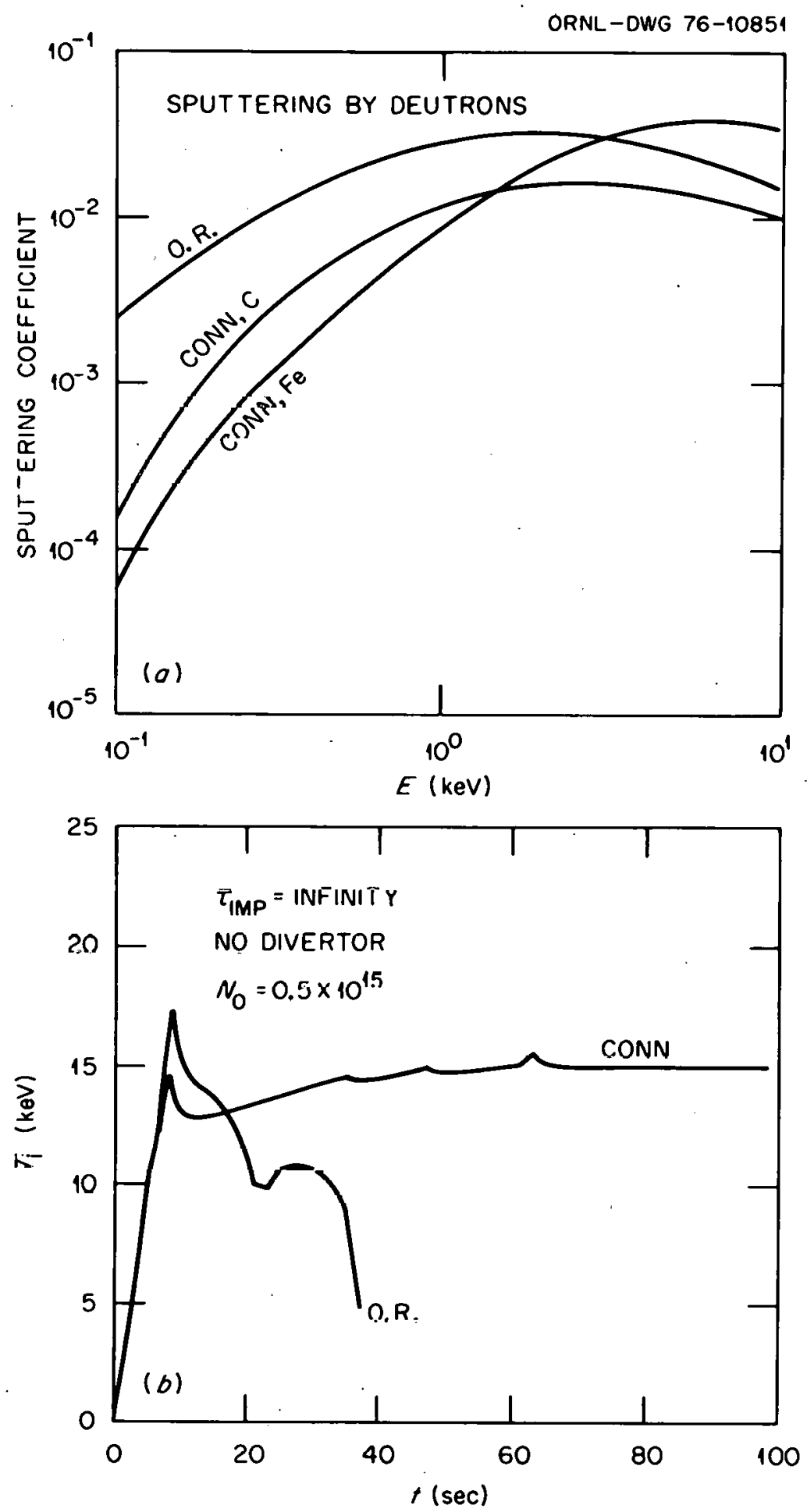

Fig. 24. Sputtering coefficient as a function of incident deuteron energy and time dependence of temperature for two sputtering models. 

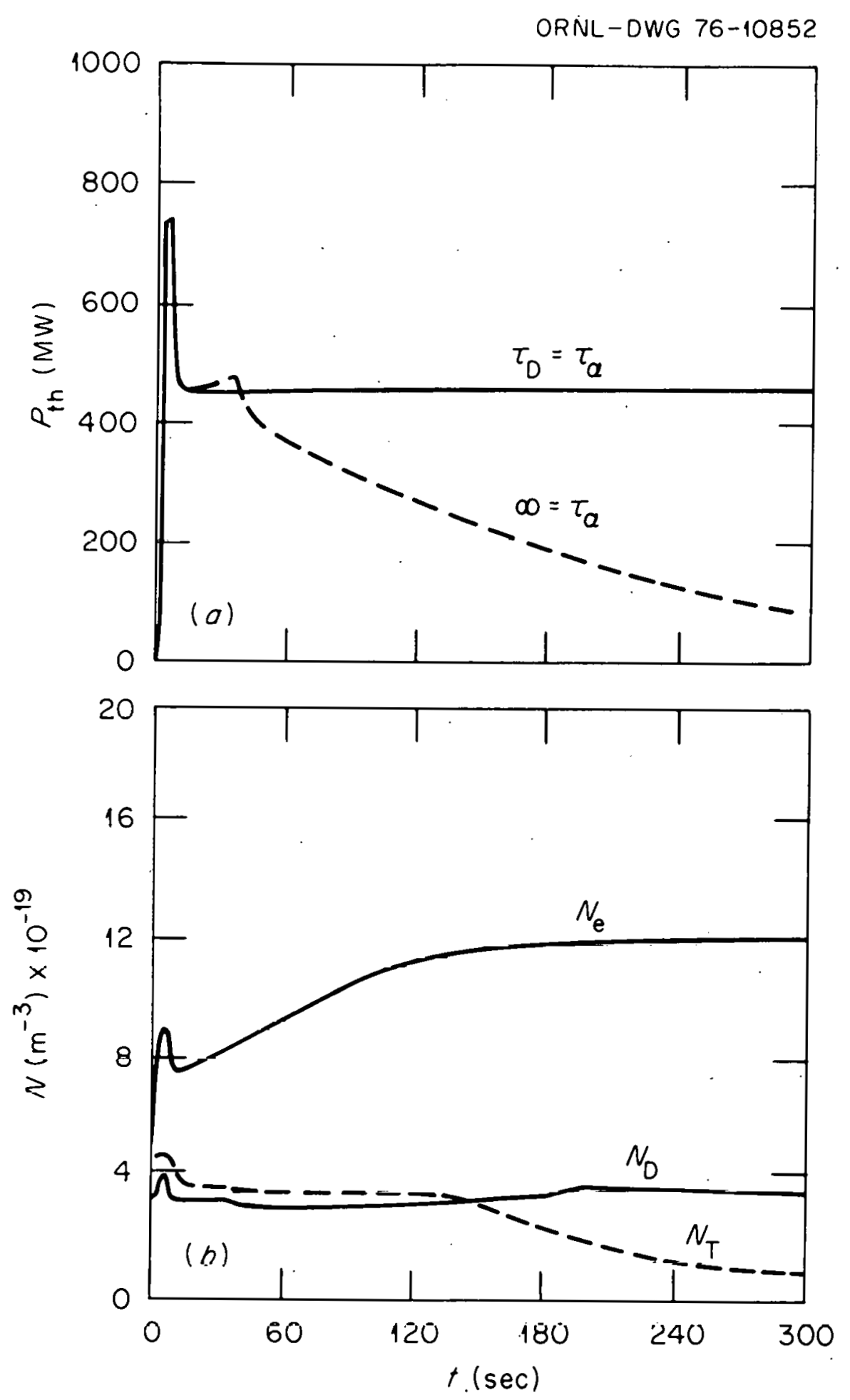

Fig, 25. Time-dependent fusion thermal power and density for two assumptions on alpha particle containment. 
However, the alpha and electron densities are increasing. Losses also increase during this period and the temperature decreases, resulting in a reactivity decrease. After $t=120 \mathrm{sec}, T \sim 10 \mathrm{keV}$ has occurred and the beams are turned on to maintain a 10-keV temperature. The deuteron density is approximately constant for $t>120 \mathrm{sec}$ due to injection. However, to maintain $B<A$, the triton density must be decreased to accommodate the increasing alpha number density. The reactor power history indicates that for $\tau_{\alpha}=\infty$, the burn time will be limited to $\sim 100 \mathrm{sec}$. This assumes, of course, that $\beta_{\theta} \leq A$ is a meaningful limit on system operation. 


\section{CONCLUSIONS}

A spatially independent, time-dependent code has been developed which permits sensitivity and trade-off studies associated with hydrogen and deuterium-tritium fueled tokamak design to be performed. The work complements that of Hiroaka et al. ${ }^{38}$ and Stacey at al. ${ }^{28}$ by including additional physical models and some spatial dependencies in the calculation.

The main objectives here were to sumarize the available model, describe the physics included in it, and outline typical results obtained from it. In the latter case, the ORNL Experimental Power Reactor Reference Design $^{39}$ and Demonstration Power Reactor were used as examples. The main conclusions derived from the code relative to low beta, tokamak power system design are summarized below.

It is not possible at present to determine the size of a tokamak in such a way that the plasma will satisfy desired criteria. This determination depends critically on plasma properties which are as yet uncertain. Using a model in which ion conduction is neoclassical or due to the dissipative trapped ion mode, electron conduction is pseudoclassical or due to the trapped particle modes, and convection is pseudoclassical or due to the trapped particle modes (all dependent on collisionality), leads to an EPR plasma size of $\sim 2 \mathrm{~m}$. In this case the trapped particle modes are assumed to be ten times less severe than estimates from a linear analysis of the instability theory. If the factor is taken to be significantly greater than ten, neoclassical ion conduction becomes the dominant transport term and ignition can be achieved in a device with a $\sim 1 \mathrm{~m}$. The particular scaling model described here also puts a premium on magnetic field strength and plasma size since, for example, the trapped ion mode transport coefficient varies as $\mathrm{B}^{6}$ and $\mathrm{a}^{4}$.

Comparison of the model to experimental results from existing devices shows that parameters obtained are consistent with operation in the dissipative trapped electron mode. The neoclassical ion conduction coefficient, however, requires reduction to achieve consistency with the ion temperature results. 
Ignition is found to be more readily achievable when high density operation is assumed. This stands to reason when trapped particle scaling is assumed, since both the first trapped electron mode and the trapped ion mode losses show a strong dependence on temperature and decrease with increased beta. Thus for a given beta, high-density, lower temperature operation would be favored with respect to scaling. of course, technological requirements such as fueling and neutral beam penetration into dense plasmas must be carefully examined if this operating mode is ạssumed.

I'here is a minimum amount of external heating power which can be used to achieve ignition in a reasonable time. In the case of a deuteriumtritium fueled system, it can be assumed to be about two times ( $\mathrm{P}_{1 \text { oss }}-\mathrm{P}_{\alpha}$ ) where $P_{\text {loss }}$ represents the sum of all power losses. In the ORNL EPR a beam power of $50 \mathrm{MW}$ provides ignition in $5 \mathrm{sec}$. Note that in a hydrogen system $P_{\alpha}=0$. Thus, the externally supplied power must provide $\mathrm{P}_{\text {loss }}$. This can lead to stringent requirements in a large hydrogen system where the objectives include a fusion plasma. For example, if $\mathrm{T}=12 \mathrm{keV}$, $\mathrm{N}=\times 10^{20} \mathrm{~m}^{-3}, \tau_{\mathrm{E}}=1 \mathrm{~s}$, and the plasma volume is about $125 \mathrm{~m}^{3}$, the beam power required is $60 \mathrm{MW}$.

The scaling model emphasized here results in a thermally stable operating point due to the strong inverse temperature dependence of $\tau_{E}$. If scaling laws such as those suggested by ORMAK and ALCATOR where $\tau_{E} \propto N$ obtain, thermal excursions will result and stable thermal operation will rely on losses in other areas such as synchrotron radiation to prevent extremely high temperatures from occurring.

Noncircular plasmas provide flexibility with respect to $q$ and provide higher beta operation. MHD equilibrium and stability results will dictate the extent to which this benefit can be meaningfully carried. Trade-off studies in this area are under way. Impurity control is critically important to tokamak plasma operation. For a low level of high-Z impurities, the resulting enhanced radiation losses are intolerable to the plasma energy balance. For low $\mathrm{Z}$ impurities, 
if $\tau_{\text {imp }} \gg \tau_{\text {ion }}$ and the system is limited to $\beta_{\theta} \sim \mathrm{A}$, maximum burn times less than $\sim 100 \mathrm{sec}$ result due to the fuel ion defect which occurs. If $\tau_{\text {imp }} \sim \tau_{\text {ion, a low }} Z$ liner may permit the long burn times necessary for the production of economically viable tokamak fusion power.

\section{ACKNOWLEDGMENTS}

This is a summary of work which has evolved over more than a year. Many discussions were held with colleagues in developing models and interpreting results. It is not possible to thank them all here. The authors acknowledge the specific contributions to this work from T. Hiroaka (JAERI), R. J. Colchin, R. W. Conn (University of Wisconsin), R. Harder (GAC), J. R. McNally, Jr., P. Peterson (GAC), and N. A. Uckan. 
THIS PAGE

\section{WAS INTENTIONALLY \\ LEFT BLANK}




\section{REFERENCES}

1. S. L. Greene, Jr., USAEC Report UCRL-70522 (1967).

2. D. G. McAlees, Alpha Particle Energetics and Neutral Beam Heating in Tokamak. Plasmas, ORNL/TM-4661 (November 1974).

3. D. J. Sigmar and G. Joyce, "Plasma Heating by Energetic Particles," Nucl. Fusion 11: 447 (1971).

4. J. M. Dawson, H. P. Furth, F. H. Tenney, "Production of Thermonuclear Power by Non-Maxwellian Ions in a Closed Magnetic Field Configuration," Phys. Rev. Lett. 26: 1156 (1971).

5. J. A. Rome et al., Neutral Beam Injection into a Tokamak: Particle Orbit Loss-Regions in Tokamaks and Their Effects on Plasma Heating, ORNL/TM-4855 (April 1975).

6. S. I. Braginskii, "Transport Processes in a P1asma," p. 217 in Reviews of Plasma Physics, Vol. I, ed. by M. A. Leontovich, Consultants Bureau, New York, 1965.

7. L. Spitzer, Jr., Physics of Fully Ionized Gases, Interscience Publishers, Inc., New York, 1956.

8. J. R. McNally, Jr. et al., Fusion Dynamics of Lossy Reactor Systems, ORNL/TM-4617, Oak Ridge (June 1974).

9. J. R. McNally, Jr., "Nuclear-Fusion Chain-Reaction Applications in Physics and Astrophysics," Nuclear Data in Science and Technology, Vo1. II, p. 41 (1973).

10. L. Spitz.er and R. Härm, Phys. Rev. 89: 977 (1953).

11. S. O. Dean et al., Status and Objectives of Tokamak Systems for Fusion Research, WASH-1295, USAEC, Washington, D.C. (1974).

12. J. W. Connor et al., "The Conductivity of a Toroidal Plasma," Nucl. Fusion 13: 211 (1973).

13. D. J. Rose and M. Clark, Jr., Plasmas and Controlled Fusion, MIT Press, Cimbridge, Massachusette and John Wiley and Sons, Ine., Nêw York, 1961.

14. J. L. Hirschfield, D. E. Baldwin, and S. C. Brown, "Cyclotron Radiation from Hot Plasmas," Phys. Fluids 4: 198 (1961).

15. D. J. Rose, "Engineering Feasibility of Controlled Fusion," Nucl. Fusion 9: 183 (1969). 
16. M. N. Rosenbluth, "Synchrotron Radiation in Tokamaks," Nucl. Fusion 10: 340 (1970).

17. J. D. Callen and R. J. Colchin (ORNL); private communication.

18. F. L. Hinton and M. N. Rosenbluth, "Transport Properties of a Toroida1 Plasma at Low-to-Intermediate Collision Frequencies," Phys. Fluids 16: 836 (1973).

19. R. D. Hazeltine and F. L. Hinton, "Collision-Dominated Plasma Transport in Toroidal Confinement Systems," Phys. Fluids 16: 1883 (1973).

20. E. C. Crume, Jr. (ORNL), private communication, December 1975.

21. A. L. Merts, R. D. Cowan, and N. H. Magee, Jr., The Calculated Power Output from a Thin Iron-Seeded Plasma, LA-6220-MS, Los Alamos, New Mexico (1976).

22. D. M. Meade et al., "The Effects of Impurities and Magnetic Divertors on High-Temperature Tokamaks," Plasma Physics and Controlled Nuclear. Fusion Research, Vol. I, p. 605 (1974).

23. R. Behrisch and B. B. Kadomtsev, "Plasma Impurities and Their Significance in Fusion Reactors," Plasma Physics and Controlled Nuclear Fusion Research, Vol. II, p. 229 (1974).

24. M. I. Guseva and V. M. Gusev, Conf. on Engineering Problems of Thermonuclear Reactors, Leningrad (July 1974).

25. T. Ohkawa and T. H. Jensen, "Parameter Studies for Tokamaks and Doublets," Plasma Phys. 12: 789 (1970).

26. Y-K. M. Peng et al., Magnetohydrodynamic Stability of Axisymmetric Tokamak Equilibria, ORNL/TM-5269, Oak Ridge (to be published).

27. R. G. Bateman (ORNL), private communication, February 1975.

28. W. M. Stacey, Jr. er al., Tokamak Experimental Power Reactor Studies, ANL/CTR-75-2, Argonne, Illinois (1975).

29. Experimental Power Reactor Conceptual Design Study, General Atomic Company, Report GA-A13534 (July 1975).

30. P. Lecoustey et al., "Scaling Laws in the TFR Tokamak," Bull. Am. Phys. Soc. 19: 973 (1974).

31. Equipe TFR, "Décharges à Fort Courant Dans TFR," Plasma Physics and Controlled Nuclear Fusion Research, Vol. I, p. 135 (1974). 
32. TFR Group, "Energy Confinement in TFR: Analysis of Losses, Sources," paper presented at the Annual Meeting on Theoretical Aspects of Controlled Nuclear Fusion Research (Project Sherwood), Naval Research Laboratory, Washington, D. C., April 1975.

33. J. D. Callen, J. F. Lyon, M. Murakami (eds.), ORMAK Plasma Confinement and Neutral Beam Injection Heating (Experiment and Theory), ORNL/TM4790, Oak Ridge (1975).

34. M. Murakami (ORNL), private communication, April 1975.

35. R. Behrisch, Nuc1. Fusion 12: 481 (1972).

36. R. Behrisch et al., "Measurements of the Erosion of Stainless Steel, Carbon, and SiC by Hydrogen Bombardment in the Energy Range of $0.5-$ $7.5 \mathrm{keV}$," to be published in J. Nucl. Mater.

37. R. W. Conn (University of Wisconsin), private communication, 1975.

38. T. Hiroaka, J. R. McNally, Jr., and D. Steiner, Dynamic Overal1 Energy Balance of Clean and Impurity-Contaminated Tokamak Reactors, ORNL/TM-4833, Oak Ridge (November 1975).

39. M. Roberts and E. S. Bettis, Oak Ridge Tokamak Experimental Power Reactor Reference Design, ORNL/TM-5042, Oak Ridge (November 1975). 
THIS PAGE

\section{WAS INTENTIONALLY LEFT BLANK}


ORNL/TM-5509

Dist. Category UC-20

\section{INTERNAL DISTRIBUTION}

1-3. Laboratory Records

4. Laboratory Records - RC

5. Y-12 Document Reference Section

6-7. Central Research Library

8. Fusion Energy Division Library

9. ORNL Patent Office

10. J. D. Callen

11. J. F. Clarke

12. R. A. Dory

13. G. G. Kelley

14. O. B. Morgan

15. M. W. Rosenthal

16. Fusion Energy Reports Office

17-25. D. G. McAlees

26-33. S. E. $\Lambda$ ttenberger

34-43. F. B. Marcus

EXTERNAL DISTRIBUTION

44. Plasma Physics Library, Princeton Plasma Physics Laboratory, Princeton Univ., Forrestal Campus, P.0. Box 451, Princeton, NJ 08540

45. Controlled Thermonuclear Research Library, Lawrence Livermore Laboratory, P.0. Box 808, Livermore, CA 94550

46. Q Division Library, c/o F. L. Ribe, Los Alamos Scientific T.ahnratory, P.n. Rox 16h.3, T.os A.tamos, NM 87544

47. Controlled Thermonuclear Research Library, c/o Weston M. Stacey, Jr., Argonne National Laboratory, 9700 S. Cass Ave., Argonne, IL 60439

48. CTR Computer Center, c/o Dr. John Killeen, Lawrence Livermore Laboratory, P.0. Box 808, Livermore, C.A 94550

49. Librarian, Culham Laboratory, Abingdon, Oxon OX14 3DB, United Kingdom

50. Ruth Lengye, Bibliothek, Max Planck Institut für Plasmaphysik, 8046 Garching bei München, Federal Republic of Germany

51. Library, Centre de Récherches en Physique des Plasmas, 21 Avenue des Bains, 1007, Lausannc, Switzcrland 
52. A. M. Dupas, Documentation S.I.G.N., Department de la Physique du Plasma et de la Fusion Controlée, Association EURATOM-CEA, Sur la Fusion, Centre d'Etudes Nucleaires, BP 85 Du TRI 38041 Grenoble, Cedex, France

53. Bibliotheque, Service du Confinement des Plasmas, CEA, B.P. No. 6, 92, Fontenay-aux-Roses (Seine) France

54. Library, International Centre for Theoretical Physics, Trieste, Italy

55. Library, Laboratorio Gas Ionizzati, Frascati, Italy

56. V. E. Ivanov, Physical-Technical Institute of the Ukranian Academy of Sciences, Sukhumi, U.S.S.R.

57. M. S. Rabinovich, Lebedev Institute of Physics, Academy of Sciences of the U.S.S.R., Leninsky Prospect 53, Mnscow, II.S.S.R.

58. Thermonuclear Laboratory, Kurchatov Institute of Atomic Energy, 46 Ulitsa Kurchatova, P.O. Box 3402, Moscow, U.S.S.R.

59. Library, Institute for Plasma Physics, Nagoya Univ., Nagoya, Japan

60. Library, FOM-Institut voor Plasma-Fysica, Rijnhuizen, Jutphaas, Netherlands

61. Plasma Hhysics Group, Department of Engineering Physics, Australian National Univ., P.0. Box 4, Canberra A.C.T. 2600, Austral1a

62. Thermonuclear Library, Japan Atomic Energy Research Institute, Tokai, Naka, Ibaraki, Japan

63. CTR Reading Room, c/o Prof. L. M. Lidsky, Room 37-391, Massachusetts Institutẹ of Technology. Cambridge, MA 02139

64. CTR Reading Room, c/o Prof. D. W. Kerst, Dept. of Physics, Sterling Hall, Univ. of Wisconsin, Madison, WI 53706

65. CTR Reading Room, c/o Prof. I. B. Bernstein, Yale Univ., New Haven, CT 06510

66. Center for Plasma Physics and Thermonuclear Research, Univ. of Texas, Physics Building 330, Austin, TX 7871.2

67. CTR Reading Room, c/o Prof. B. D. Fried, Physics Dept., Univ. of California, Los Angéles, CA 90024 
68. CTR Reading Room, c/o Prof. David C. Montgomery, Physics \& Astronomy Dept., Univ. of Iowa, Iowa City, IA 52240

69. Magneto-Fluid-Dynamics Library, Courant Institute of Mathematical Science, New York Univ., New York, NY 10012

70. CTR Reading Room, c/o Prof. Allan N. Kaufman, Physics Dept., Univ. of California, Berkeley, CA 94720

71. CTR Reading Room, c/o Prof. W. B. Thompson, Physics Dept., Univ. of California, La Jolla, CA 92037

72. CTR Reading Room, c/o Prof. Alvin W. Trivelpiece, Dept. of Physics \& Astronomy, Univ. of Maryland, College Park, MD 20742

73. CTR Reading Room, c/o Prof. T. Kammash, 103 Research Admin. BIdg., N. Campus, Univ. of Michigan, Ann Arbor, MI 48105

74. CTR Reading Room, c/o Dr. Ravi N. Sudan, Phillips Hall, Cornell Univ., Ithaca, NY 18540

75. Prof. Marshall N. Rosenbluth, Institute for Advanced Study, Princeton, NJ 08540

76. CTR Reading Room, c/o Prof. R. Gross, Plasma Research Laboratory, Columbia Univ., New York, NY 10027

77. CTR Reading Room, c/o Prof. Roy Gould, California Institute of Technology, Pasadena, CA 91103

78. Dr. Nicholas A. Krall, Science Applications, Inc., P.0. Box 2354, 1200 Prospect St., La Jolla, CA 92037

79. CTR Reading Room, c/o Dr. Jay P. Boris, Plasma Physics, Naval Research Laboratory, Washington, DC 20390

80. CTR Library, General Atomic Co., P.0. Box 81608, San Diego, CA 92138

81. CTR Library, c/o Dr. Alan F. Haught, United Technologies Research Laboratories, East Hartford, CT 06108

82. Dr. Robert E. Price, Division of Magnetic Fusion Energy, Energy Research and Development Administration, Washington, DC 20545

83. Dr. James Williams, Division of Magnetic Fusion Energy, Energy Research and Development Administration, Washington, DC 20545

84. Dr. Arthur Sleeper, Division of Magnetic Fusion Energy, Energy Research and Devellopment Administration, Washington, DC 20545 
85. Dr. Frank Coffman, Division of Magnetic Fusion Energy, Energy Research and Development Administration, Washington, DC 20545

86. Mr. M. Murphy, Division of Magnetic Fusion Energy, Energy Research and Development Administration, Washington, DC 20545

87. Dr. Paul H. Rutherford, Princeton Plasma Physics Laboratory, Princeton Univ., Princeton, NJ 08540

88. Dr. L. D. Pearlstein, L-388, Lawrence Livermore Laboratory, P.0. Box 808, Livermore, CA 94550

89. Dr. J. P. Friedberg, Los Alamos Scientific Laboratory, Los Alamos, NM 87544

90. Dr. David W. Ross, Center for Plasma Physics \& Thermonuclear Research, Dept. of Physics, Univ. of Texas, Austin, TX 78712

91. Dr. Gareth E. Guest, General Atomic Co., P.0. Box 81608, San Diego, CA 92138

92. Dr. Claude Mercier, Service du Theorie des Plasmas, Centre d'Etudes Nucleaires, Fontenay-aux-Roses (Seine) France

93. Dr. J. B. Taylor, Culham Laboratory, Abingdon, Oxon OX14 3DB, United Kingdum

94. Dr, D. Pfirsch, Institute for Plasma Physics, 8046 Garching bei München, Federal Republic of Germany

95. Dr. V. D. Shafranov, I. V. Kurchatov Institute of Atomic Energy, 46 Ulitsa Kurchatova, P.0. Box 3402, Moscow, U.S.S.R.

96. Dr: Harold Grad, Courant Institute of Mathematical Science, New York Univ., 251 Mercer St., New York, NY 10012

97. Dr. J. G. Cordey, Gulham Laboratory, Abingdon, Oxon 0x1/ 3DB, United Kingdom

98. Dr. David Baldwin, E-388, Lawrence Livermore Laboratory, P.0. Box 808, Livermore, CA 94550

99. Prof. Bruno Coppi, Dept. of Physics, Massachusetts Institute of Technology, Cambridge, MA 02139

100. Dr. Harold P. Furth, Princeton Plasma Physics Laboratory, Princeton Univ., P.0. Box 451, Princeton, NJ 08540 
101. Research and Technical Support Division, Energy Research and Development Administration, P.O. Box E, Oak Ridge, TN 37830

102-304. Given distribution as shown in TID-4500, Controlled Thermonuclear Processes (25 copies NTIS) 